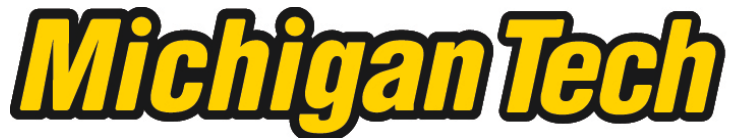 \\ Michigan Technological University Create the Future Digital Commons @ Michigan Tech
}

Dissertations, Master's Theses and Master's Reports - Open

Dissertations, Master's Theses and Master's

Reports

2013

\section{The Laboratory Evaluation of Bio Oil Derived From Waste Resources as Extender for Asphalt Binder}

Xu Yang

Michigan Technological University

Follow this and additional works at: https://digitalcommons.mtu.edu/etds

Part of the Civil Engineering Commons

Copyright 2013 Xu Yang

\section{Recommended Citation}

Yang, Xu, "The Laboratory Evaluation of Bio Oil Derived From Waste Resources as Extender for Asphalt Binder", Master's Thesis, Michigan Technological University, 2013.

https://doi.org/10.37099/mtu.dc.etds/654

Follow this and additional works at: https://digitalcommons.mtu.edu/etds

Part of the Civil Engineering Commons 


\title{
THE LABORATORY EVALUATION OF BIO OIL DERIVED FROM WASTE WOOD RESOURCES AS EXTENDER FOR ASPHALT BINDER
}

\author{
By \\ Xu Yang \\ A THESIS \\ Submitted in partial fulfillment of the requirements for the degree of \\ MASTER OF SCIENCE \\ In Civil Engineering
}

MICHIGAN TECHNOLOGICAL UNIVERSITY

2013

(C) Xu Yang 2013 
This thesis has been approved in partial fulfillment of the requirements for the Degree of MASTER OF SCIENCE in Civil Engineering

Department of Civil and Environmental Engineering

Thesis Advisor: Zhanping You

Committee Member: Qingli Dai

Committee Member: Jacob Hiller

Committee Member: Patricia Heiden

Department Chair: David Hand 


\section{TABLE OF CONTENTS}

TABLE OF CONTENTS........................................................................................

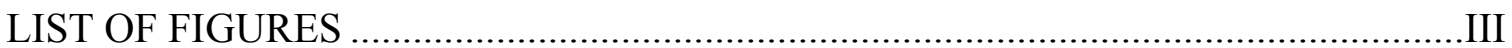

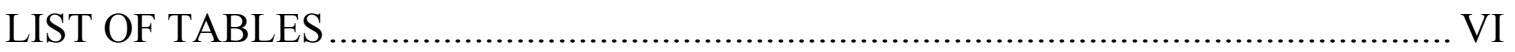

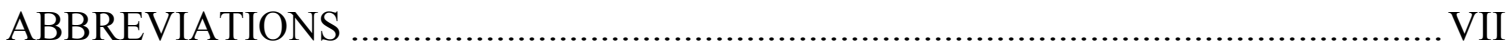

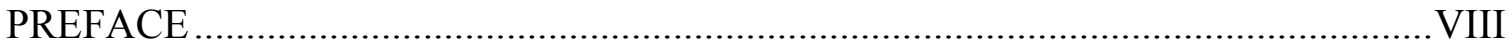

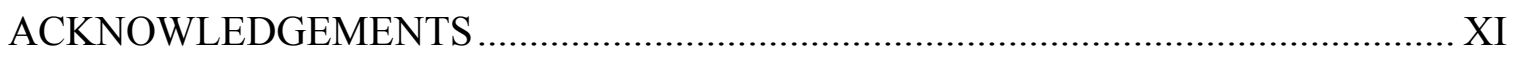

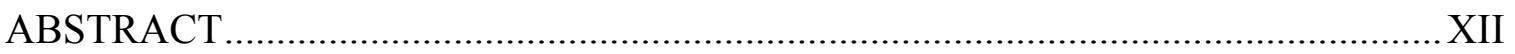

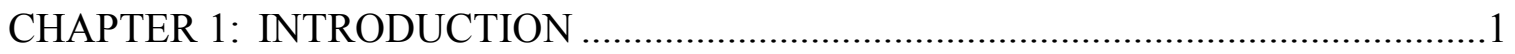

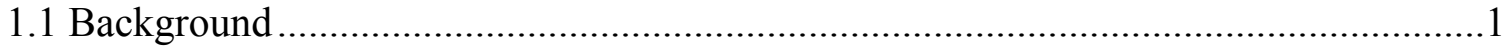

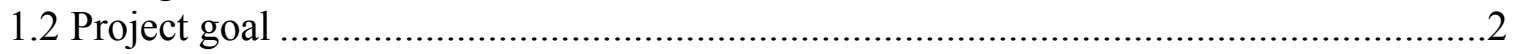

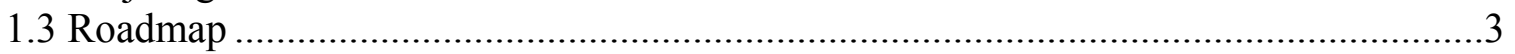

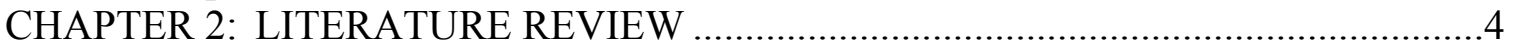

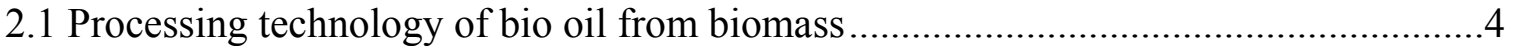

2.2 Elemental analysis of bio oil and petroleum asphalt ................................................

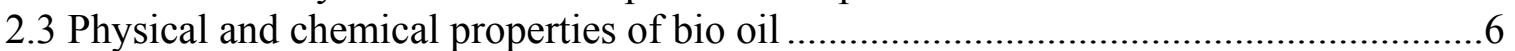

CHAPTER 3: EXPERIMENTAL PLAN AND SAMPLE PREPARATION .....................7

3.1 Experimental Plan............................................................................................

3.1.1 Rheological Property Characterization of Asphalt Binders Modified by Bio Oil7

3.1.2 Rheological Property Characterization of Asphalt Binders Partially Replaced by Bio Oil 8

3.1.3 Mechanical Performance Evaluation of Hot Mix Asphalt Modified by Bio Oil .9

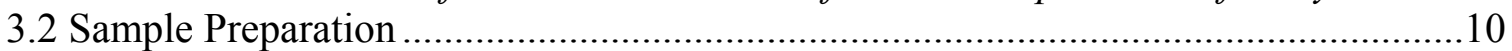

3.2.1 Preparation of asphalt binders blended with bio oil.......................................10

3.2.2 Preparation of asphalt mixture samples containing bio oil ..............................10 CHAPTER 4: LABORATORY EVALUATION OF BIO OIL AS MODIFIER ON RHEOLOGICAL PROPERTIES OF ASPHALT BINDERS ${ }^{1}$ ….......................................12

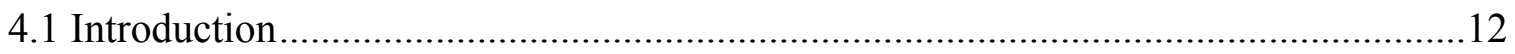

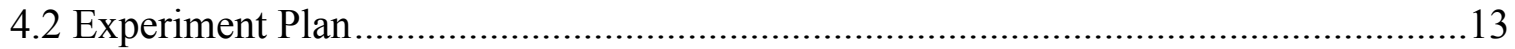

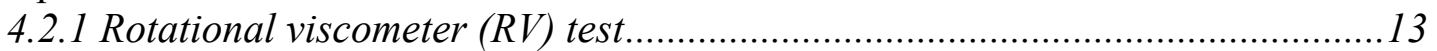

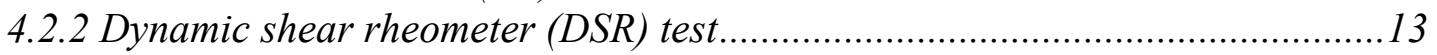

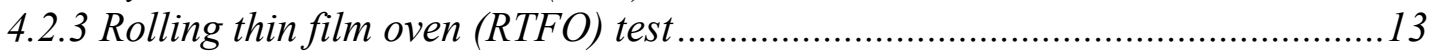

4.2.4 Pressure Aging Vessel (PAV) test .........................................................14

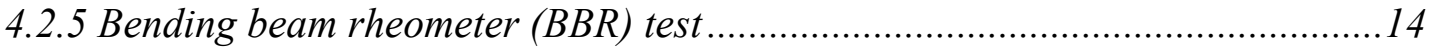

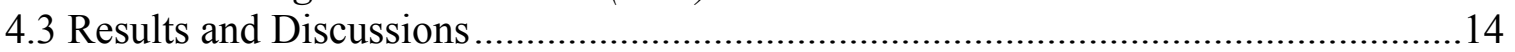

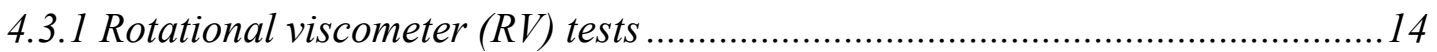

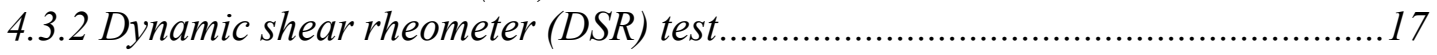

4.3.3 Bending beam rheometer (BBR) test .........................................................25

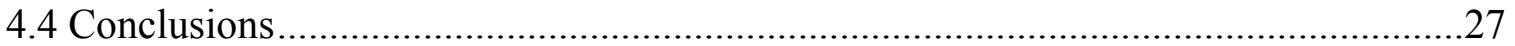

CHAPTER 5: EVALUATION OF THE RHEOLOGICAL PROPERTIES OF ASPHALT

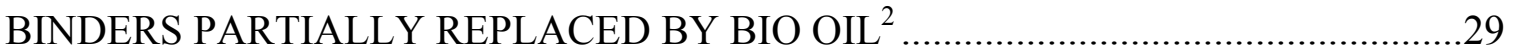

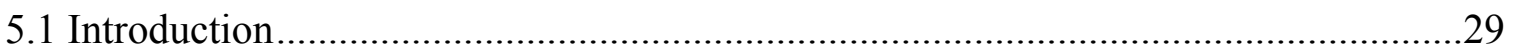

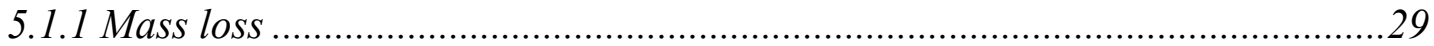

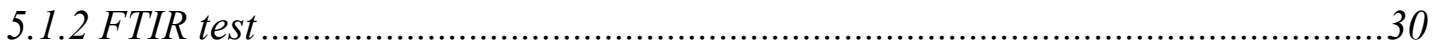




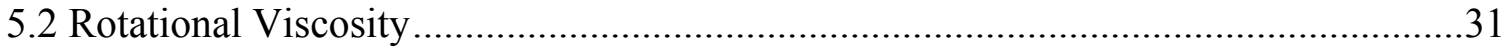

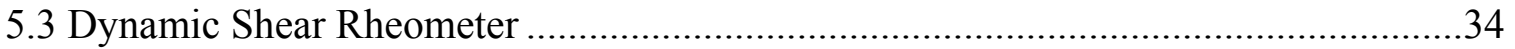

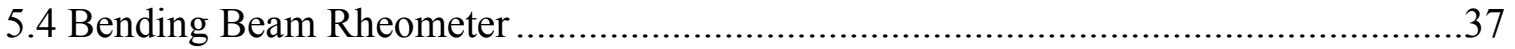

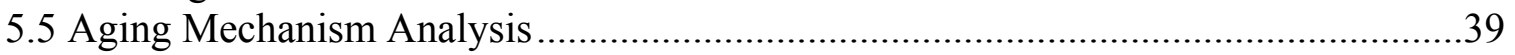

5.6 Findings and Conclusions ...................................................................................

CHAPTER 6: MECHANICAL PERFORMANCE EVALUATION FOR ASPHALT

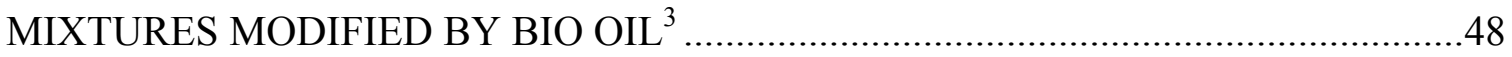

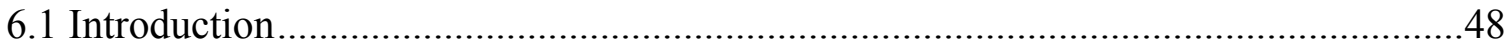

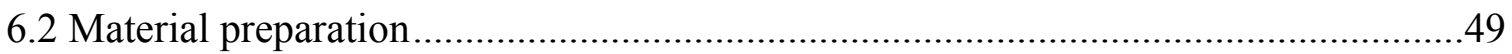

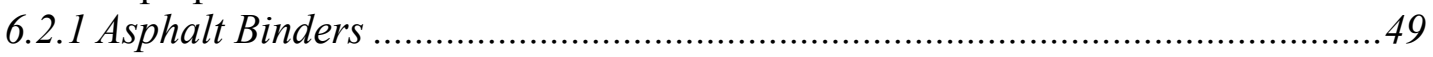

6.2.2 Aggregates and Gradation ......................................................................49

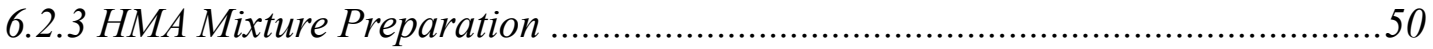

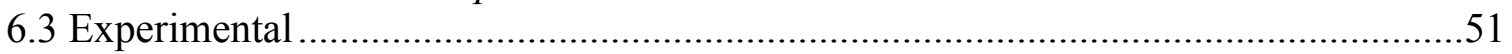

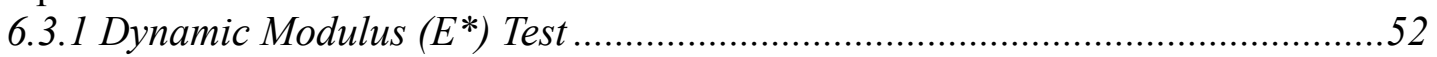

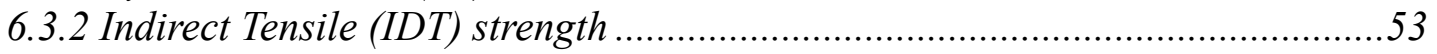

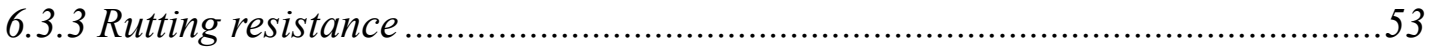

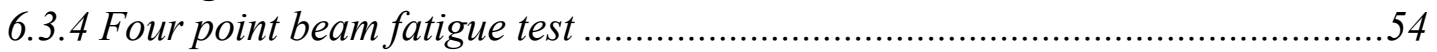

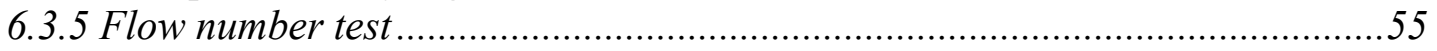

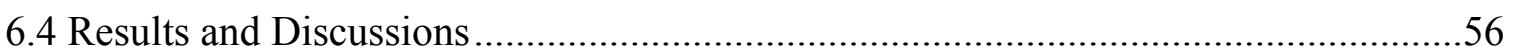

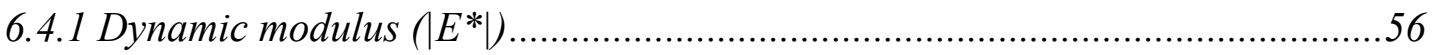

6.4.3 Indirect tensile (IDT) test and moisture susceptibility ..................................59

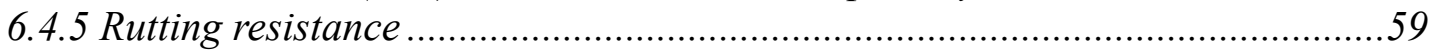

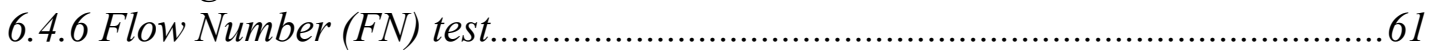

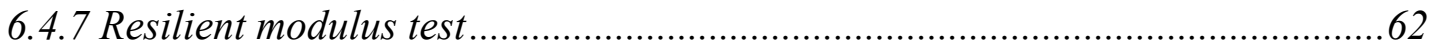

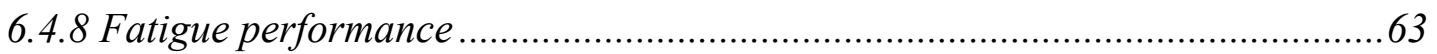

6.4.9 Relation between initial dissipated energy and fatigue life...............................64

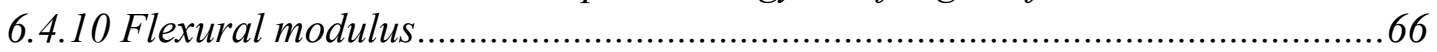

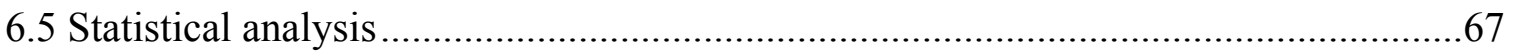

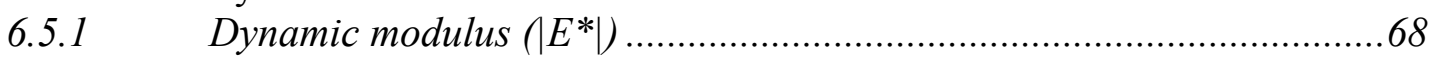

6.5.2 Asphalt pavement analyzer (APA) …………................................68

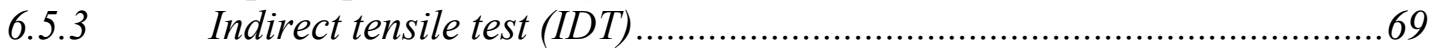

6.5.4 Fatigue performance .................................................................. 70

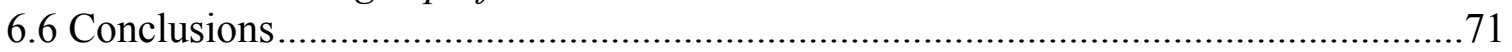

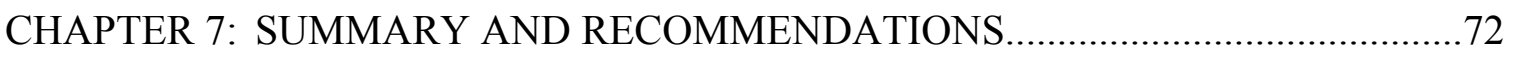

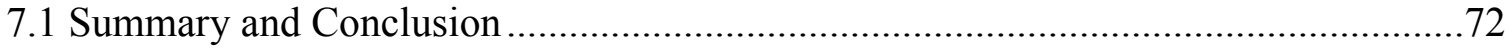

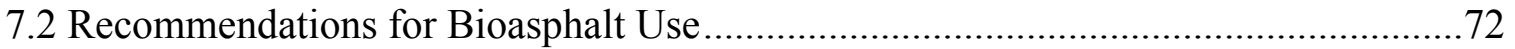

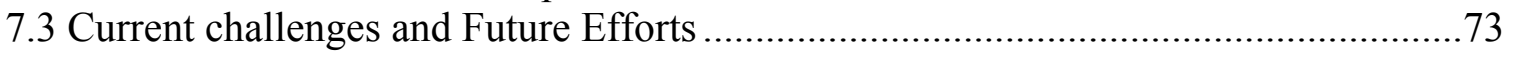

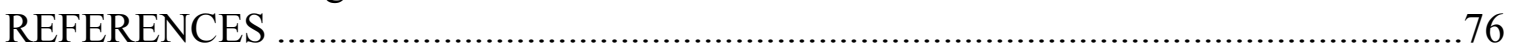




\section{LIST OF FIGURES}

Figure 2-1: The schematic of the pyrolysis process....................................................... 4

Figure 4-1: The rotational viscosities of asphalt binders before and after RTFO aging... 16

Figure 4-2: The aging indexes of control and bio oil modified asphalt binders during RTFO aging 17

Figure 4-3: $\left|\mathrm{G}^{*}\right|$ Master curve plot for control asphalt binder, $5 \%$ and $10 \%$ OB modified asphalt binders before and after RTFO aging

Figure 4-4: $\left|\mathrm{G}^{*}\right|$ Master curve plot for control asphalt binder, 5\% and 10\% DWB modified asphalt binders before and after RTFO aging...................................... 19

Figure 4-5: $\left|\mathrm{G}^{*}\right|$ Master curve plot for control asphalt binder, 5\% and 10\% PMB modified asphalt binders before and after RTFO aging....................................... 20

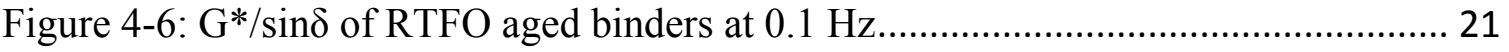

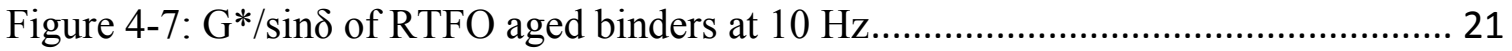

Figure 4-8: High critical temperatures for RTFO aged asphalt binders .......................... 22

Figure 4-9: $\left|\mathrm{G}^{*}\right|$ master curve plot for control asphalt binder and OB modified asphalt

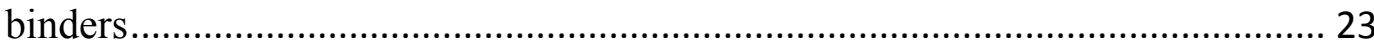

Figure 4-10: $\left|\mathrm{G}^{*}\right|$ master curve plot for control asphalt binder and DWB modified asphalt binders

Figure 4-11: $\left|\mathrm{G}^{*}\right|$ master curve plot for control asphalt binder and PMB modified asphalt binders 24

Figure 4-12: $\left|\mathrm{G}^{*}\right|$ master curve for control asphalt binder and PMB modified asphalt .... 27

Figure 5-1: RV test results for control asphalt binder, $\mathrm{OB}, \mathrm{DWB}$, and asphalt binders containing 30\% OB, 70\% OB, 30\% DWB and 70\% DWB.............................. 32

Figure 5-2: RV test results for control asphalt binder, and asphalt binders containing 30\%

OB, $70 \%$ OB, 30\% DWB and 70\% DWB after RTFO aging. 33

Figure 5-3: The aging factors of the binder blending containing bio binders subjected to RTFO aging 
Figure 5-4: Master curve plot for $\left|\mathrm{G}^{*}\right|$ of virgin control binder and binder blending containing bio binders (temperature range 40 to $70^{\circ} \mathrm{C}$, reference temperature $\left.58^{\circ} \mathrm{C}\right)$

Figure 5-5: Master curve plot for $\left|\mathrm{G}^{*}\right|$ of control asphalt binder and binder blending containing bio binders after RTFO aging 36

Figure 5-6: $\mathrm{G}^{*} / \sin \delta$ for control asphalt binder and binder blending containing bio binders at $58^{\circ} \mathrm{C}$ and $1.59 \mathrm{~Hz}$ 37

Figure 5-7: Creep stiffness test results of control binder and binder blending containing bio binders 38

Figure 5-8: m-values at $60 \mathrm{sec}$ of control binder and binder blending containing bio binders 38

Figure 5-9: The mass loss of control asphalt binder and bind blending containing bio binders during the RTFO aging ..... 40

Figure 5-10: FTIR spectra of control asphalt binder and binder blending containing bio binders before RTFO aging (after baseline correction) 44

Figure 5-11: FTIR spectra of control asphalt binder and binder blending containing bio binders before RTFO aging (after baseline correction) 45

Figure 5-12: Ratio of $\mathrm{C}=\mathrm{O}$ bonding of control asphalt binder and binder blending containing bio binder before and after RTFO aging .... 46

Figure 5-13: Ratio of $\mathrm{S}=\mathrm{O}$ bonding of control asphalt binder and binder blending containing bio binder before and after RTFO aging.... 46

Figure 6-1: Rotational viscosities of asphalt binders before and after RTFO aging ........ 51

Figure 6-2: The set up and the strain-stress relation of dynamic modulus test................. 53

Figure 6-3: The indirect tensile (IDT) strength test ................................................ 53

Figure 6-4: The asphalt pavement analyzer (APA) test ................................................ 54

Figure 6-5: The four point beam fatigue test ......................................................... 55

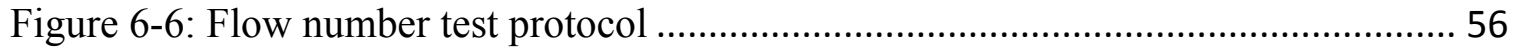

Figure 6-7: Dynamic modulus master curve plot for control asphalt mixture, 5\% and 10\%

OB modified asphalt mixture................................................................... 57 
Figure 6-8: Dynamic modulus master curve plot for control asphalt mixture, 5\% and 10\% DWB modified asphalt mixture ................................................................. 58

Figure 6-9: Dynamic modulus master curve plot for control asphalt mixture, 5\% and 10\%

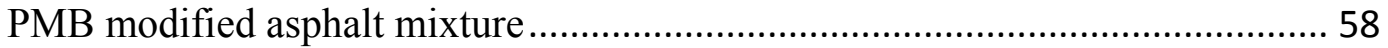

Figure 6-10: Indirect tensile strength results for dry and conditioned asphalt mixtures .. 59

Figure 6-11: Rutting depth development of control asphalt mixture and bio oil modified

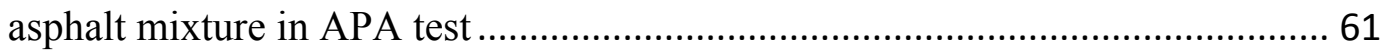

Figure 6-12: Flow numbers of asphalt mixtures at $45{ }^{\circ} \mathrm{C}$ obtained from the flow number

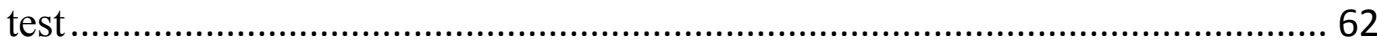

Figure 6-13: Resilient moduli of asphalt mixtures at $45.0^{\circ} \mathrm{C}$ obtained from the dynamic

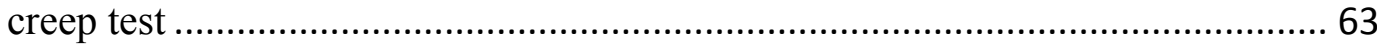

Figure 6-14: Four point beam fatigue test results for control asphalt mixture and bio oil

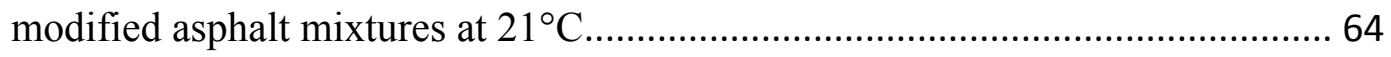

Figure 6-15: The initial dissipated energy during the four point beam fatigue test under

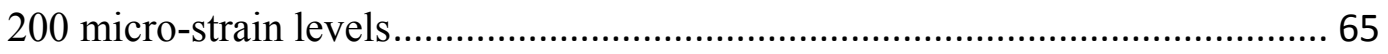

Figure 6-16: relationship between the fatigue life and the initial dissipated energy in the

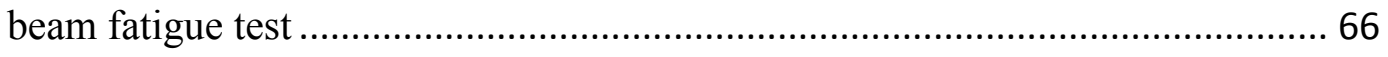

Figure 6-17: Flexural moduli of asphalt mixtures from four point beam bending test at $21^{\circ} \mathrm{C}$ 


\section{LIST OF TABLES}

Table 2-1: Elemental composition of asphalt from different sources.............................. 5

Table 3-1: Rheological test plan for bio oil modified asphalt binders.............................. 8

Table 3-2: Rheological test plan for asphalt binders partially replaced by bio oils........... 9

Table 3-3: Mechanical performance test plan for bio oil modified HMA mixtures ........... 9

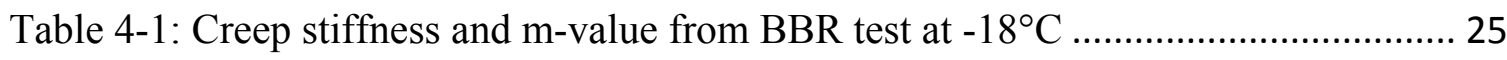

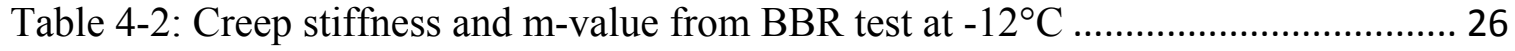

Table 6-1: Detailed gradation of the HMA mixture used in this study ........................... 49

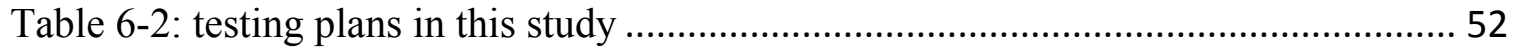


HMA-Hot Mix Asphalt

\section{ABBREVIATIONS}

OB-Original Bio Oil

DWB-Dewatered Bio Oil

PMB-Polymer Modified Bio Oil

APA-Asphalt Pavement Analyzer

IDT-Indirect Tensile Strength

FN-Flow Number

RV-Rotational Viscometer

DSR-Dynamic Shear Rheometer

RTFO-Rolling Thin Film Oven

PAV-Pressure Aging Vessel

BBR-Bending Beam Rheometer

FTIR-Fourier Transform Infrared Microscopy 


\section{PREFACE}

Currently, most of the asphalt materials used in the HMA mixtures are petroleum resource based. Many researchers are striving to develop alternative materials that can be applied in the design and construction of the asphalt pavement. Transportation policy makers are also increasingly considering the use of alternative materials to promote sustainable transportation. Bio oil which can be generated from renewable biomass materials has attracted the attention of researchers. More research is needed to evaluate the feasibility of using these alternative paving materials and to explore the state of practice.

Even though some research strides have been made in developing bioasphalt for the asphalt pavement industry, they are not comprehensive enough to provide a guiding framework on the utilization of bioasphalt in both asphalt binder modifiers and pavements. In Michigan, the attempt to explore and use bioasphalt for advanced sustainable pavements has not been pursued. Therefore, this research will open up the field of bioasphalt development and utilization for durable asphalt transportation infrastructure in Michigan. It will also provide a solid research basis for other interesting bioasphalt research avenues in the State. Thus, the main content of this study are: 1) background and the literature review for the bio oil production as well as the physical and chemical properties of bio oil generated from biomass materials, which is shown in Chapter 1 and Chapter 2; 2) rheological performance evaluation of asphalt binders modified and partially replaced by bio oil generated from waste wood resources, including high temperature and low temperature evaluation, aging simulation and fatigue evaluation, which are shown in Chapter 4 and Chapter 5; 3) mechanical performance evaluation for bio oil modified asphalt mixture, including rutting performance, dynamic modulus, moisture susceptibility, fatigue evaluation, which is illustrated in Chapter 6; 4) recommendations for the application of bioasphalt, which is described in Chapter 7. Chapter 4 is from an article published by International Journal of Pavement Research and Technology, Vol. 6, Issue 4, 2013. The title of this paper is "Performance Evaluation of Asphalt Binder Modified by Bio-oil Generated from Waste Wood Resources", by Xu Yang, Zhanping You and Qingli Dai. The dissertation author (Xu Yang) conducted the 
experiments and wrote this article with Dr. Zhanping You and Dr. Qingli Dai. Chapter 5 is an article submitted to Construction and Building Materials. The title of this paper is "Mechanical Performance of Asphalt Mixtures Modified by Bio Oils Derived from Waste Wood Resources", by Xu Yang, Zhanping You and Qingli Dai. The dissertation author (Xu Yang) conducted the experiments and wrote the article with Dr. Zhanping You and Dr. Qingli Dai. Chapter 6 is an article submitted to ASCE Journal of Materials in Civil Engineering. The title of this paper is "Rheological Property Evaluation and Aging Analysis of Asphalt Binders blended with High Percentage of Bio-binders", by Xu Yang, Zhanping You, Qingli Dai and Julian Mills-Beale. The dissertation author (Xu Yang) did the experiments and wrote the paper with Dr. You, Dr. Dai, and Dr. Mills-Beale.

Three types of bio oils are studied in this study: the original bio oil (OB), dewatered bio oil (DWB) and polymer modified bio oil (PMB). Rotational Viscometer (RV), Dynamic Shear Rheometer (DSR), Bending Beam Rheometer (BBR), Rolling Thin Film Oven (RTFO) and Pressure Aging Vessel (PAV) test were conducted to characterize the rheological properties of asphalt binders modified and partially replaced by bio oil. Asphalt Pavement Analyzer (APA), Tensile Strength Ratio (TSR), Four Point Beam Fatigue and Dynamic Modulus $\left(\mathrm{E}^{*}\right)$ were conducted for the mechanical performance evaluation of asphalt mixtures modified by bio oil. Statistical analysis is also utilized to analyze the test results. The rheological test results showed that: 1) virgin bio oil is overall softer than the control asphalt binder PG 58-28; 2) bio oil ages much faster than the control asphalt binder; 3) the addition of bio oil into the control asphalt binder can improve the rutting performance while sacrifice the fatigue and low temperature performance. The mechanical performance test results showed that: 1) the dynamic modulus $\left(\left|\mathrm{E}^{*}\right|\right)$ of some $\mathrm{OB}$ and DWB modified asphalt mixtures were slightly lower than that of the control asphalt mixture while the $\left|\mathrm{E}^{*}\right|$ of $\mathrm{PMB}$ modified asphalt mixtures were higher than that of the control asphalt mixture; 2) the rutting depth of most of the bio oil modified asphalt mixtures were slightly higher than that of the control asphalt mixture; 3) most of the bio oil modified asphalt mixtures had higher fatigue lives than the control asphalt mixture; 4) the control asphalt mixture and 5\% bio oil modified asphalt mixture had higher TSR value than that of the $10 \%$ bio oil modified asphalt mixtures. 


\section{ACKNOWLEDGEMENTS}

I would like to express my sincere appreciation to my advisor, Dr. Zhanping You, for his guidance and leadership on this research. His temperament, enthusiastic and insistent attitude to research and the financial support inspired me to achieve my research goals. I would like to express my respect and esteem for him. I would also like to thank Dr. Jacob Hiller and Dr. Qingli Dai for serving on y committee and offering their input on my thesis.

I also would like to acknowledge Dr. Julian-Mills Beale of California Baptist University for his contribution to the preliminary research and his assistance for the laboratory work. I would like to acknowledge Miss Su Ting Lau for her significant assistance to the laboratory tests. I would also like to thank Dr. Baron Colbert, who was my office mate and group folk. I learned a lot from him, not only for the research but all others such as the American culture. I'd also like to thank my group members, Shu Wei Goh, Hui Yao, Mohd Rosli, David Poter and Aboelkasim Diab, Xiao Sun and Zigeng Wang. Without their contribution, I cannot finish my research smoothly.

Financial support for this research is from the Michigan Department of Transportation project under Grant No. 2009-0750 Z1. Any opinions, findings and conclusions or recommendations expressed in this study are those of author's and do not necessarily reflect the views of the Michigan Department of Transportation. 


\begin{abstract}
A shortage of petroleum asphalt is creating opportunities for engineers to utilize alternative pavement materials. Three types of bio oils, original bio oil (OB), dewatered bio oil (DWB) and polymer-modified bio oil (PMB) were used to modify and partially replace petroleum asphalt in this research. The research investigated the procedure of producing bio oil, the rheological properties of asphalt binders modified and partially replaced by bio oil, and the mechanical performances of asphalt mixtures modified by bio oil. The analysis of variance (ANOVA) is conducted on the test results for the significance analysis. The main finding of the study includes: 1) the virgin bioasphalt is softer than the traditional asphalt binder PG 58-28 but stiffer after RTFO aging because bio oil ages much faster than the traditional asphalt binder during mixing and compaction; 2) the binder test showed that the addition of bio oil is expected to improve the rutting performance while reduce the fatigue and low temperature performance; 3) both the mass loss and the oxidation are important reasons for the bio oil aging during RTFO test; the mixture test showed that 1) most of the bio oil modified asphalt mixture had slightly higher rutting depth than the control asphalt mixture, but the difference is not statistically significant; 2) the dynamic modulus of some of the bio oil modified asphalt mixture were slightly lower than the control asphalt mixture, the $\mathrm{E}^{*}$ modulus is also not statistically significant; 3 ) most of the bio oil modified asphalt mixture had higher fatigue lives than the control asphalt mixture; 4) the inconsistence of binder test results and mixture test results may be attributed to that the aging during the mixing and compaction was not as high as that in the RTFO aging simulation. 5) the implementation of Michigan wood bioasphalt is anticipated to reduce the emission but bring irritation on eyes and skins during the mixing and compaction.
\end{abstract}




\section{Chapter 1: Introduction}

\subsection{Background}

Asphalt binder has been a major pavement material since last century. It is recorded that the first asphalt pavement in the United States is constructed in Washington D.C. in 1876. Nowadays, more than the $90 \%$ of the pavements in US are asphalt pavement. Compared to cement pavement, the asphalt pavement has advantages such as: 1) smoother and more quiet for driving, and 2) less time consuming to construct and repair. As a result, a large amount of asphalt materials are consumed every year because of the high demand in asphalt pavement industry. Data from industry showed that the asphalt demand were higher than the production from 2005 to 2009. Although the asphalt production can meet the industry demand from 2010, there is a slight increase for the demand compared to that in 2009. In addition, the long going demand of this industry motivates the researchers to seek alternative materials for asphalt binder. The limited inventory of crude oil has pushed the industry to find new and alternative energy resources. As a result, if the supply of crude oil is cut, the asphalt industry is in risk of falling into the severe situation.

To reduce the demand of fresh asphalt binders, some positive approaches were applied, such as the recycling of asphalt pavement materials. Recycled asphalt pavement (RAP) is a very effective way to reduce the use of fresh asphalt binder. The RAP materials have been used since 1970's, when the crude oil crisis motivated the high price of crude oil and the petroleum based asphalt binders. During last few decades, good experiences have been obtained for the RAP use. So far as now, all the Departments of Transportation (DOTs) in the US have made guidelines for the implementation of RAP materials. Some DOTs allow the RAP use as high as 50\% of the new asphalt pavement materials.

Some other recycled approaches have also been used, such as recycled cement concrete (RCC) (Yang, Du et al. 2011)and crumb rubber (Jensen and Abdelrahman 2006; Wang, Dang et al. 2012). Similar as the RAP, RCC is a recycled material from the cement pavement. However, because RCC has a high air voids and absorption to asphalt 
binder, it's not an ideal material in the asphalt pavement. The crumb rubber is obtained from the waste tires and is proved to be a good modifier for the traditional asphalt binders. When it is added into the asphalt binder, it can also reduce the total amount of petroleum based asphalt binder while improving the asphalt properties.

Besides of using recycled materials to reduce the demand of fresh asphalt binders, finding alternative binder materials is also a good approach. The main idea of this approach is to find materials that have the similar properties as the petroleum based asphalt binders and use them in the pavement industry. Previous investigations showed that the lignin and modified lignin products can be potentially used in the asphalt industry. Previous research showed that many these materials can be used to generate bio oils, such as microalgae (Chailleux, Audo et al. 2012), animal waste (Fini, Kalberer et al. 2011), cornstover (Raouf and Williams 2010), urban yard waste (Hill and Jennings 2011), etc.

The application of these bio oils generated from difference biomass resources on the asphalt pavement should be investigated to evaluate if it can be a good alternative for the petroleum based asphalt binder.

\subsection{Project goal}

As mentioned before, the main goal of this project is to evaluate the feasibility of using bio oil as an alternative binder in the asphalt pavement industry. Two steps are set to achieve the goal. First, bio oil serves as a modifier for the petroleum asphalt binders, where bio oil replace only low percent of the asphalt binder (up to $10 \%$ ). Secondly, the bio oil performs as an extender, where bio oil replaces a high percentage of the asphalt binder (up to 70\%). The effect of bio oil on the rheological properties of asphalt binders are evaluated by Superpave ${ }^{\mathrm{TM}}$ binder performance test, including rotational viscometer (RV) test, dynamic shear reheometer (DSR) test, bending beam rheometer (BBR) test. The short-term and long-term aging of asphalt binders are also simulated by rolling thin film oven (RTFO) test and pressure aging vessel (PAV) test, respectively. Meanwhile,

the effect of bio oil on the pavement performance of asphalt mixtures are also evaluated through simple performance tests, including dynamic modulus $\left(\left|\mathrm{E}^{*}\right|\right)$ test, indirect tensile (IDT) strength test, asphalt pavement analyzer (APA) test. 


\subsection{Roadmap}

The roadmap of this research is shown as following:

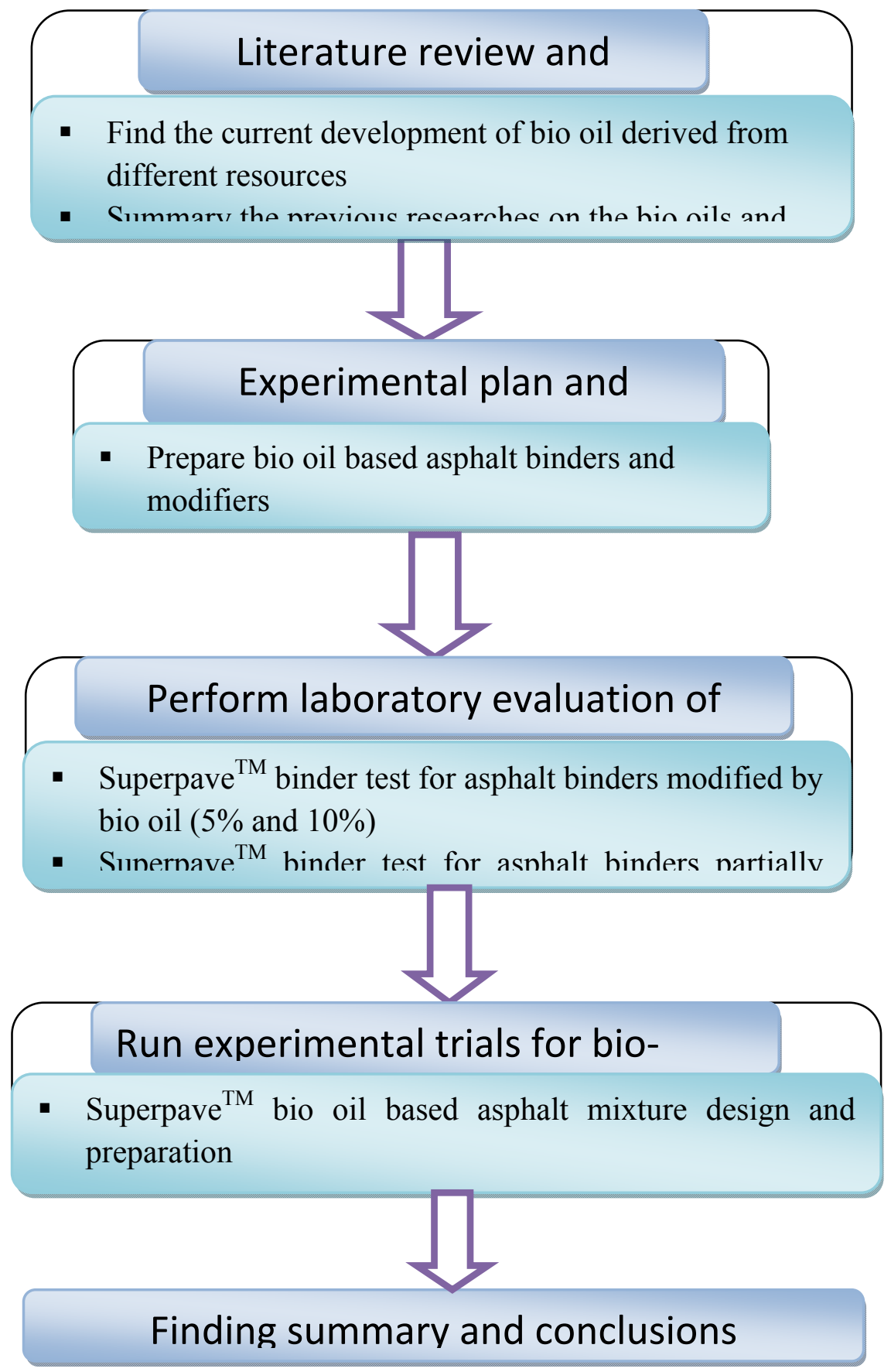




\section{Chapter 2: Literature Review}

\subsection{Processing technology of bio oil from biomass}

A number of processing technologies have been developed for the generation of bio oil from biomass materials such as animal waste, wood, yard waste, etc. Most of the yield technologies involve with a pyrolysis process on the original biomass. Pyrolysis process can be divided into fast, intermediate and slow pyrolysis according to the residence time of the solid phase in the reactor. Sometimes, pressure, vacuum, catalysis, or some other materials is used to help the decomposition of the biomass. It is found that a fast pyrolysis process is a promising approach to generate high percent bio oil compared to the slow pyrolysis (U.S.D.O.E. 2005; Brown 2010). Williams et al (Williams, Satrio et al. 2008) successfully yield bio oils from wood waste using fast pyrolysis process. For most of the pyrolysis process, the biomass is preheated to reduce the water content before the pyrolysis. Then, it is rapidly heated to $450-600^{\circ} \mathrm{C}$ in the absence of air in the pyrolysis process. A mixed vapor and bio chars will be generated during this process. After this, the vapor can be separated as liquid bio oil and gas with a condensation. The gases produced can be the energy source to heat the biomass in return while the bio char and the liquid bio oils will be stored. The schematic of the process is shown in

Figure 2-1.

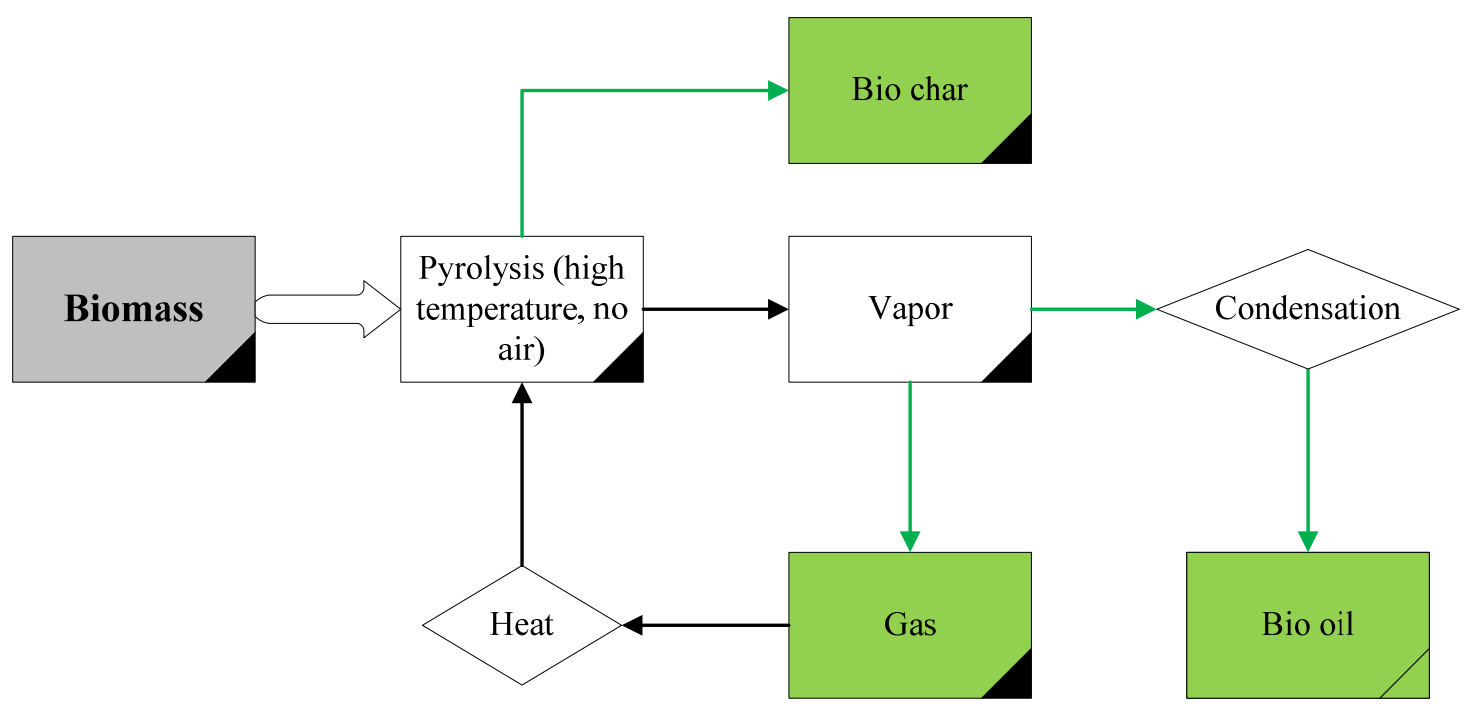

Figure 2-1: The schematic of the pyrolysis process 


\subsection{Elemental analysis of bio oil and petroleum asphalt}

The elemental analysis for the bio oils generated from waste wood resources and the petroleum asphalt are shown in Table 2-1. It is found that the petroleum asphalt has higher Carbon $(\mathrm{C})$ and Hydrogen $(\mathrm{H})$ elements but lower oxygen $(\mathrm{O})$ element than the bio oils from wood waste, swine waste and switchgrass. Comparison among the three types of bio oils showed that the bio oil from swine waste has much higher $\mathrm{N}$ element than the rest two. Because the relative element amount can influence the functional and polar groups in asphalt, the physical and chemical properties of bio oils and petroleum asphalt may be very different.

Table 2-1: Elemental composition of asphalt from different sources

\begin{tabular}{|c|c|c|c|c|c|}
\hline \multicolumn{2}{|c|}{ Asphalt type } & $\mathrm{C}(\%)$ & $\mathrm{H}$ & $\mathrm{N}$ & $\mathrm{O}(\%)$ \\
\hline & etroleum asphalt (Fini, Kalberer et al. 2011) & 81.6 & 10.8 & 0.77 & 0.9 \\
\hline \multirow{12}{*}{$\begin{array}{r}\text { Bio } \\
\text { oil }\end{array}$} & swine waste (Fini, Kalberer et al. 2011) & 72.58 & 9.76 & 4.47 & 13.19 \\
\hline & waste wood resources (Czernik and Bridgwater & 56.4 & 6.2 & 0.1 & 37.3 \\
\hline & switchgrass (Mullen and Boateng 2008) & 47.53 & 6.81 & 0.51 & 45.19 \\
\hline & Alfalfa, early bud (Mullen and Boateng 2008) & 53.88 & 8.47 & 4.59 & 32.73 \\
\hline & Alfalfa, full flower (Mullen and Boateng 2008) & 56.84 & 7.86 & 3.73 & 31.3 \\
\hline & Cornstover (Roaouf, Metwally et al. 2010) & 46.5 & 5.9 & -- & 46.2 \\
\hline & $\begin{array}{l}\text { Oakwood/Oak flour (Roaouf, Metwally et al. } \\
\qquad 2010 \text { ) }\end{array}$ & 60.5 & 6.5 & -- & 34.6 \\
\hline & Coffee residue (Chaiya 2011) & 32.38 & 10.1 & 2.08 & -- \\
\hline & Laurel (Ertaş and Hakkı Alma 2010) & 49.65 & 8.1 & 5.0 & 41.63 \\
\hline & Tea waste (Uzun, Apaydin-Varol et al. 2010) & 69.26 & 8.97 & 6.19 & 15.58 \\
\hline & Rapeseed (Onay and Koçkar 2006) & 72.8 & 10.8 & 3.3 & 13.1 \\
\hline & Soybean (Sensöz and Kaynar 2005) & 67.89 & 7.77 & $\begin{array}{c}10.8 \\
4\end{array}$ & -- \\
\hline
\end{tabular}




\subsection{Physical and chemical properties of bio oil}

As mentioned before, the element components of bio oils are different from that of the petroleum asphalt, the physical and chemical properties may also be different. In addition, the properties of bio oils from different biomass resources may also be different. There are some previous researches focusing on the rheological and chemical properties of asphalt. Williams (Williams 2008) conducted some researches on bio oils generated from corn stover, switch grass and oak wood waste and found that the addition of bio oil derived from these resources can increase the stiffness of the petroleum asphalt and enhance the high temperature performance of base asphalt. On the other hand, You et al (2011) investigated the properties of bio oil generated from swine waste and found that this type of bio oil can decrease the stiffness of base asphalt and improve the low temperature performance. This opposite result is possibly due to the different resources of bio oils, whose element compositions are also different as shown in Table 2-1. Bio oils from other biomass resources are also investigated in previous researches. Zofka and Yut (2012) derived bio oil from waste coffee grounds and used it to modify the traditional asphalt and found that the bio oil generated from the coffee grounds can serve as a solvent in the petroleum asphalt. Chailleux et al (2012) extracted bio oil from microalgae and found the bio oil has similar thermo-dependent behavior as the traditional asphalt. Barras (2008) produced bio oils from saw dust and yard waste and found alkanes with eight to nine carbon atoms similar gasoline and alkanes with 12 to 18 carbons similar as diesel. Peralta et al (2012) used crumb rubber modified bio oil to replace the petroleum asphalt binder in the hot mix asphalt and concluded that this types of bio oil can be developed effectively to replace the traditional asphalt binder. Uzun et al (2010) dealt with the tea waste which can produce liquid and solid products and found that the liquid product can be used as liquid fuel while the solid product is not suitable for adsorption purpose due to the low surface area. Ertas and Alma (2010) produced bio oils and bio chars from laurel extraction residues and investigated their properties, and illustrated that the bio oil from the laurel extraction residues can be important fuel source and chemical feedstocks. Similarly, studies from Onay and Kockar (2006) showed that the bio oils generated from rapeseed can be used as diesel fuel and the chemical feedstocks. 


\section{Chapter 3: Experimental Plan and Sample Preparation}

In this chapter, the overall experimental plan and the preparation of the samples of this study will be described. The experimental plan includes the effects of bio oils on both the asphalt binders and the asphalt mixtures.

\subsection{Experimental Plan}

The experimental plan of this study mainly includes: 1) rheological property evaluation of asphalt binders modified bio oils; 2) Mechanical performance evaluation of HMA mixtures modified by bio oils.

\subsubsection{Rheological Property Characterization of Asphalt Binders Modified by Bio Oil}

The main task of this section is to characterize the rheological properties of asphalt binders modified by bio oil. Superpave $\mathrm{e}^{\mathrm{TM}}$ binder test is conducted on the control asphalt binder, $5 \%$ and $10 \%$ bio oil modified asphalt binders. These tests and the functions are: Rotational Viscosity (RV) test to determine the mixing and compaction temperature of asphalt binders; Rolling Thin Film Oven (RTFO) test to simulate the short-term aging of asphalt binders during the construction period; Pressure Aging Vessel (PAV) test to simulate the long-term aging of asphalt binders during the serving life; Dynamic Shear Rheometer (DSR) test for virgin and RTFO aged asphalt binders to evaluate the high temperature performance of asphalt binders and mixtures; DSR test for PAV aged asphalt binders to evaluate the fatigue performances of asphalt mixtures during the service life; Bending Beam Rheometer (BBR) test to evaluate the low temperature performances of asphalt binders and mixtures.

The asphalt binders used in this study include petroleum based asphalt binder PG 58-28 and bio oil generated from waste wood resources collected in upper Michigan region in US. Three types of bio oils were used in this study, including original bio oil (i.e., OB), dewatered bio oil (i.e., DWB) and polymer modified bio oil (i.e., PMB). The original bio oil is the bio product yield directly from the waste wood resources. The water content of this type of bio oil is about $15-30 \%$ by weight. It is mainly resulted from the water in the 
bio mass resources. The dewatered bio oil is obtained through a process reducing the water content of the bio oil to about 5\% (Raouf and Williams 2009). The polymer modified bio oil is a product that polyethylene modifiers are added into the bio oil.

Table 3-1: Rheological test plan for bio oil modified asphalt binders

\begin{tabular}{|c|c|c|c|c|c|c|c|}
\hline Test Equipment & \multirow{2}{*}{ Control } & \multicolumn{2}{|c|}{ OB } & \multicolumn{2}{c|}{ DWB } & \multicolumn{2}{c|}{ PMB } \\
\cline { 5 - 8 } & & $5 \%$ & $10 \%$ & $5 \%$ & $10 \%$ & $5 \%$ & $10 \%$ \\
\hline RV test & $\mathrm{XXX}$ & $\mathrm{XXX}$ & $\mathrm{XXX}$ & $\mathrm{XXX}$ & $\mathrm{XXX}$ & $\mathrm{XXX}$ & $\mathrm{XXX}$ \\
\hline DSR for virgin binders & $\mathrm{XXX}$ & $\mathrm{XXX}$ & $\mathrm{XXX}$ & $\mathrm{XXX}$ & $\mathrm{XXX}$ & $\mathrm{XXX}$ & $\mathrm{XXX}$ \\
\hline DSR for RTFO aged binders & $\mathrm{XXX}$ & $\mathrm{XXX}$ & $\mathrm{XXX}$ & $\mathrm{XXX}$ & $\mathrm{XXX}$ & $\mathrm{XXX}$ & $\mathrm{XXX}$ \\
\hline DSR for PAV aged binders & $\mathrm{XXX}$ & $\mathrm{XXX}$ & $\mathrm{XXX}$ & $\mathrm{XXX}$ & $\mathrm{XXX}$ & $\mathrm{XXX}$ & $\mathrm{XXX}$ \\
\hline RTFO for virgin & $\mathrm{XXX}$ & $\mathrm{XXX}$ & $\mathrm{XXX}$ & $\mathrm{XXX}$ & $\mathrm{XXX}$ & $\mathrm{XXX}$ & $\mathrm{XXX}$ \\
\hline PAV test & $\mathrm{XXX}$ & $\mathrm{XXX}$ & $\mathrm{XXX}$ & $\mathrm{XXX}$ & $\mathrm{XXX}$ & $\mathrm{XXX}$ & $\mathrm{XXX}$ \\
\hline BBR test & $\mathrm{XXX}$ & $\mathrm{XXX}$ & $\mathrm{XXX}$ & $\mathrm{XXX}$ & $\mathrm{XXX}$ & $\mathrm{XXX}$ & $\mathrm{XXX}$ \\
\hline
\end{tabular}

*note: X means one replicate

\subsubsection{Rheological Property Characterization of Asphalt Binders Partially Replaced by Bio Oil}

In this section, the bio oil serves as extenders in the base asphalt binders. Rheological properties of $10 \%, 30 \%$ and $70 \%$ of bio oil blended asphalt binders are studied. Preliminary research showed that if using the standard RTFO and PAV aging process, the bio oil would be over aged, a modified RTFO and PAV aging process was proposed (Metwally and Williams 2010). The difference of the modified and standard RTFO test lies in the aging time and aging temperature, which is reduced to 20 minutes at $120^{\circ} \mathrm{C}$ from 85 minutes at $163^{\circ} \mathrm{C}$ respectively. Because the tests in this part deals with high percentage of bio oil blended asphalt binders, the aging of the mixed asphalt binders would be very high. As a result, both the RTFO and PAV test are adopted as the modified procedure as mentioned above. Other Superpave ${ }^{\mathrm{TM}}$ binder tests including RV test, DSR test and BBR test follow the standard test procedures. The detailed test plan is listed as Table 3-2. 
Table 3-2: Rheological test plan for asphalt binders partially replaced by bio oils

\begin{tabular}{|c|c|c|c|c|c|c|c|c|c|c|}
\hline $\begin{array}{c}\text { Test } \\
\text { equipment }\end{array}$ & \multirow{2}{*}{ Control } & \multicolumn{3}{|c|}{ DWB } & \multicolumn{3}{c|}{ DWB } & \multicolumn{3}{c|}{ PMB } \\
\cline { 3 - 10 } & & $10 \%$ & $30 \%$ & $70 \%$ & $10 \%$ & $30 \%$ & $70 \%$ & $10 \%$ & $30 \%$ & $70 \%$ \\
\hline RV test & $\mathrm{XXX}$ & $\mathrm{XXX}$ & $\mathrm{XXX}$ & $\mathrm{XXX}$ & $\mathrm{XXX}$ & $\mathrm{XXX}$ & $\mathrm{XXX}$ & $\mathrm{XXX}$ & $\mathrm{XXX}$ & $\mathrm{XXX}$ \\
\hline RTFO test & $\mathrm{XXX}$ & $\mathrm{XXX}$ & $\mathrm{XXX}$ & $\mathrm{XXX}$ & $\mathrm{XXX}$ & $\mathrm{XXX}$ & $\mathrm{XXX}$ & $\mathrm{XXX}$ & $\mathrm{XXX}$ & $\mathrm{XXX}$ \\
\hline DSR test & $\mathrm{XXX}$ & $\mathrm{XXX}$ & $\mathrm{XXX}$ & $\mathrm{XXX}$ & $\mathrm{XXX}$ & $\mathrm{XXX}$ & $\mathrm{XXX}$ & $\mathrm{XXX}$ & $\mathrm{XXX}$ & $\mathrm{XXX}$ \\
\hline PAV test & $\mathrm{XXX}$ & $\mathrm{XXX}$ & $\mathrm{XXX}$ & $\mathrm{XXX}$ & $\mathrm{XXX}$ & $\mathrm{XXX}$ & $\mathrm{XXX}$ & $\mathrm{XXX}$ & $\mathrm{XXX}$ & $\mathrm{XXX}$ \\
\hline BBR test & $\mathrm{XXX}$ & $\mathrm{XXX}$ & $\mathrm{XXX}$ & $\mathrm{XXX}$ & $\mathrm{XXX}$ & $\mathrm{XXX}$ & $\mathrm{XXX}$ & $\mathrm{XXX}$ & $\mathrm{XXX}$ & $\mathrm{XXX}$ \\
\hline
\end{tabular}

*note: $\mathrm{X}$ means one replicate

\subsubsection{Mechanical Performance Evaluation of Hot Mix Asphalt Modified by Bio Oil}

In this part, the mechanical performances of HMA mixture modified by bio oils are evaluated. The related performance tests are: Asphalt Pavement Analyzer (APA) test and Flow Number (FN) test for rutting resistance evaluation; Dynamic Modulus ( $\left.\mathrm{E}^{*}\right)$ test for the stiffness property evaluation; Indirect Tensile (IDT) test for the tensile strength evaluation; Tensile Strength Ratio (TSR) test for moisture susceptibility evaluation; beam fatigue test for fatigue life evaluation.

Considering that high percentage of bio oil blended asphalt mixture would use a lot of bio oils beyond of the research team's storage, only low percentage of bio oil containing HMA mixture are studied. The detailed test plan is listed as Table 3-3.

Table 3-3: Mechanical performance test plan for bio oil modified HMA mixtures

\begin{tabular}{|c|c|c|c|c|c|c|c|}
\hline \multirow{2}{*}{ Test equipment } & \multirow{2}{*}{ Control } & \multicolumn{2}{|c|}{ OB } & \multicolumn{2}{c|}{ DWB } & \multicolumn{2}{c|}{ PMB } \\
\cline { 3 - 8 } & & $5 \%$ & $10 \%$ & $5 \%$ & $10 \%$ & $5 \%$ & $10 \%$ \\
\hline APA test & $\mathrm{XXX}$ & $\mathrm{XXX}$ & $\mathrm{XXX}$ & $\mathrm{XXX}$ & $\mathrm{XXX}$ & $\mathrm{XXX}$ & $\mathrm{XXX}$ \\
\hline E* test $^{*} \mathrm{XXX}$ & $\mathrm{XXX}$ & $\mathrm{XXX}$ & $\mathrm{XXX}$ & $\mathrm{XXX}$ & $\mathrm{XXX}$ & $\mathrm{XXX}$ \\
\hline IDT test & $\mathrm{XXX}$ & $\mathrm{XXX}$ & $\mathrm{XXX}$ & $\mathrm{XXX}$ & $\mathrm{XXX}$ & $\mathrm{XXX}$ & $\mathrm{XXX}$ \\
\hline TSR test & $\mathrm{XXX}$ & $\mathrm{XXX}$ & $\mathrm{XXX}$ & $\mathrm{XXX}$ & $\mathrm{XXX}$ & $\mathrm{XXX}$ & $\mathrm{XXX}$ \\
\hline Beam Fatigue test & $\mathrm{XXX}$ & $\mathrm{XXX}$ & $\mathrm{XXX}$ & $\mathrm{XXX}$ & $\mathrm{XXX}$ & $\mathrm{XXX}$ & $\mathrm{XXX}$ \\
\hline FN test & $\mathrm{XXX}$ & $\mathrm{XXX}$ & $\mathrm{XXX}$ & $\mathrm{XXX}$ & $\mathrm{XXX}$ & $\mathrm{XXX}$ & $\mathrm{XXX}$ \\
\hline
\end{tabular}

*note: X means one replicate 


\subsection{Sample Preparation}

\subsubsection{Preparation of asphalt binders blended with bio oil}

- Mixing condition of bio oil and base asphalt

Before the mixing of bio oil and base asphalt, the base asphalt is heated to about $120^{\circ} \mathrm{C}$. Since the bio oil is stored in plastic bottles and it's not proper to heat it in the oven, a water bath is used to take out the bio oil from the bottle. Thus, the temperature to heat the bio oil samples is about 90 to $100^{\circ} \mathrm{C}$. After the heating, the bio oil and base asphalt are mixed with the designed fractions. The mixing temperature for bio oil and base asphalt are $90^{\circ} \mathrm{C}$ and $120^{\circ} \mathrm{C}$ respectively.

\section{- High shear mixing of base asphalt and bio oil}

The mixing procedure of base asphalt PG 58-28 and bio oil was conducted by the high speed mechanical shearing equipment. During the mixing, the screw of the mixer rotated with a high speed, which causes a whirl flow inside the asphalt binder liquid. The whirl flow made the base asphalt and bio oil mix well. The mixing condition was $5000 \mathrm{rpm}$ at $110^{\circ} \mathrm{C}$ for 15 minutes. The higher speed can make stronger whirl flow, which is beneficial for the uniformly mixing of the two components. The higher the mixing temperature is, the easier is the mixing process because of the higher fluidity. However, the high temperature may cause a significant aging during the mixing, which will have great influence on the following testing. Williams (2009) pointed that $120^{\circ} \mathrm{C}$ is a convenient mixing temperature for bio oil and asphalt. The research team found the mixing can also be conducted very well under $110^{\circ} \mathrm{C}$, so $110^{\circ} \mathrm{C}$ was selected as the mixing temperature. To avoid the aging caused by long mixing time but make sure the mixing is very well, the mixing time was determined as 15 minutes.

\subsubsection{Preparation of asphalt mixture samples containing bio oil}

The mixture samples of asphalt pavement analyzer (APA) test, Indirect tensile strength (IDT) test, tensile strength ratio (TSR) test, dynamic modulus (E*) test and flow number (FN) test are prepared by the Superpave ${ }^{\mathrm{TM}}$ Gyratory Compactor (SGC) for 86 gyrations. Three asphalt mixture samples with different binder contents are compacted first and the rice test is conducted to determine the bulk specific gravity (Gmb) and the maximum 
theoretical specific gravity (Gmm). Based on the tested Gmm and Gmb, the optimum binder content is determined.

- APA test

The standard test procedure for the APA test is according to AASHTO TP 63. The mixture sample tested in the APA test is cylinder with $150 \mathrm{~mm}$ in diameter and $75 \mathrm{~mm}$ in height. The air voids of the sample are $4 \%$.

- Dynamic shear modulus ( $\left.E^{*}\right)$ and FN test

The recommended specimen size for $\mathrm{E}^{*}$ test is $100 \mathrm{~mm}$ in diameter by $200 \mathrm{~mm}$ high, it may be possible to use smaller specimen heights with success. The specimen size prepared in this study is $100 \mathrm{~mm}$ in diameter by about $150 \mathrm{~mm}$ high compacted by the SGC to a $4 \%$ air voids. The sample preparation of FN test is the same as that of the $\mathrm{E}^{*}$ test.

- Indirect Tensile Strength (IDT) and Tensile Strength Ratio (TSR) test

The sample preparations for IDT test and TSR test are in accordance with AASHTO TP 9 and AASHTO T 283. The sample size is $100 \mathrm{~mm}$ in diameter by $63.5 \pm 1.5 \mathrm{~mm}$ high. The specimen is compacted to a targeted $7 \%$ air void. 


\section{Chapter 4: Laboratory Evaluation of Bio Oil as Modifier on Rheological Properties of Asphalt Binders ${ }^{1}$}

In this chapter, the bio oil is used as the modifier for traditional asphalt binder and the effect of bio oil modifier on the rheological properties of asphalt binders is investigated. Bio oil replaces up to $10 \%$ of the base asphalt by weight. The rheological properties of asphalt binders include viscosity at high temperature, complex shear modulus and phase angle at medium temperatures, creep stiffness and $\mathrm{m}$-value at low temperatures. The corresponding test methods include rotational viscometer, dynamic shear rheometer, bending beam rheometer. The short- and long-term aging is also simulated by the rolling thin film oven and pressure aging vessel test.

\subsection{Introduction}

Asphalt binder is one of the three main components of asphalt mixtures (binder, aggregate and air voids) and that the asphalt binder properties have important relationship with the short-term and long-term performances of asphalt mixtures. In addition, the rheological properties of virgin asphalt binders can determine the mixing and compaction temperature of asphalt mixtures during the construction period. Rutting, thermal cracking and fatigue cracking are the most concerned distresses that truncate or impede the pavement service ability and service life from functional and structural perspectives. The mixing and compaction temperatures have relation with the energy needed to heat the asphalt mixture materials and the emissions to the environment. A lower mixing and compaction temperature is encouraged nowadays for the energy saving and the environmental friendly. Rutting is described as the progressive permanent deformation in the pavement caused by the displacement of the asphalt mixture particles under wheel load especially at high temperatures. Thermal cra ${ }^{1}$ cking, also called as low temperature cracking, occurs when the tensile stress or strain exceed the stress or strain capacity of

\footnotetext{
${ }^{1}$ Text was published in International Journal of Pavement Research and Technology - Yang, X., You. Z, Dai, Q., (2013) "Performance Evaluation of Asphalt Binder Modified by Bio-oil Generated from Waste Wood Resources", 6(4): 431-439. International Journal of Pavement Research and Technology.
} 
asphalt pavement at low temperatures. Normally, thermal cracking occurs from the surface of asphalt pavement. Fatigue cracking is caused by the repeated tensile strength. Although the tensile stress or strain is lower the capacity of the asphalt pavement, the repeated stress would also cause a cracking finally. Since the asphalt binder properties has close relation with the performance of asphalt mixtures, some testing methods for asphalt binder properties have been well developed to indicate the potential performance of asphalt mixtures.

\subsection{Experiment Plan}

\subsubsection{Rotational viscometer (RV) test}

The RV test is to determine the viscosity at high temperature and furthermore the workability of asphalt binders. The RV test for virgin asphalt binder can determine the mixing and compaction temperatures of asphalt mixtures during the construction. The RV test follows the standard AASHTO T 316 (2011). The test temperatures are 90, 110, 130, 150 and $165^{\circ} \mathrm{C}$ in this study.

\subsubsection{Dynamic shear rheometer (DSR) test}

DSR test is to determine the visco-elastic property of asphalt binders in a high temperature and frequency range. The standard procedure of DSR test follows AASHTO T 315 (2010). In this study, the DSR test is conducted for virgin, RTFO- and PAV-aged asphalt binders. For virgin and RTFO aged asphalt binders, the test temperatures asphalt are $40,46,52,58,64$ and $70^{\circ} \mathrm{C}$, while the frequencies are $0.1,0.5,1,5,10$ and $25 \mathrm{~Hz}$. For the PAV aged asphalt binders, the test temperatures are $13,19,25,31$ and $37^{\circ} \mathrm{C}$, while the frequencies are $0.1,0.5,1,5$ and $10 \mathrm{~Hz}$.

\subsubsection{Rolling thin film oven (RTFO) test}

The RTFO test is to simulate the short term aging of asphalt binders during the construction. The standard RTFO test follows the AASHTO T 240 (2009). The asphalt binders are conditioned in the oven at $163^{\circ} \mathrm{C}$ for 85 minutes. 


\subsubsection{Pressure Aging Vessel (PAV) test}

The PAV test is to simulate the long term aging of asphalt binders during the service life. The standard PAV test follows AASHTO R 28 (2009). In the test, the RTFO aged asphalt binders are exposed in the aging condition with $2.1 \mathrm{MPa}$ and $100^{\circ} \mathrm{C}$ for 24 hours.

\subsubsection{Bending beam rheometer (BBR) test}

The BBR test is to investigate the low temperature performance (thermal cracking) of asphalt binders. The test procedure follows AASHTO T 313 (2010). The materials used in the BBR test are the PAV aged asphalt binders. The SuperpaveTM binder test recommends $-18^{\circ} \mathrm{C}$ as the test temperature for $\mathrm{PG} 58-28$. To better understand the low temperature performance of asphalt binders, $-12^{\circ} \mathrm{C}$ is added as a second test temperature.

\subsection{Results and Discussions}

\subsubsection{Rotational viscometer (RV) tests}

Figure 4-1 illustrates the rotational viscosities of control asphalt binder and bio oil modified asphalt binders before and after the standard RTFO aging. Before the RTFO aging, the rotational viscosities of $5 \%$ and $10 \%$ OB modified asphalt binders were $13.3 \%$ and $7.7 \%$ lower than the control asphalt binder in average, respectively; the rotational viscosities of 5\% and 10\% DWB modified asphalt binders were $12.1 \%$ and $7.6 \%$ lower than the control asphalt binder in average, respectively; the rotational viscosities of 5\% and 10\% PMB modified asphalt binders were $8.4 \%$ and $12.4 \%$ lower than the control asphalt binder in average, respectively. After the RTFO aging, the rotational viscosities of $5 \%$ and $10 \%$ OB modified asphalt binders were averagely $1.2 \%$ and $8.5 \%$ higher than that of the control binder, respectively; the rotational viscosities of 5\% and $10 \%$ DWB modified asphalt binders were averagely $2.9 \%$ and $14.9 \%$ higher than that of the control binder, respectively; the rotational viscosities of 5\% and 10\% PMB modified asphalt binders were averagely $3.6 \%$ and $4.7 \%$ lower than that of the control binder, respectively.

The test results for virgin asphalt binders indicate that the bio oil is generally softer than the control asphalt binder before RTFO aging. As a result, when bio oil is blended into the control asphalt binder, the viscosities of the blends decrease. The OB, 
DWB and PMB modified asphalt binders had rotational viscosities $10.5 \%, 9.8 \%$ and $10.3 \%$ lower than the control asphalt binder, respectively. This means that the three types of bio oils had close effect on the rotational viscosity when blended into the asphalt binder. Since the rotational viscosity of the asphalt binders can determine the mixing and compaction temperatures of asphalt mixture, the addition of bio oil is likely to reduce the mixing and compaction temperatures of asphalt binders.

However, after the RTFO aging, both the OB and DWB modified asphalt binders showed higher viscosities than the control asphalt binder. Although the viscosities of PMB modified asphalt binders were still lower than that of the control asphalt binder, but the difference was much lower than that before RTFO aging. Because of the increase of the viscosity is resulted from the aging of asphalt binder, this means that the bio oil modified asphalt binder aged faster than the control asphalt binder. To detailedly analyze the aging property of bio oil modified asphalt binders, the term aging index is introduced. The aging index is determined as the ratio of the viscosities after and before the RTFO aging, as shown below (Brown, Kandhal et al. 2009):

$$
\text { Aging index }=\frac{\text { viscosity of aged binders }}{\text { viscosity of vergin binders }}
$$

Based on the equation above, the aging indexes of the control and bio oil modified asphalt binders were obtained and displayed in Figure 4-2. The aging indexes of $5 \%$ and $10 \%$ OB, $5 \%$ and $10 \%$ DWB, and $5 \%$ and $10 \%$ PMB modified asphalt binders were $17.64 \%, 18.82 \%, 18.15 \%, 26.13 \%, 6.62 \%$ and $9.97 \%$ higher than the control asphalt binder, respectively. This shows that with the increase of bio oil content, the aging index also increased. Comparison among the three types of bio oils showed that the DWB modified asphalt binder had the highest aging index, followed by the OB and PMB modified asphalt binders. It is noticed that the PMB modified asphalt binders showed significantly lower aging index than the other two binders. 


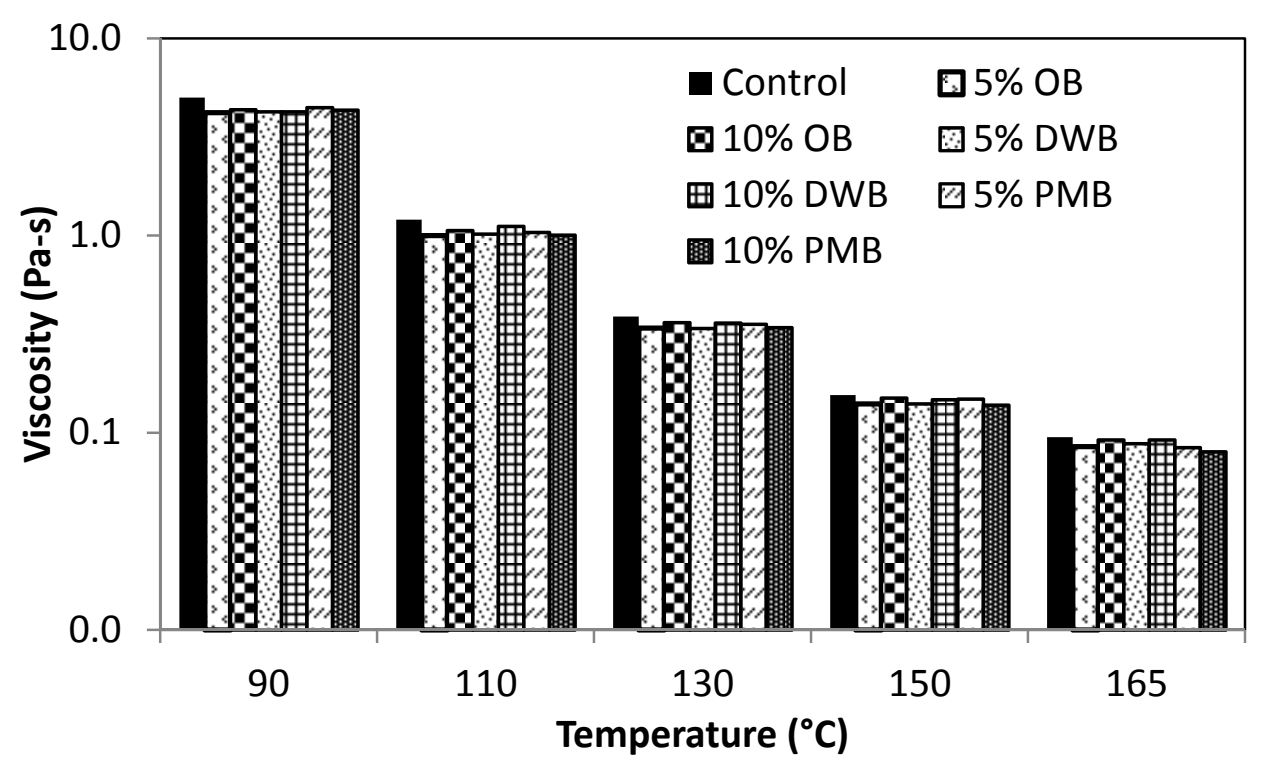

(a) The rotational viscosities of bio oil modified asphalt binders before RTFO aging

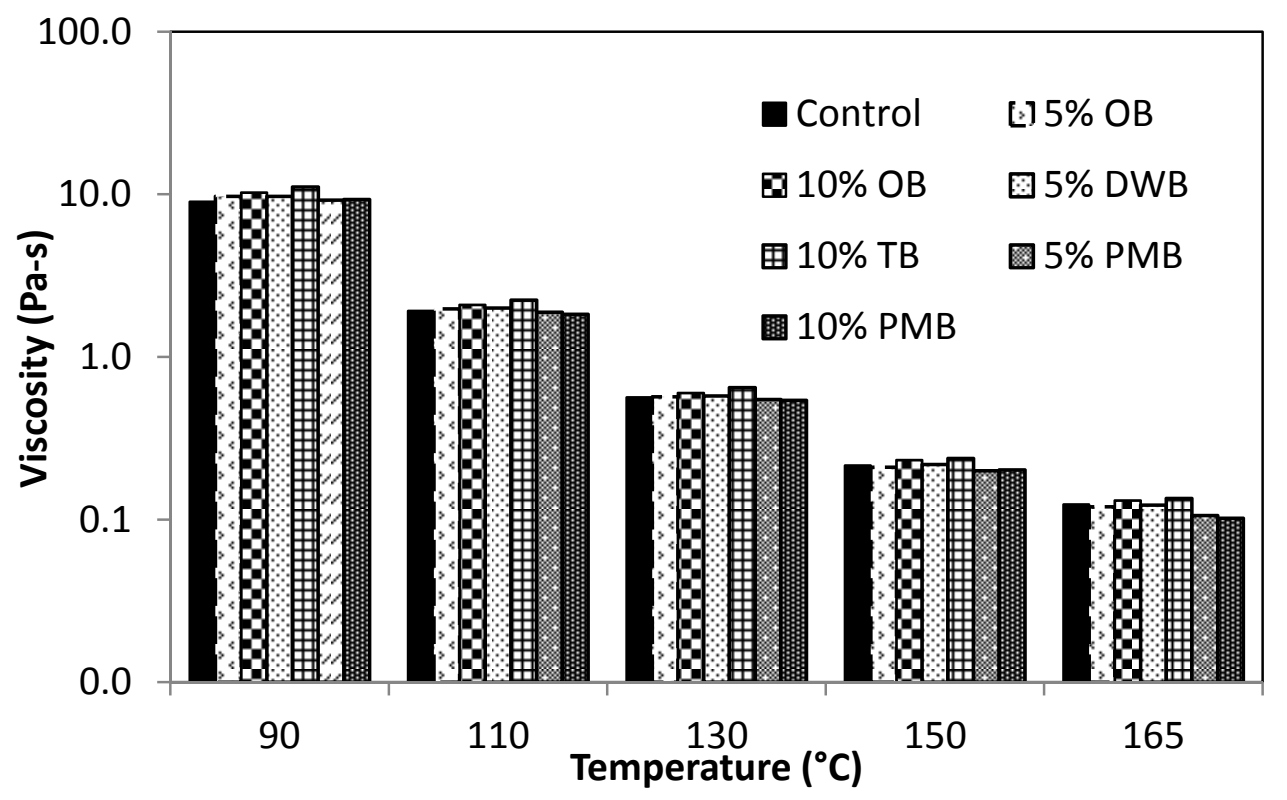

(b) The rotational viscosities of bio oil modified asphalt binders before RTFO aging Figure 4-1: The rotational viscosities of asphalt binders before and after RTFO aging 


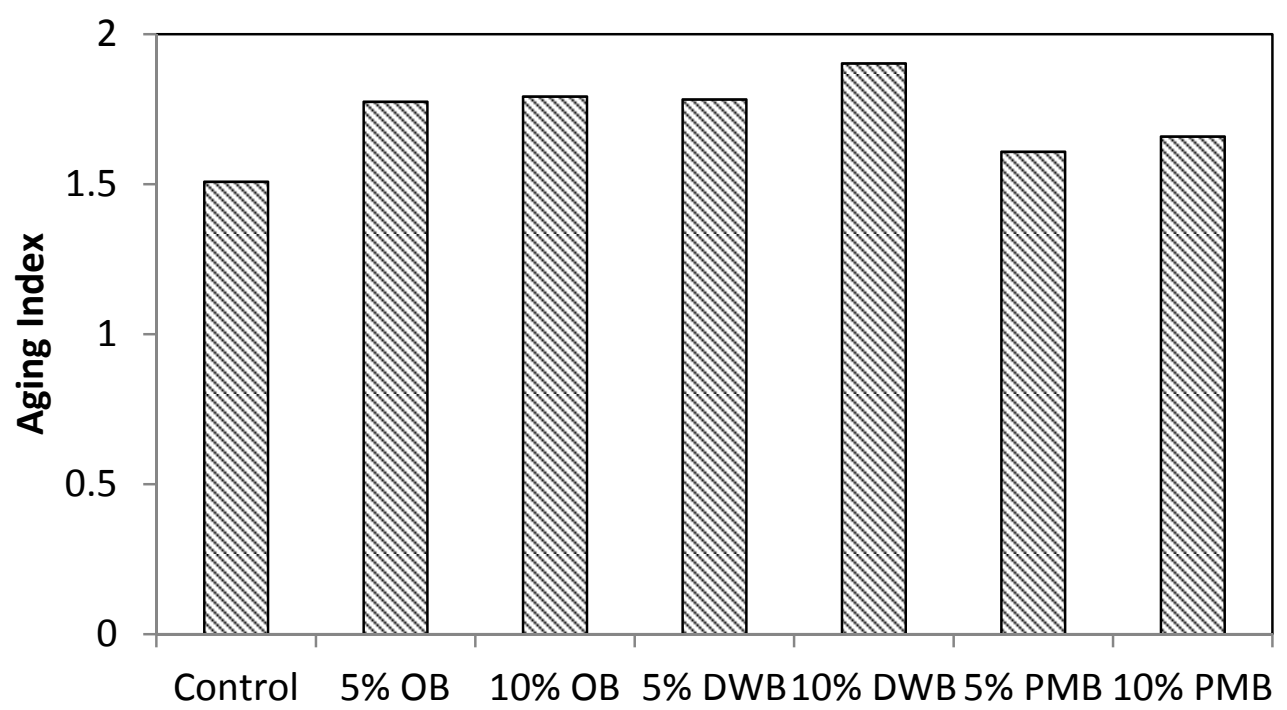

Figure 4-2: The aging indexes of control and bio oil modified asphalt binders during RTFO aging

\subsubsection{Dynamic shear rheometer (DSR) test}

\section{DSR for virgin and RTFO aged binders}

Figure 4-3 to Figure 4-5 display the $\left|\mathrm{G}^{*}\right|$ master curve for control and bio oil modified asphalt binders in the DSR test before and after RTFO aging. The $\left|\mathrm{G}^{*}\right| \mathrm{s}$ of OB, DWB and PMB modified asphalt binders were $6.3 \%, 0.4 \%$ and $16.8 \%$ higher than that of the control asphalt binder. The higher $\left|\mathrm{G}^{*}\right|$ of the PMB modified asphalt binder is possibly resulted from the polymer added in the bio oil, which makes the bio oil slightly stiffer. It is also observed from the master curve that the bio oil modified asphalt binders had obvious higher $\left|\mathrm{G}^{*}\right|$ than the control asphalt binder in lower reduced frequency area (high temperature and low frequency). Since it is thought that the $\left|G^{*}\right|$ has a correlation with the rutting performance of asphalt binders, and rutting is easier to occur at high temperature and low frequency condition, the higher $\left|\mathrm{G}^{*}\right| \mathrm{s}$ of bio oil modified asphalt binders in the low reduced frequency area is beneficial to the rutting performance.

After the RTFO aging, it is found that the bio oil modified asphalt binders had $\left|\mathrm{G}^{*}\right|$ s significantly higher than the control asphalt binder. Further, with the increase of bio oil content in the asphalt binder, the $\left|\mathrm{G}^{*}\right| \mathrm{s}$ after RTFO aging also increased. The average $\left|\mathrm{G}^{*}\right|$ of $5 \%$ and $10 \%$ OB modified asphalt binders were $41.7 \%$ and $49.5 \%$ higher than that of the control binder, respectively; the average $\left|\mathrm{G}^{*}\right|$ of $5 \%$ and $10 \%$ DWB modified 
asphalt binders were $41.2 \%$ and $71.3 \%$ higher than that of the control binder, respectively; the $\left|\mathrm{G}^{*}\right|$ of $5 \%$ and $10 \%$ DWB modified asphalt binders were $59.7 \%$ and $65.6 \%$ higher than that of the control binder in average, respectively. The higher $\left|\mathrm{G}^{*}\right|$ of bio oil modified asphalt binders is mainly from the fast aging of bio oil.

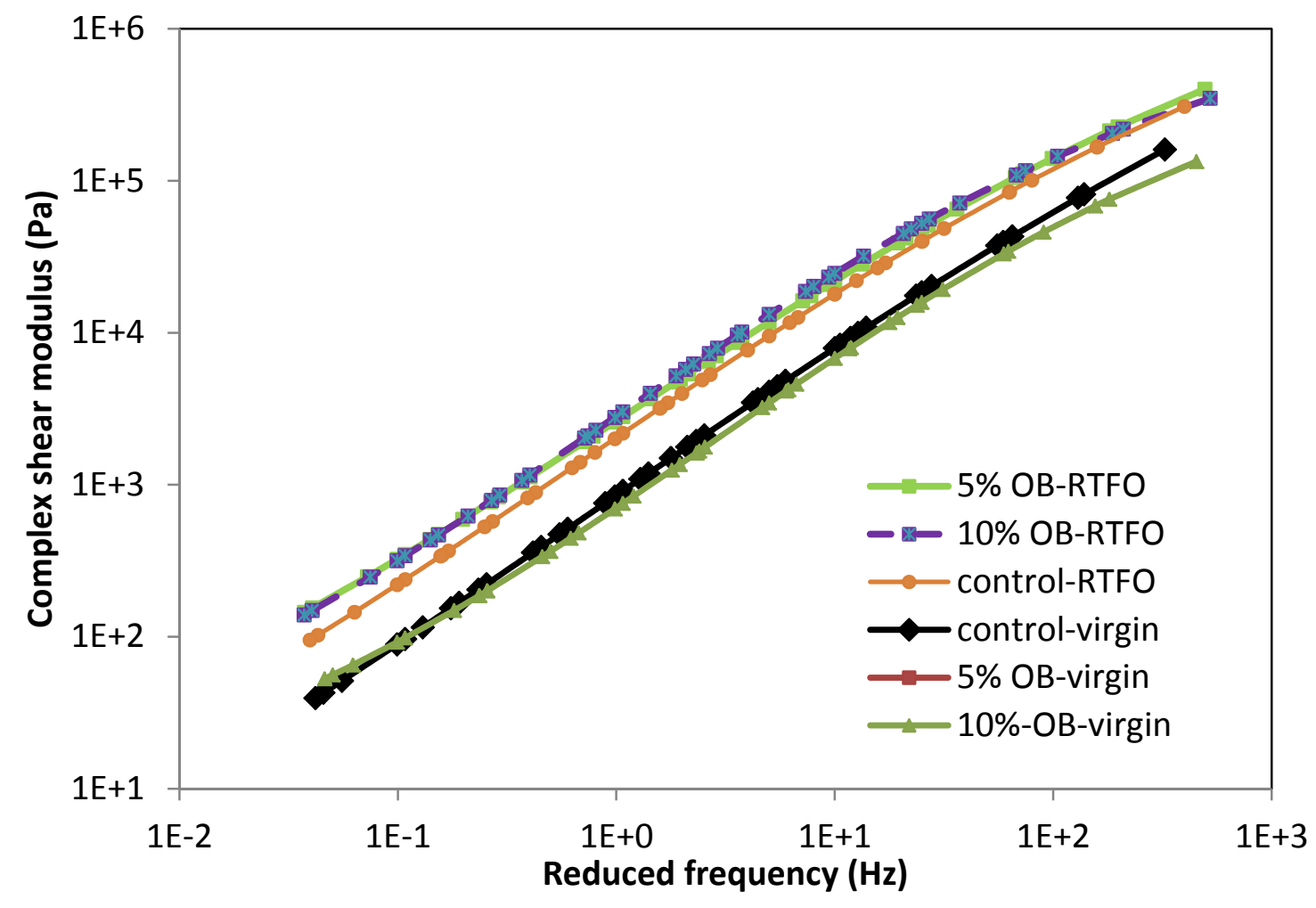

Figure 4-3: $\left|G^{*}\right|$ Master curve plot for control asphalt binder, 5\% and 10\% OB modified asphalt binders before and after RTFO aging 


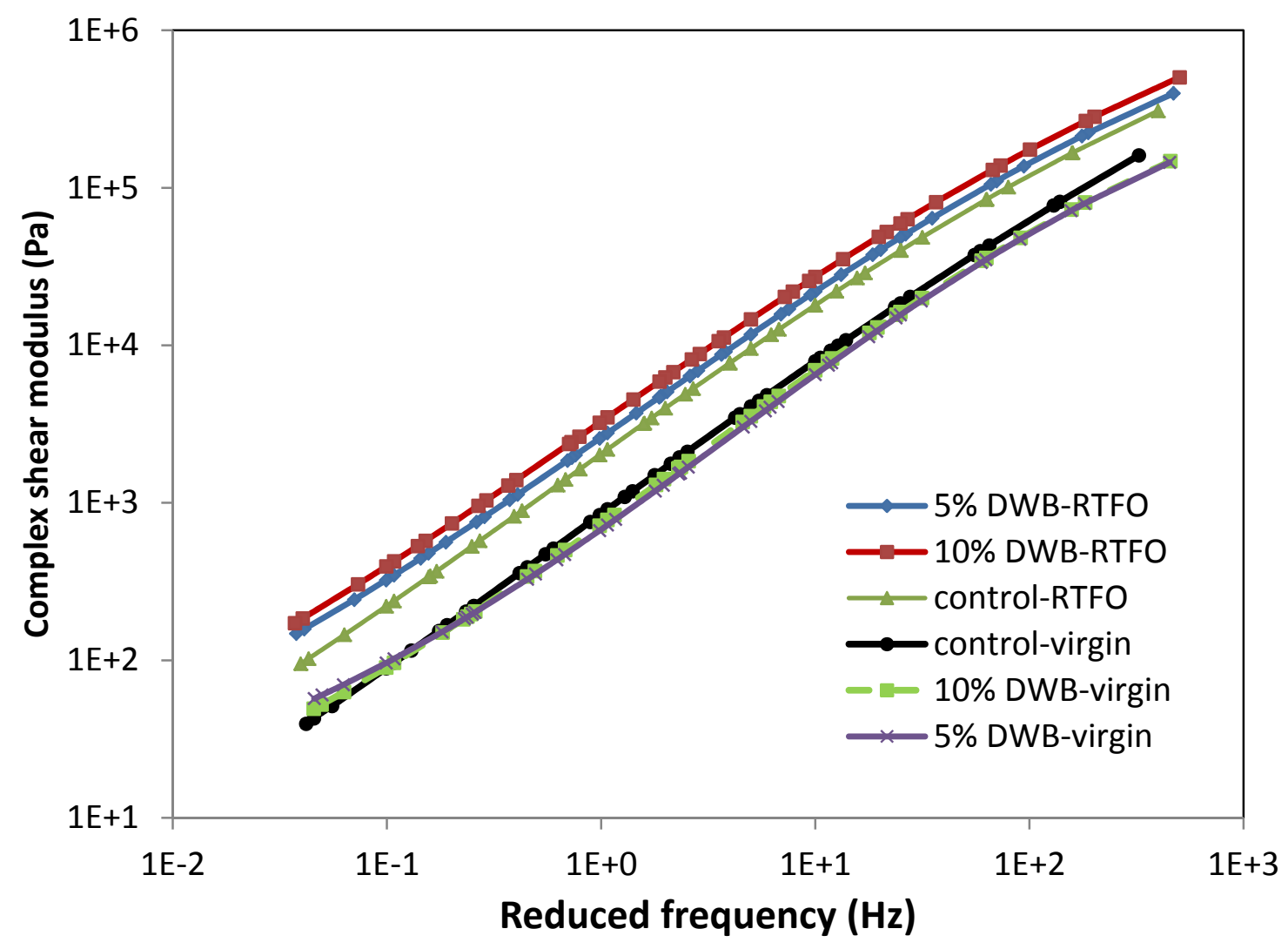

Figure 4-4: $\mid$ G*| Master curve plot for control asphalt binder, 5\% and 10\% DWB modified asphalt binders before and after RTFO aging 


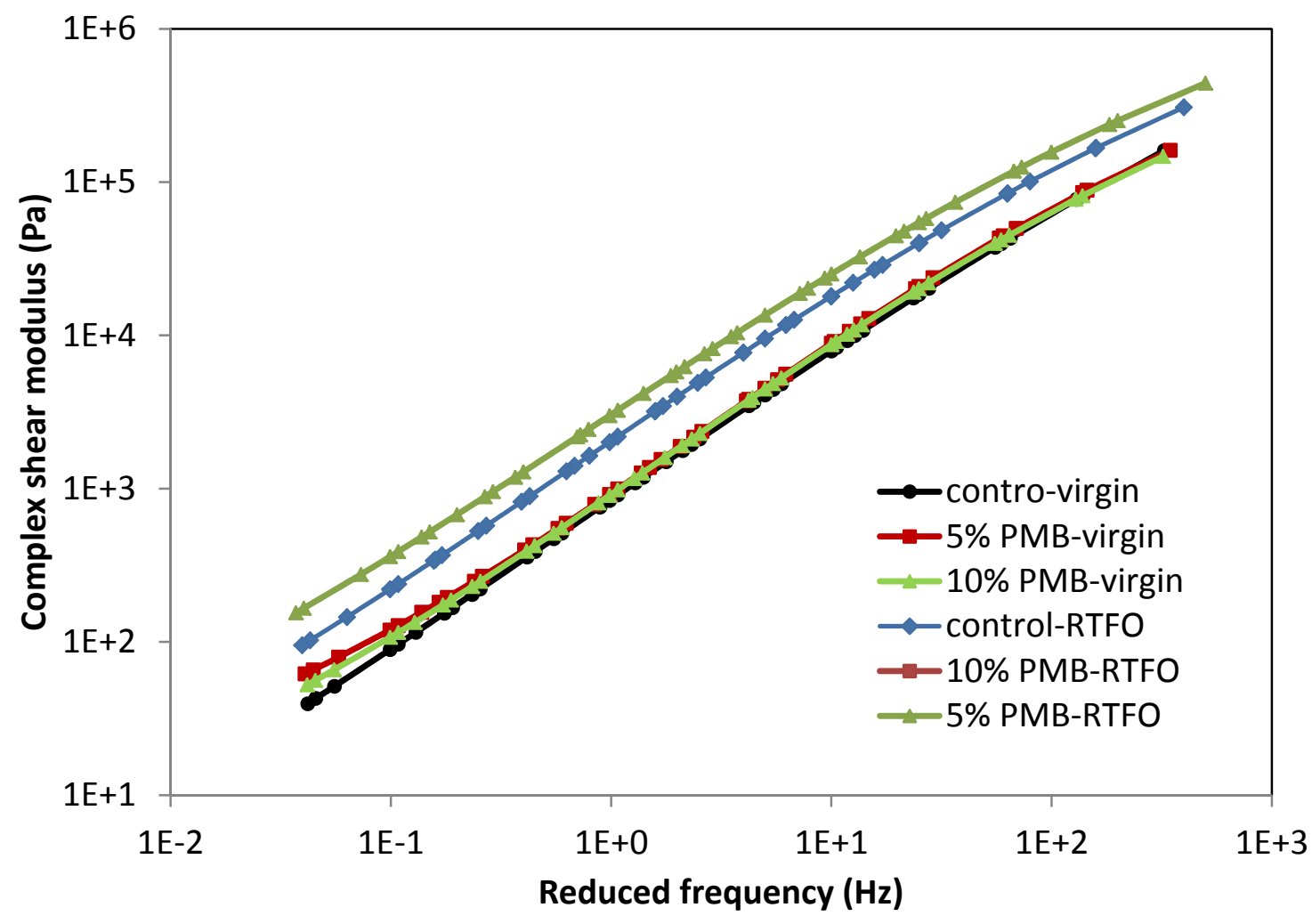

Figure 4-5: $\mid \mathrm{G} *$ Master curve plot for control asphalt binder, 5\% and 10\% PMB modified asphalt binders before and after RTFO aging

When an asphalt pavement is open to traffic, the asphalt mixture has experienced short term aging. This means that it is more reasonable to evaluate the high temperature performance of asphalt binder based on the properties after short term (RTFO) aging. Superpave ${ }^{\mathrm{TM}}$ specification recommends that a higher $\mid \mathrm{G}^{*} / \sin \delta$ at high temperature is desirable for the rutting resistance. Figure 4-6 and Figure 4-7 illustrate the $G^{*} / \sin \delta$ values of the RTFO aged asphalt binders at the three highest test temperatures. The frequencies were 0.1 and $10 \mathrm{~Hz}$, respectively. It is found that with the increase of bio oil content, the $\mathrm{G}^{*} / \sin \delta$ also increased. This means that with the increase of bio oil content, the high temperature performance of asphalt binders are improved. Comparison among the three types of bio oils showed that the OB modified asphalt binders had the lowest $\mathrm{G}^{*} / \sin \delta$ compared to the two others. The average $\mathrm{G}^{*} / \sin \delta$ values of DWB and PMB modified asphalt binders were close to each other. 


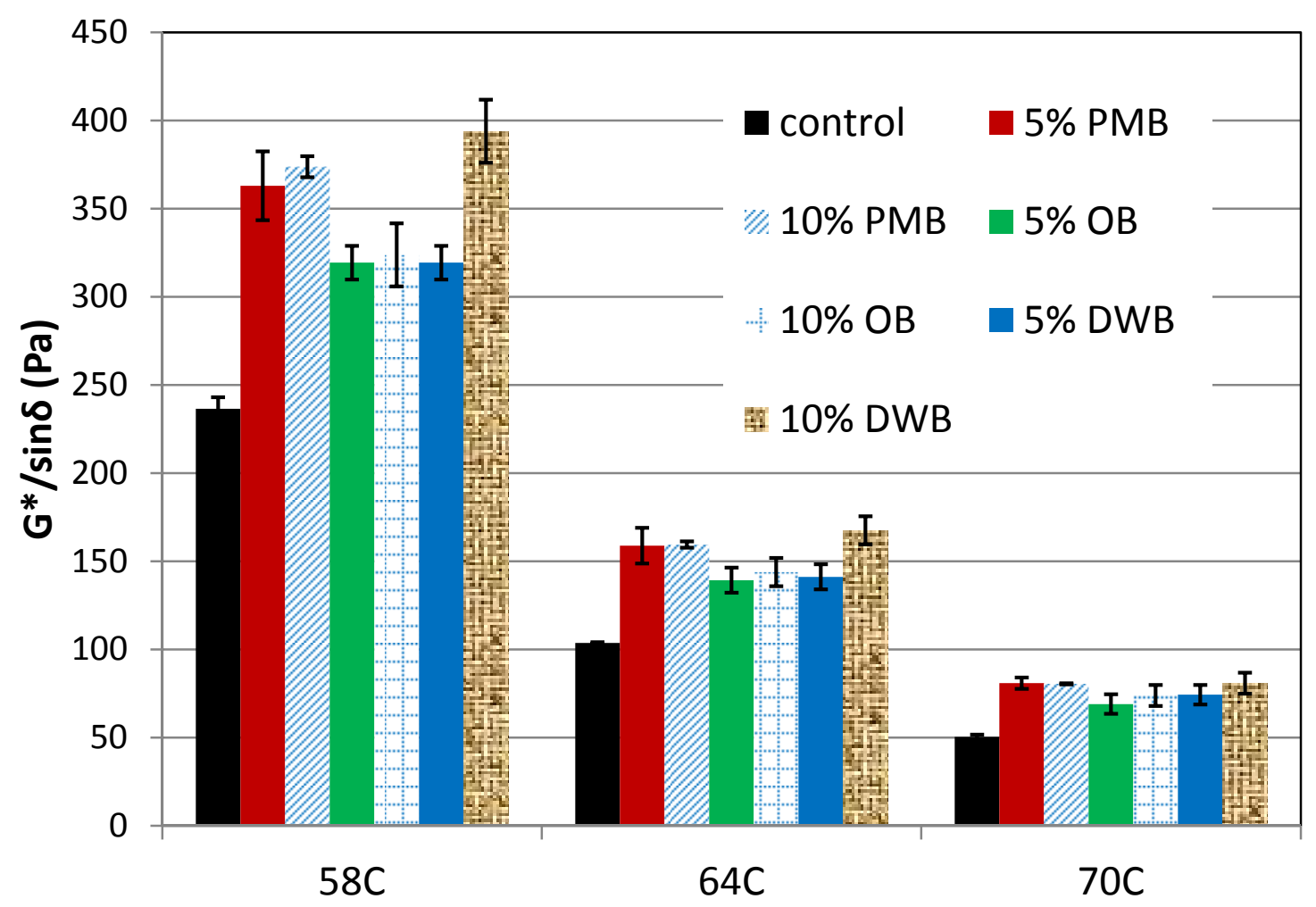

Figure 4-6: $G * / \sin \delta$ of RTFO aged binders at $0.1 \mathrm{~Hz}$

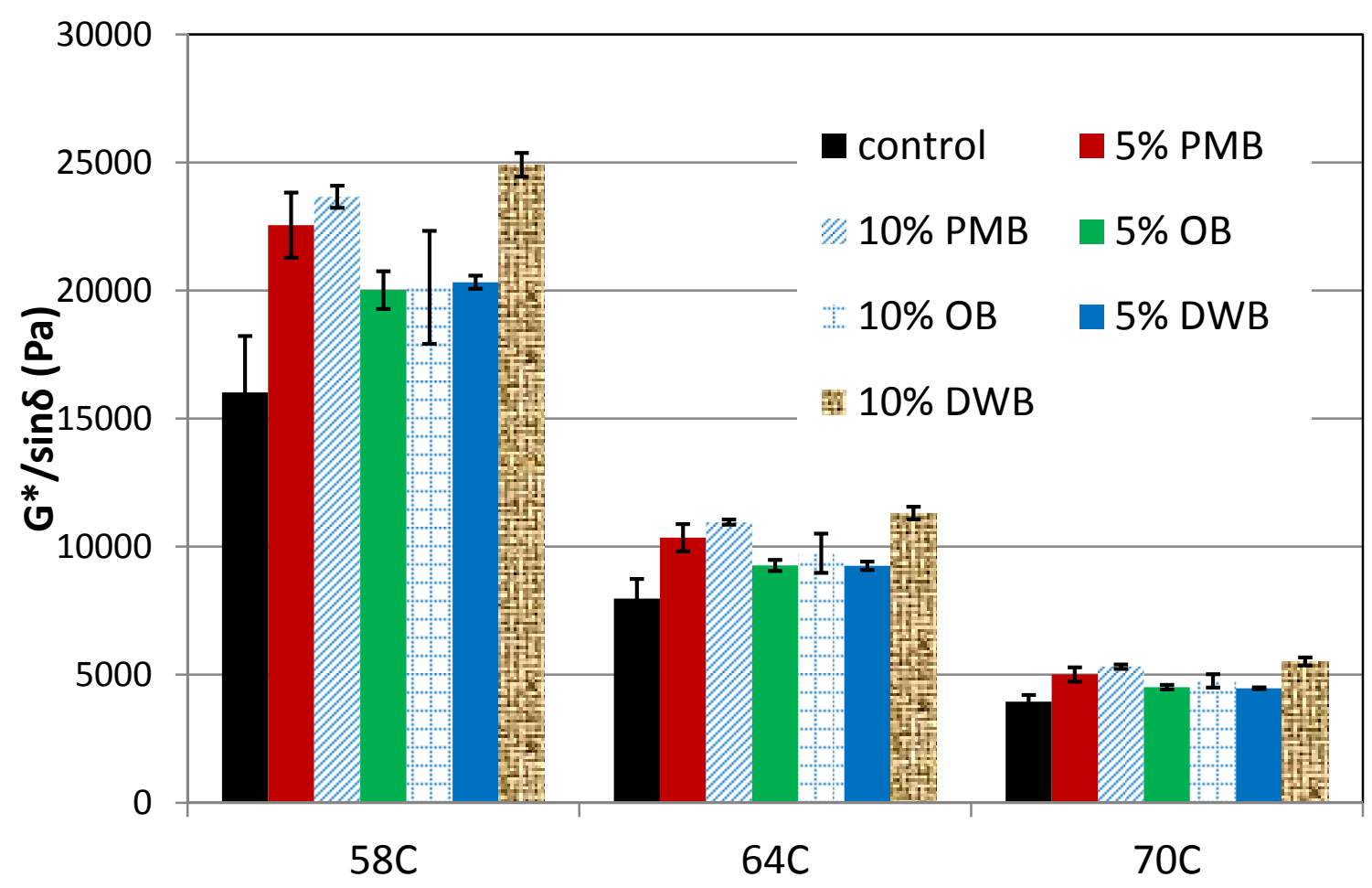

Figure 4-7: $G^{*} / \sin \delta$ of RTFO aged binders at $10 \mathrm{~Hz}$ 
Superpave ${ }^{\mathrm{TM}}$ specification recommends minimum $\mathrm{G}^{*} / \sin \delta$ value as $2.2 \mathrm{KPa}$ for RTFO aged binders at the high critical temperature. Based on this, the high critical temperatures of the control asphalt binder and bio oil modified asphalt binders were obtained based on the DSR test results, as shown in Figure 4-8. It is found that with the increase of the bio oil content, the high critical temperature also increased. The critical temperature of $5 \%$ and $10 \% \mathrm{OB}, 5 \%$ and $10 \% \mathrm{DWB}$, and $5 \%$ and $10 \%$ PMB modified asphalt binders were $1.95,2.32,1.32,1.48,1.21$ and $2.69^{\circ} \mathrm{C}$ higher than that of the control asphalt binder. Comparison among the three types of bio oils showed that the $\mathrm{OB}$ modified asphalt binders had the lowest average critical temperature, followed by the DWB and PMB modified asphalt binders.

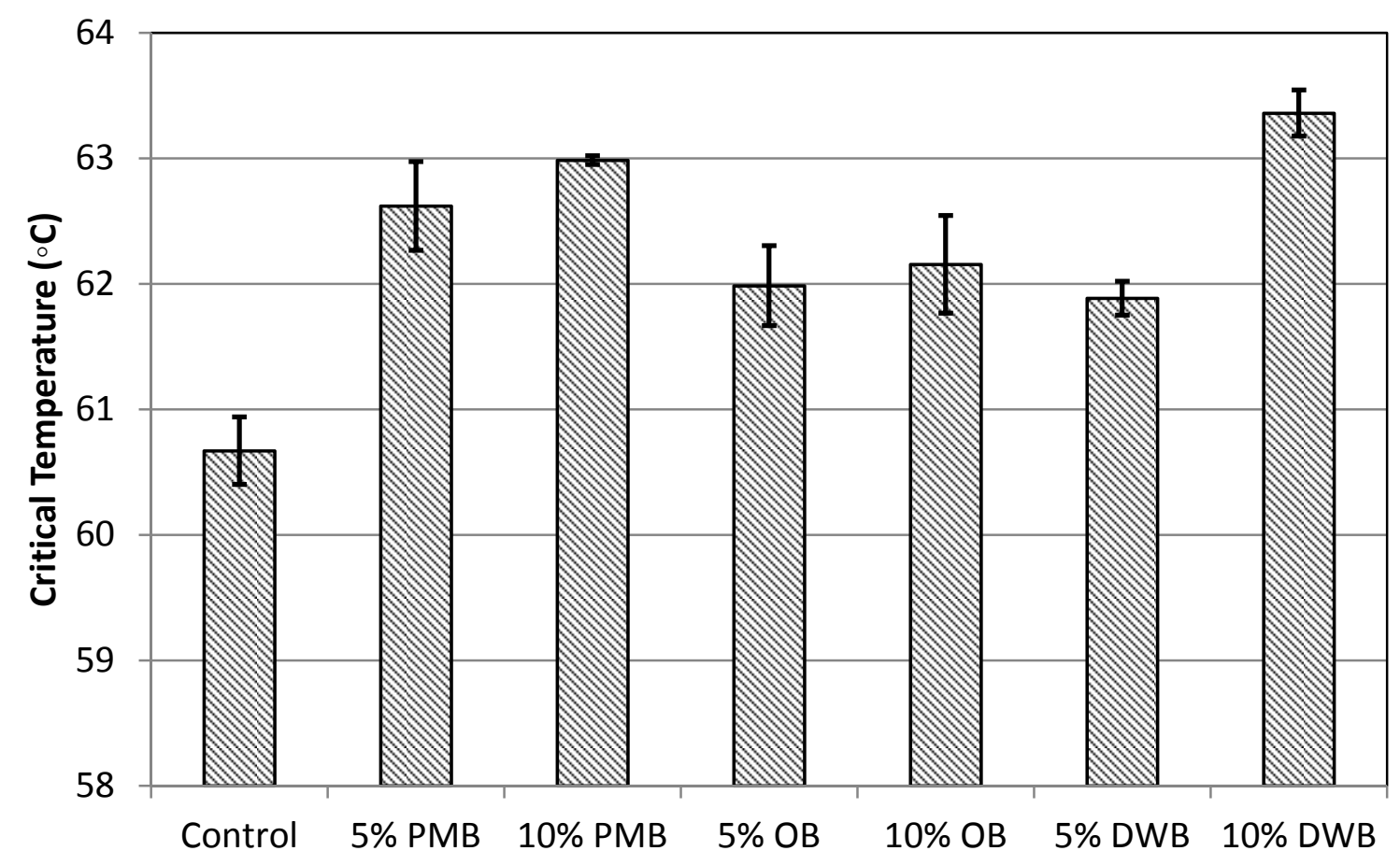

Figure 4-8: High critical temperatures for RTFO aged asphalt binders

\section{DSR for PAV aged binders}

The DSR test for PAV aged asphalt binders was conducted to characterize the visco-elastic property of asphalt binders at medium temperatures. Figure 4-9 to Figure 4-11 display the $\left|\mathrm{G}^{*}\right|$ master curves plot for control asphalt binder and three types of bio oil modified asphalt binders after PAV aging. It is observed that with the increase of bio oil percent in the asphalt binders, the $\left|\mathrm{G}^{*}\right|$ showed a significant increase. The $\left|\mathrm{G}^{*}\right| \mathrm{s}$ of $5 \%$ 
and $10 \%$ OB modified asphalt binders were $186.3 \%$ and $267.7 \%$ higher than that of the control binder, respectively; The $\left|\mathrm{G}^{*}\right| \mathrm{s}$ of $5 \%$ and $10 \%$ DWB modified asphalt binders were $180.7 \%$ and $215.7 \%$ higher than that of the control binder, respectively; The $\left|\mathrm{G}^{*}\right| \mathrm{s}$ of $5 \%$ and $10 \%$ PMB modified asphalt binders were $187.1 \%$ and $250.7 \%$ higher than that of the control binder, respectively. Compared with the $\left|\mathrm{G}^{*}\right|$ increase after the RTFO aging, it is found that the bio oil modified asphalt binders ages also faster than the control asphalt binder during the standard PAV aging. It is thought that there is a lower $\left|G^{*}\right| \sin \delta$ is desirable for a better fatigue cracking performance, so the Superpave ${ }^{\mathrm{TM}}$ binder specification has requirement that $\left|\mathrm{G}^{*}\right| \sin \delta<5000 \mathrm{KPa}$. Based on the DSR test result for PAV aged asphalt binders, all of the bio oil modified asphalt binders can meet this requirement.

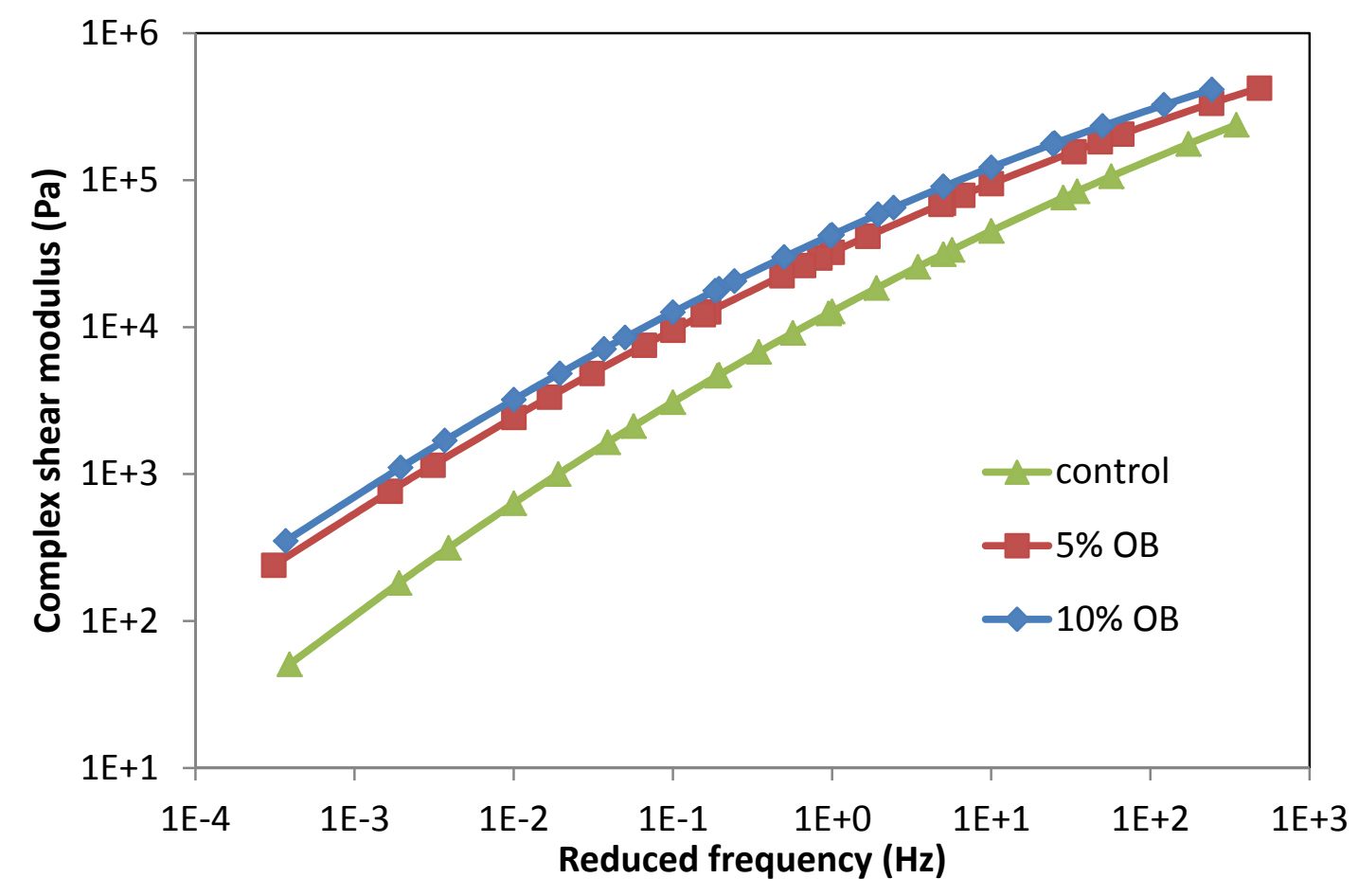

Figure 4-9: $\left|G^{*}\right|$ master curve plot for control asphalt binder and OB modified asphalt binders 


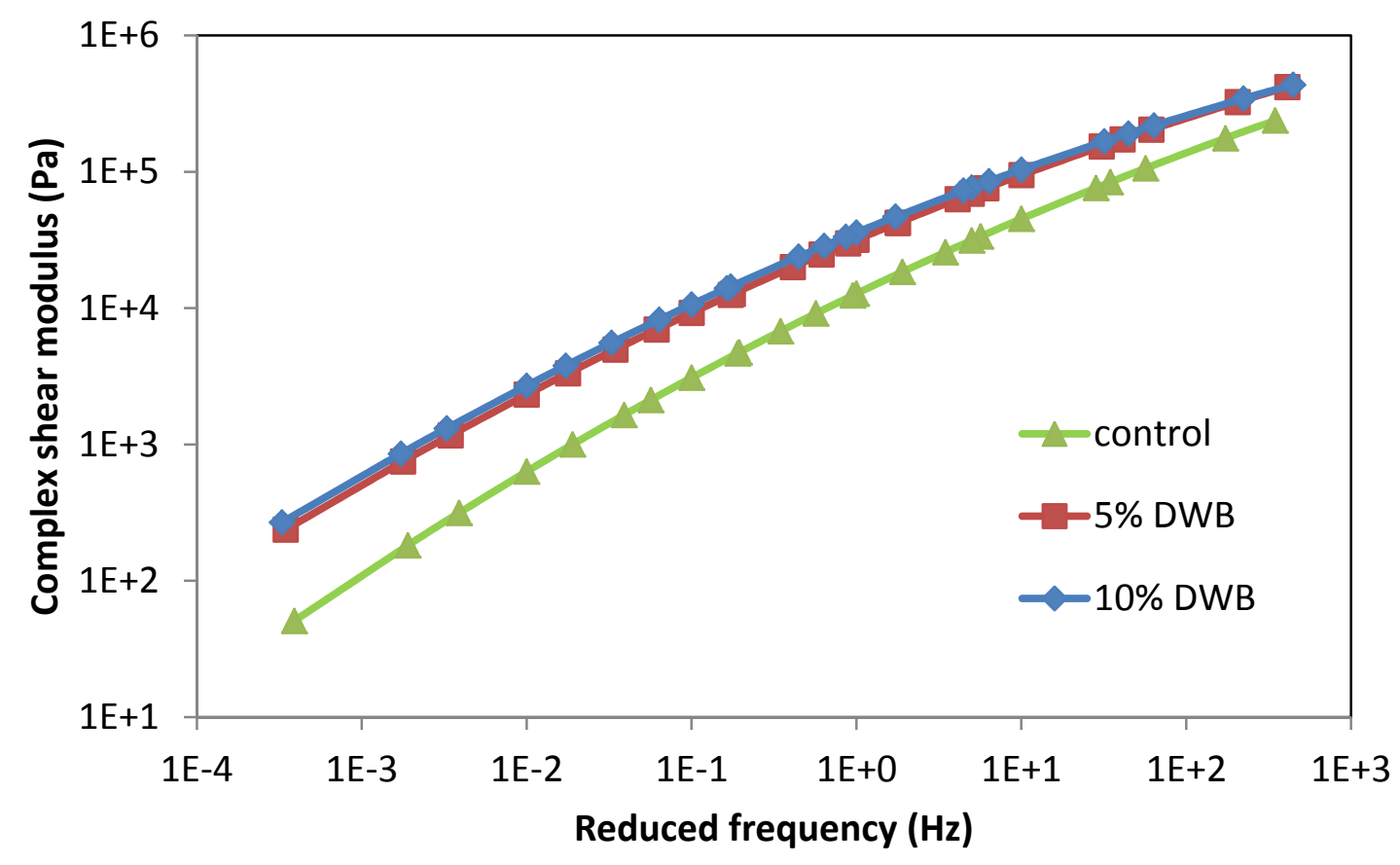

Figure 4-10: $\left|G^{*}\right|$ master curve plot for control asphalt binder and DWB modified asphalt binders

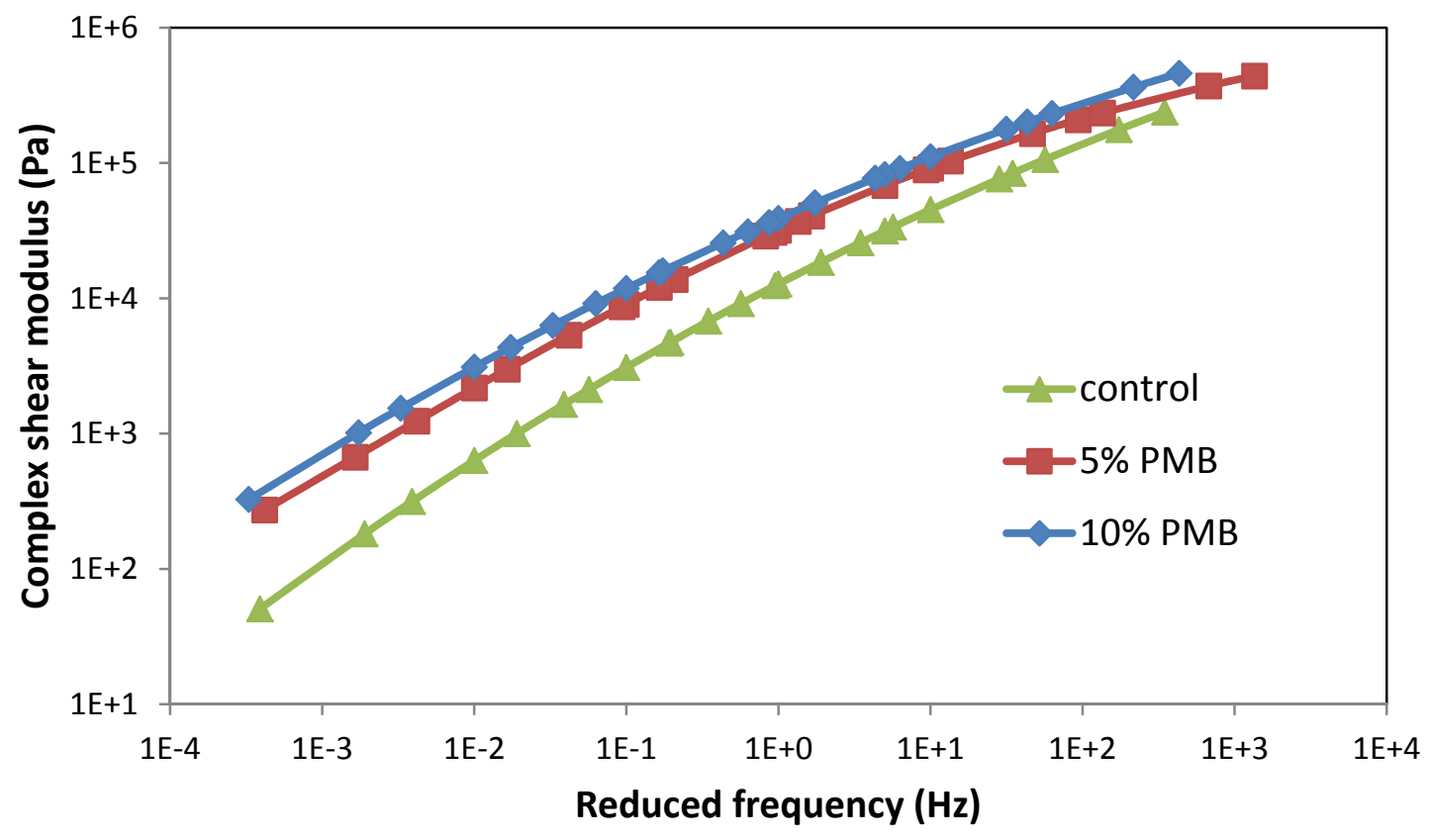

Figure 4-11: $\left|G^{*}\right|$ master curve plot for control asphalt binder and PMB modified asphalt binders 


\subsubsection{Bending beam rheometer (BBR) test}

The low temperature performances of asphalt binders are evaluated through the bending beam rheometer (BBR) test. SuperpaveTM recommends a test temperature $18^{\circ} \mathrm{C}$ for $\mathrm{PG} 58-28$. In this study, $-12^{\circ} \mathrm{C}$ was also selected for the test to get more information of asphalt binder properties at low temperatures. Table 4-1 and Table 4-2 show the creep stiffness and m-value at 60s for control asphalt binder and the three types of bio oil modified asphalt binders at $-12^{\circ} \mathrm{C}$ and $-18^{\circ} \mathrm{C}$. Based on the test result, it is found that all of the bio oil modified asphalt binders can meet the requirement for the creep stiffness, but most of the bio oil modified asphalt binders failed for the m-value results. The creep stiffness of $5 \%$ and $10 \%$ OB modified binders were $32.3 \%$ and $47.7 \%$ higher than that of the control binder at $-18^{\circ} \mathrm{C}$. The $\mathrm{m}$-values of $5 \%$ and $10 \% \mathrm{OB}$ modified asphalt binders were 0.19 and 0.60 at $-18^{\circ} \mathrm{C}$. The creep stiffness of $5 \%$ and $10 \%$ OB modified binders were $36.6 \%$ and $42.0 \%$ higher than that of the control binder at $18^{\circ} \mathrm{C}$. The m-values of $5 \%$ and $10 \%$ OB modified asphalt binders were 0.56 and 0.66 lower than that of the control binder at $-18^{\circ} \mathrm{C}$. The creep stiffness of $5 \%$ and $10 \% \mathrm{PMB}$ modified binders were $45.5 \%$ and $56.3 \%$ higher than that of the control binder at $-18^{\circ} \mathrm{C}$. The m-value of 5\% and 10\% PMB modified asphalt binders were 0.53 and 0.72 lower than that of the control binder at $-18^{\circ} \mathrm{C}$. It is thought that lower creep stiffness and a higher m-value are desirable for the low temperature performance. Thus, the addition of bio oil would have negative effect on the low temperature performance of asphalt binders. Comparison among the three types of bio oils showed that the OB modified asphalt binders had the lowest stiffness and highest m-value compared to the DWB and PMB modified asphalt binders. This indicates that the $\mathrm{OB}$ can perform better than the other DWB and PMB at low temperature conditions.

Table 4-1: Creep stiffness and m-value from $\mathrm{BBR}$ test at $-18^{\circ} \mathrm{C}$

\begin{tabular}{|c|c|c|c|c|c|c|}
\hline \multirow{2}{*}{$\begin{array}{l}\text { Asphalt } \\
\text { Binder }\end{array}$} & \multicolumn{3}{|c|}{ Creep stiffness at 60s (MPa) } & \multicolumn{3}{|c|}{ m-value at 60s } \\
\hline & $\begin{array}{c}\text { Testing } \\
\text { value }\end{array}$ & specification & $\begin{array}{c}\text { Pass } \\
\text { or fail }\end{array}$ & $\begin{array}{c}\text { Testing } \\
\text { value }\end{array}$ & specification & $\begin{array}{c}\text { Pass or } \\
\text { fail }\end{array}$ \\
\hline
\end{tabular}




\begin{tabular}{|c|c|c|c|c|c|c|}
\hline Control & 176 & $<300$ & Pass & 0.347 & $>0.3$ & Pass \\
\hline $5 \%$ OB & 233.0 & $<300$ & Pass & 0.328 & $>0.3$ & Pass \\
\hline $10 \%$ OB & 260 & $<300$ & Pass & 0.287 & $>0.3$ & Fail \\
\hline $5 \%$ DWB & 240.5 & $<300$ & Pass & 0.291 & $>0.3$ & Fail \\
\hline $\begin{array}{c}10 \% \\
\text { DWB }\end{array}$ & 250 & $<300$ & Pass & 0.281 & $>0.3$ & Fail \\
\hline $5 \%$ PMB & 256 & $<300$ & Pass & 0.294 & $>0.3$ & Fail \\
\hline $10 \%$ PMB & 275 & $<300$ & Pass & 0.275 & $>0.3$ & Fail \\
\hline
\end{tabular}

Table 4-2: Creep stiffness and m-value from BBR test at $-12^{\circ} \mathrm{C}$

\begin{tabular}{|c|c|c|c|}
\hline $\begin{array}{c}\text { Asphalt } \\
\text { Binder }\end{array}$ & Creep stiffness at 60s (MPa) & m-value at 60s & Pass or fail \\
\hline Control & 46.4 & 0.414 & Pass \\
\hline $5 \%$ OB & 97 & 0.332 & Pass \\
\hline $10 \%$ OB & 121 & 0.369 & Pass \\
\hline $5 \%$ DWB & 92.8 & 0.337 & Pass \\
\hline $10 \%$ DWB & 103 & 0.330 & Pass \\
\hline $5 \%$ PMB & 108.9 & 0.375 & Pass \\
\hline $10 \%$ PMB & 122 & 0.348 & Pass \\
\hline
\end{tabular}

To directly evaluate the effect of bio oils on the asphalt low temperature performance, the critical low temperatures for each asphalt binder is found based on the BBR test results. The critical temperature is determined as the temperature where the creep stiffness and the m-value just pass the specification value. For most of the bio oil modified asphalt binders, because the stiffness can meet the requirement, the critical low temperatures were determined by the m-values.

Figure 4-12 shows the critical low temperatures of control and the bio oil modified asphalt binders. Compared to control binder, the 5\% and 10\% OB modification increased the critical temperature by 0.63 and $3.33^{\circ} \mathrm{C}$ respectively; $5 \%$ and $10 \%$ DWB modification increased the critical temperature 3.58 and $4.73^{\circ} \mathrm{C}$ respectively; The $5 \%$ and 
$10 \%$ PMB modification increased the critical temperature by 2.62 and $4.32^{\circ} \mathrm{C}$ respectively. Comparison among the three types of bio oils showed that the OB modified asphalt binders had the lowest critical temperature. This indicates that the $\mathrm{OB}$ as a modifier is better than DWB and PMB for the low temperature performance consideration.

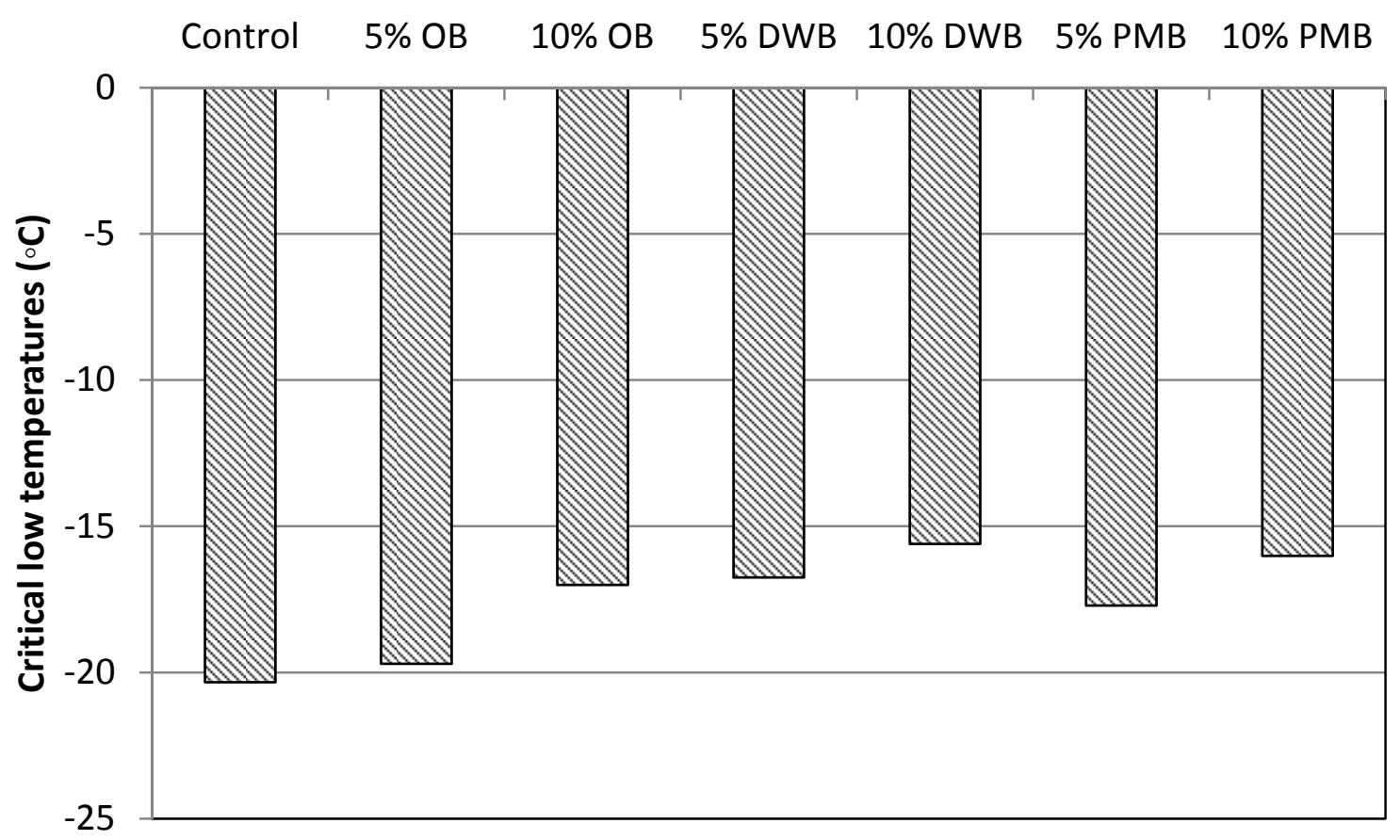

Figure 4-12: $\left|G^{*}\right|$ master curve for control asphalt binder and PMB modified asphalt

\subsection{Conclusions}

In this study, the evaluation of bio oil derived from waste wood resources as an extender for petroleum asphalt binder is investigated through laboratory binder tests. Based on the test result, some conclusions are made:

1) The addition of bio oil can reduce the rotational viscosity of virgin asphalt binders, and hence can reduce the mixing temperature;

2) The addition of bio oil can increase the dynamic shear modulus and improve the high temperature performance of asphalt binders;

3) Bio oil has negative effect on the low temperature performance because of the higher stiffness and lower m-value. 
4) The original bio oil (OB) has the lowest effect on the asphalt binder properties compared to de-watered bio oil (DWB) and polymer modified bio oil (PMB).

One of the main concerns of the application of bio oil is the fast aging. To reduce the aging effect of bio oil on the asphalt binder performance, one potential way is to reduce the short-term aging time, which will also require less construction time in the practice. Also, the original bio oil is preferred to the dewatered and polymer modified bio oils. 


\section{Chapter 5: Evaluation of the Rheological Properties of Asphalt Binders Partially Replaced by Bio Oil ${ }^{2}$}

In this chapter, the traditional asphalt is replaced by the bio oil up to $70 \%$ by weight to investigate the feasibility of bio oil as an extender or alternative for traditional asphalt binder in the pavement engineering. The rheological properties of the asphalt binders and the corresponding tests are the same as last chapter.

\subsection{Introduction}

Since bio oil is a sustainable material that has wide application potential in the future, it is necessary to study the properties of asphalt binders containing high percentage of bio oils. In another word, bio oil would serve as an extender instead of a modifier as investigated in Chapter 4 . In this chapter, $10 \%, 30 \%, 70 \%$ and $100 \%$ bio oil blended asphalt binders are prepared and the rheological properties are studied by RV test, RTFO test, PAV test, DSR test and BBR test. The bio oil and control asphalt binder were mixed by the high shear mixer for 15 minutes at $110^{\circ} \mathrm{C}$. The aging of the asphalt binder during the construction is mainly from two aspects, the loss of volatiles occurrence and oxidation. In this study, both the loss of volatiles and oxidation during the RTFO test are evaluated. The loss of volatiles is determined by the mass loss in the RTFO test while the oxidation is determined by the oxygen $(\mathrm{O})$ bonding changes using FTIR test (Fourier Transform Infrared Spectroscopy).

\subsubsection{Mass loss}

Mass loss of asphalt binders is determined by the percent weight reduction due to the loss of volatiles at high temperatures. It is calculated using the equation below. Superpave specification recommends that the mass loss of asphalt binder sub ${ }^{2}$ jected to standard RTFO test should be lower than $1 \%$.

\footnotetext{
${ }^{2}$ Text prepared for submission to ASCE Journal of Materials in Civil Engineering-Yang, X., You. Z, Dai, Q., Mills-Beale, J., (2013). Rheological Property Evaluation and Aging Analysis of Asphalt Binders blended with High Percentage of Bio-binders. ASCE Journal of Materials in Civil Engineering.
} 


$$
\text { mass loss }=\frac{\text { weight before aging }- \text { weight after aging }}{\text { weight before aging }} \times 100
$$

\subsubsection{FTIR test}

FTIR is a technique that can determine the functional characteristics of a material. The quantitative and qualities analysis can be conducted using FTIR by observing the absorbance spectra. FITR is also utilized to analyze the oxidative aging of asphalt binders by observing the amount change of carbonyl $(\mathrm{C}=\mathrm{O})$ and sulfoxide $(\mathrm{S}=\mathrm{O})$ (Mills-Beale, You et al. 2012). The oxidative aging index is determined by the bond ratio changes before and after the aging. The bond ratio is determined by the equations below (Lamontagne, Durrieu et al. 2001):

$$
\begin{aligned}
& \mathrm{I}_{\mathrm{S}=\mathrm{O}}=\frac{\text { Area of the sulfoxide band centered around } 1030 \mathrm{~cm}^{-1}}{\sum \text { Area of the spectra bands between } 600 \mathrm{~cm}^{-1} \text { and } 2000 \mathrm{~cm}^{-1}} \\
& \mathrm{I}_{\mathrm{C}=\mathrm{O}}=\frac{\text { Area of the carbonyl band centered around } 1700 \mathrm{~cm}^{-1}}{\sum \text { Area of the spectra bands between } 600 \mathrm{~cm}^{-1} \text { and } 2000 \mathrm{~cm}^{-1}}
\end{aligned}
$$

Table 5-1: IR absorptions for representative functional groups for bio oils and asphalt, from (Silverstein, Bassler et al. 1981; Scholze and Meier 2001; Karlsson and Isacsson 2003)

\begin{tabular}{|l|l|l|}
\hline Wavenumber $\left(\mathrm{cm}^{-1}\right)$ & Molecular Motion & Functional Group \\
\hline $700-900$ & C-H bend & Aromatics \\
\hline 1725 & $\mathrm{C}=\mathrm{O}$ stretch & Aldehydes \\
\hline 1715 & $\mathrm{C}=\mathrm{O}$ stretch & Ketones \\
\hline 1600 & $\mathrm{C}=\mathrm{C} \& \mathrm{C}=\mathrm{O}$ stretch & Aromatics \\
\hline 1465 & $\mathrm{CH}_{2}$ bend & Alkanes \\
\hline 1375 & $\mathrm{CH}$ bend & Alkanes \\
\hline 1214 & $\mathrm{C}-\mathrm{C}, \mathrm{C}-\mathrm{O} \& \mathrm{C}=\mathrm{O}$ stretch & Acids, ester \\
\hline 1120 & $\mathrm{C}-\mathrm{O}-\mathrm{C}$ stretch & Ether \\
\hline 1035 & $\mathrm{C}-\mathrm{O}$ & Alcohol \\
\hline 1030 & $\mathrm{~S}=\mathrm{O}$ & Sulfoxides \\
\hline
\end{tabular}




\begin{tabular}{|l|l|l|}
\hline $3300-3500$ & $\mathrm{O}-\mathrm{H}$ & Alcohol, acids \\
\hline
\end{tabular}

\subsection{Rotational Viscosity}

Figure 1 displays the RV test results for the control asphalt binder and binder blending containing bio binders. The viscosities of pure OB and DWB are also included in the figure, represented as $100 \% \mathrm{OB}$ and $100 \% \mathrm{DWB}$. Overall, with the increase of the bio binder content in the binder blending, the rotational viscosity decreases except for the $30 \%$ OB. The viscosities of $70 \%$ and $100 \%$ OB are $33.6 \%$ and $71.1 \%$ lower than that of the control asphalt binder, respectively. The viscosities of $30 \%, 70 \%$ and $100 \%$ DWB are $20.7 \%, 42.3 \%$ and $64.0 \%$ lower than that of the control asphalt binder. The test results indicate that the bio binder is softer than the asphalt binder in the temperature range $100^{\circ} \mathrm{C}$ to $140^{\circ} \mathrm{C}$. Comparison between the untreated and treated bio binders shows that the treated bio binder has a little higher viscosity than the untreated bio binder. This phenomenon may due to the moisture in the untreated bio binder. When the binder blending is heated at higher than $100^{\circ} \mathrm{C}$, the moisture volatilizes and reduces the viscosity with similar mechanism of warm mix asphalt. With the testing time continuing, the moisture in the bio binder escapes out and the viscosity goes up again. This can interpret the swerves of the curves of $70 \%$ and $100 \%$ untreated bio binders. Since the mixing temperature is determined by the rotational viscosities of asphalt binder, it is expected that the addition of bio binder into the asphalt binder can reduce the mixing temperature and thus save the energy needed to heat the binder and aggregate. 


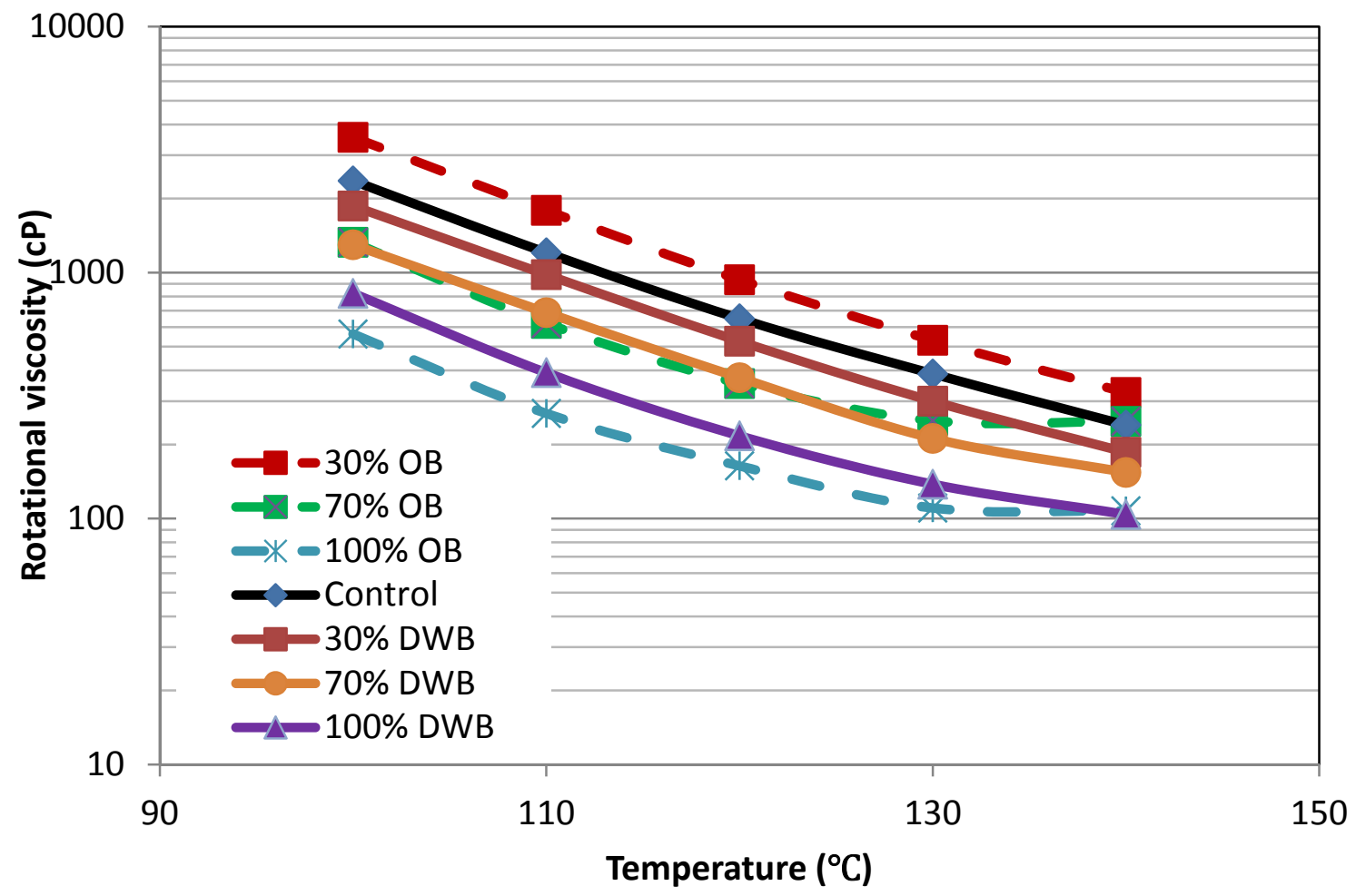

Figure 5-1: RV test results for control asphalt binder, $\mathrm{OB}, \mathrm{DWB}$, and asphalt binders containing $30 \%$ OB, $70 \%$ OB, 30\% DWB and $70 \%$ DWB

Figure 5-2 illustrates the RV test results of control asphalt binder and binder blending containing 30\% OB, 70\% OB, 30\% DWB and 70\% DWB after RTFO aging. With the increase of the bio binder content, the rotational viscosity of the binder blending increases. The rotational viscosities of $30 \%$ and $70 \% \mathrm{OB}$ are $40.6 \%$ and $290.8 \%$ higher than that of the control asphalt binder, respectively. The rotational viscosities of $30 \%$ and $70 \%$ DWB are $64.2 \%$ and $86.9 \%$ higher than that of the control asphalt binder, respectively. This trend is totally different from that before the RTFO aging. The reason for this is probably that the aging of bio binder is quicker than the control asphalt binder. To verify this hypothesis, the aging factors of the control asphalt binder and binder blending containing bio binders are obtained as shown in Figure 5-3. The aging factor is determined as the ratio of the viscosity after RTFO aging to the viscosity before RTFO aging. For the binder blending containing treated bio binder, with the increase of bio binder content, the aging factor increases. However, it was found that the aging factor of $30 \% \mathrm{OB}$ is even a little lower than that of the control asphalt binder. Considering that the 
$30 \%$ OB before RTFO aging has higher rotational viscosity than the control asphalt binder, which is out of trend, it is probably that the $30 \%$ OB has already been aged before the RTFO aging. The aging may from the mixing or the heating to take the bio binder from the container. Thus, it is safe to conclude that with the increase of the bio binder, the aging factor of the binder blending also increases.

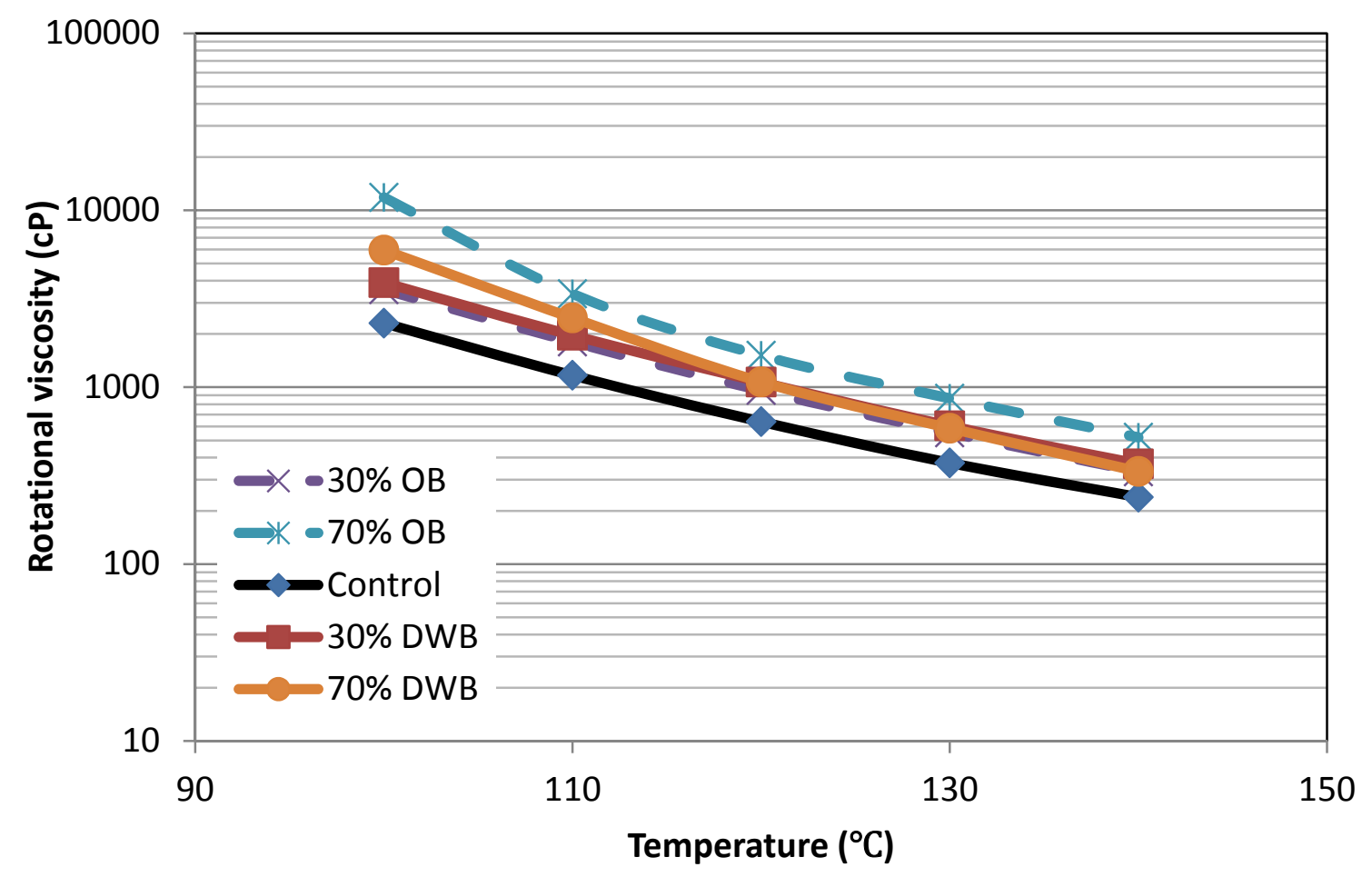

Figure 5-2: $\mathrm{RV}$ test results for control asphalt binder, and asphalt binders containing $30 \%$ OB, $70 \%$ OB, $30 \%$ DWB and $70 \%$ DWB after RTFO aging 


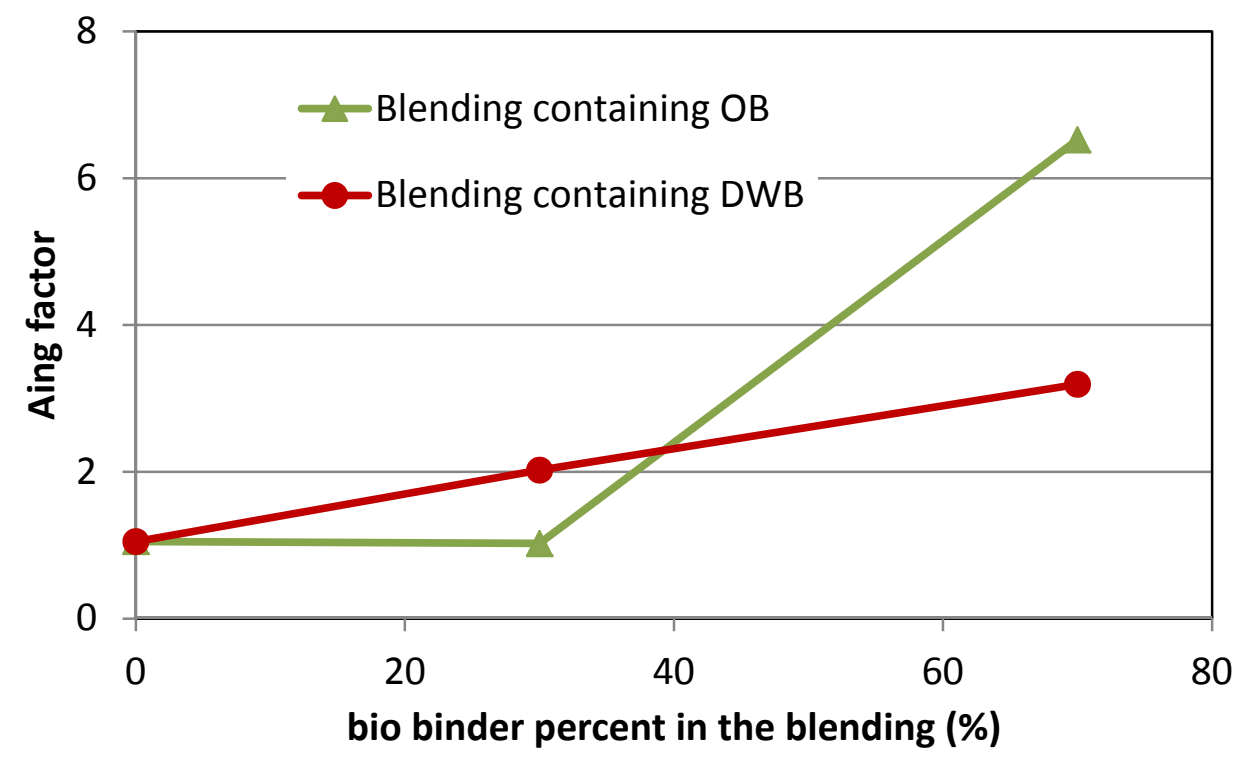

Figure 5-3: The aging factors of the binder blending containing bio binders subjected to RTFO aging

\subsection{Dynamic Shear Rheometer}

Figure 5-4 illustrates the master curve plot for the predicted complex shear modulus $\left(\left|\mathrm{G}^{*}\right|\right)$ for the control asphalt binder and binder blending containing bio binders. The reference temperature to shift the data points is $58^{\circ} \mathrm{C}$. With the increase of the bio binder content, the $\left|\mathrm{G}^{*}\right|$ of the binder blending decreased. This trend is similar as the RV test result, in which the binder blending containing $30 \%$ OB is thought to be over aged before the test. The $\left|\mathrm{G}^{*}\right| \mathrm{s}$ of the binder blending containing $30 \%$ and $70 \%$ DWB were $15.9 \%$ and $27.7 \%$ lower than that of the control asphalt binder in average, respectively. The $\left|\mathrm{G}^{*}\right|$ of the binder blending containing $70 \%$ OB was $31.6 \%$ lower than that of the control asphalt binder in average. This indicates that the virgin bio binder is also softer than the control asphalt binder PG 58-28. It is also found that in the low reduced frequency (high temperature and low frequency) area, the $\left|\mathrm{G}^{*}\right|$ difference between the blending containing bio binder and control asphalt binder is lower compared that in the high reduced frequency area (low temperature and high frequency). Since rutting is easier to occur at high temperature and low frequency, the results indicate that the addition of bio binder is helpful for the rutting performance of asphalt binders. 


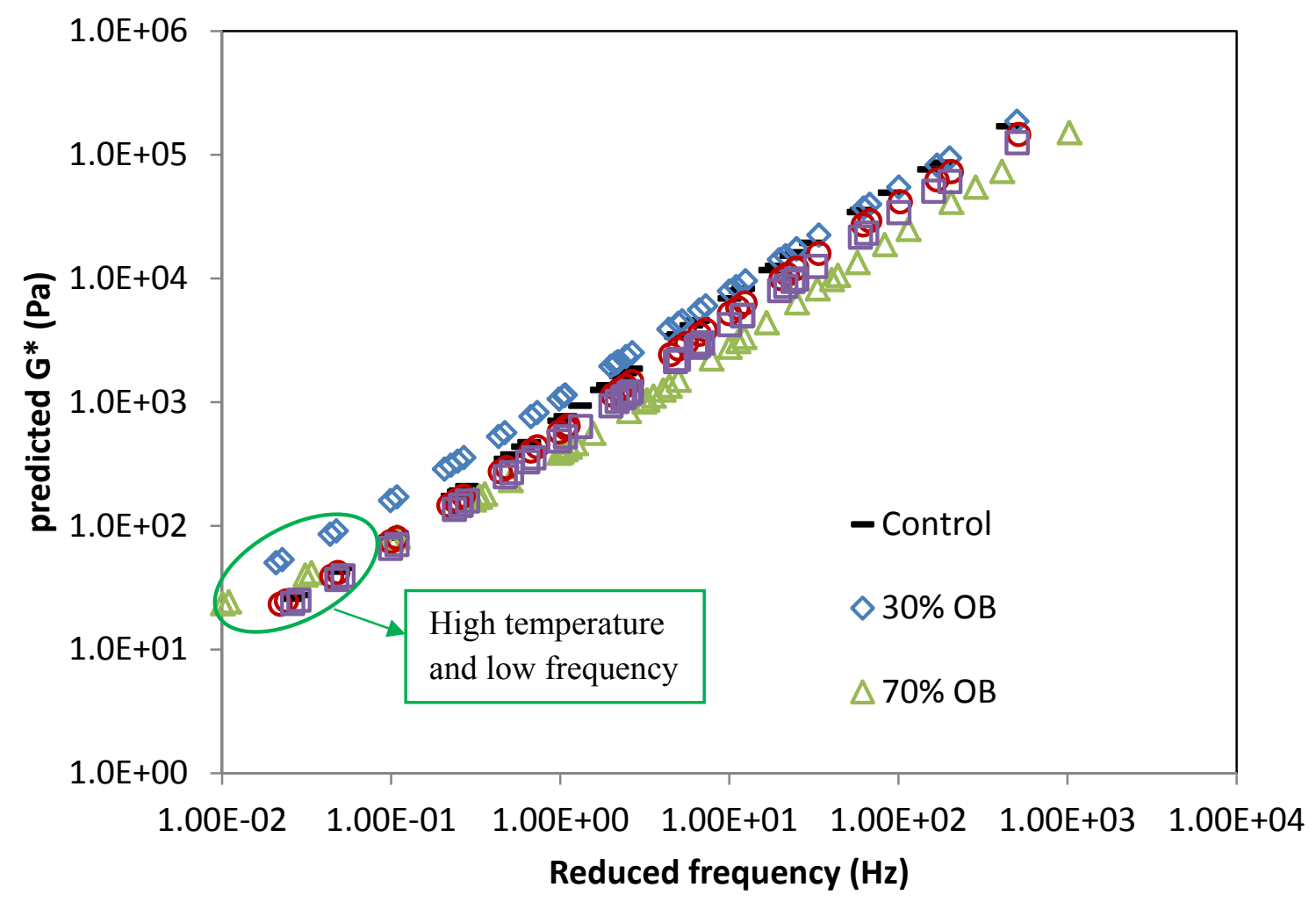

Figure 5-4: Master curve plot for $\left|\mathrm{G}^{*}\right|$ of virgin control binder and binder blending containing bio binders (temperature range 40 to $70^{\circ} \mathrm{C}$, reference temperature $58^{\circ} \mathrm{C}$ )

Figure 5-5 displays the master curve plot for the predicted $\left|\mathrm{G}^{*}\right| \mathrm{s}$ of control asphalt binder and binder blending containing bio binders after RTFO aging. With the increase of bio binder content in the binder blending, the $\left|\mathrm{G}^{*}\right|$ shows an increase trend. The $\left|\mathrm{G}^{*}\right| \mathrm{s}$ of the binder blending containing $30 \%$ and $70 \%$ OB were $23.2 \%$ and $437.5 \%$ higher than the control asphalt binder in average, respectively. The $\left|\mathrm{G}^{*}\right| \mathrm{s}$ of the binder blending containing $30 \%$ and $70 \%$ DWB were $40.1 \%$ and $223.2 \%$ higher than the control asphalt binder in average, respectively. This indicates that after the RTFO aging, the bio binders are stiffer than the control asphalt binder. Similarly, this is thought due to the fast aging of bio binder when subjected to high temperature and abundant fresh air.

$\mathrm{G}^{*} / \sin \delta$ is the rutting performance index in the SuperpaveTM design method. Minimum $\mathrm{G}^{*} / \sin \delta$ values are specified for both the virgin binders and RTFO aged binders. Figure 5-6 shows the $\mathrm{G}^{*} / \sin \delta$ values tested for the virgin and RTFO aged binders at $58^{\circ} \mathrm{C}$ and $1.59 \mathrm{~Hz}$. Before the RTFO aging, the blending containing bio binders has lower $\mathrm{G}^{*} / \sin \delta$ than the control asphalt binder. However, after the RTFO aging, the 
$\mathrm{G}^{*} / \sin \delta$ values of blending containing bio binders are much higher than that of the control asphalt binder. Although $\mathrm{G}^{*} / \sin \delta$ requirements are recommended for both the virgin and RTFO aged binder for rutting consideration in the Superpave ${ }^{\mathrm{TM}}$ specification, considering rutting normally occurs after the placement of the pavement, when asphalt mixtures have already experienced short-term ageing, it is more reasonable to specify $\mathrm{G}^{*} / \sin \delta$ for only RTFO aged asphalt binders.

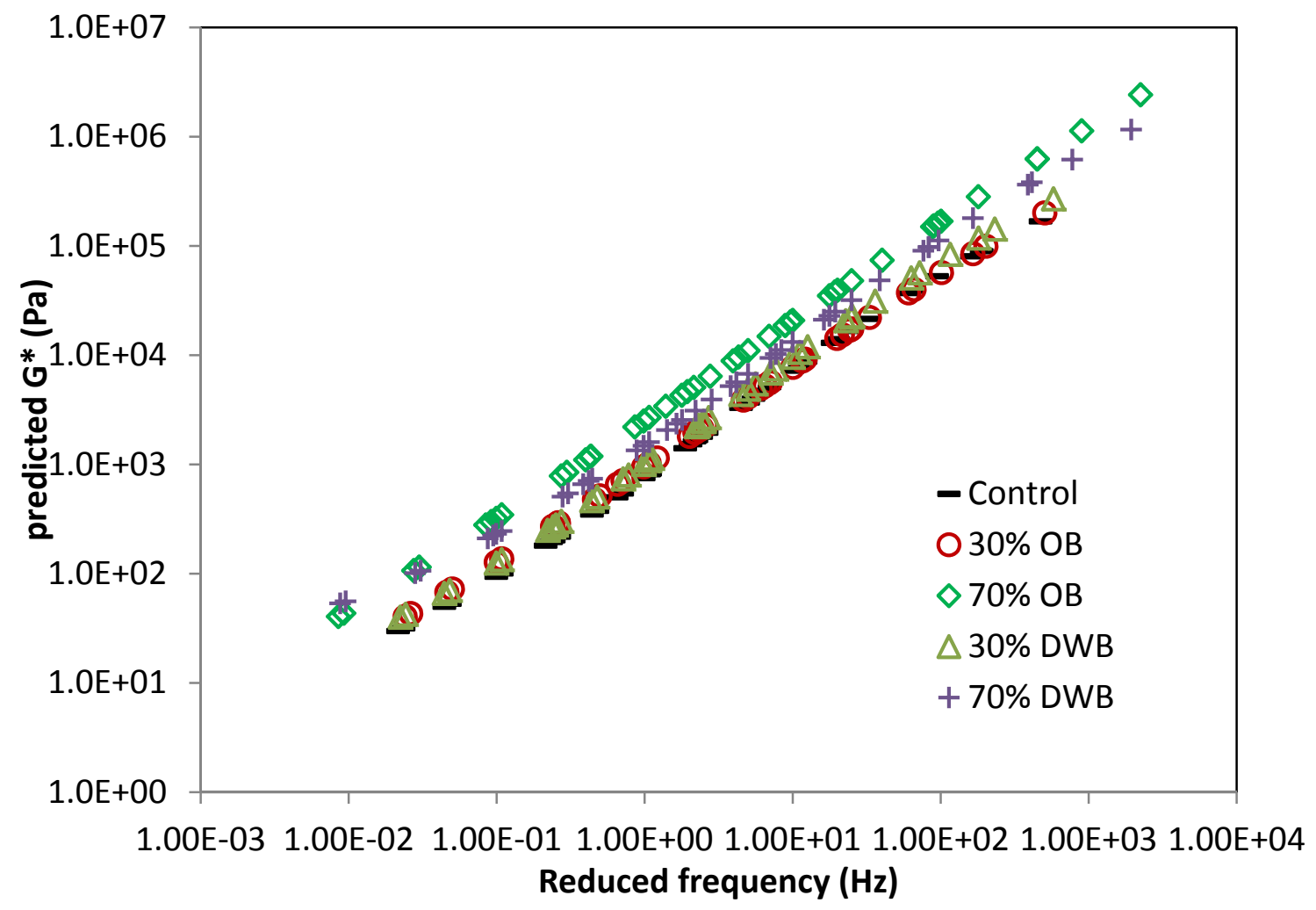

Figure 5-5: Master curve plot for $\left|\mathrm{G}^{*}\right|$ of control asphalt binder and binder blending containing bio binders after RTFO aging 


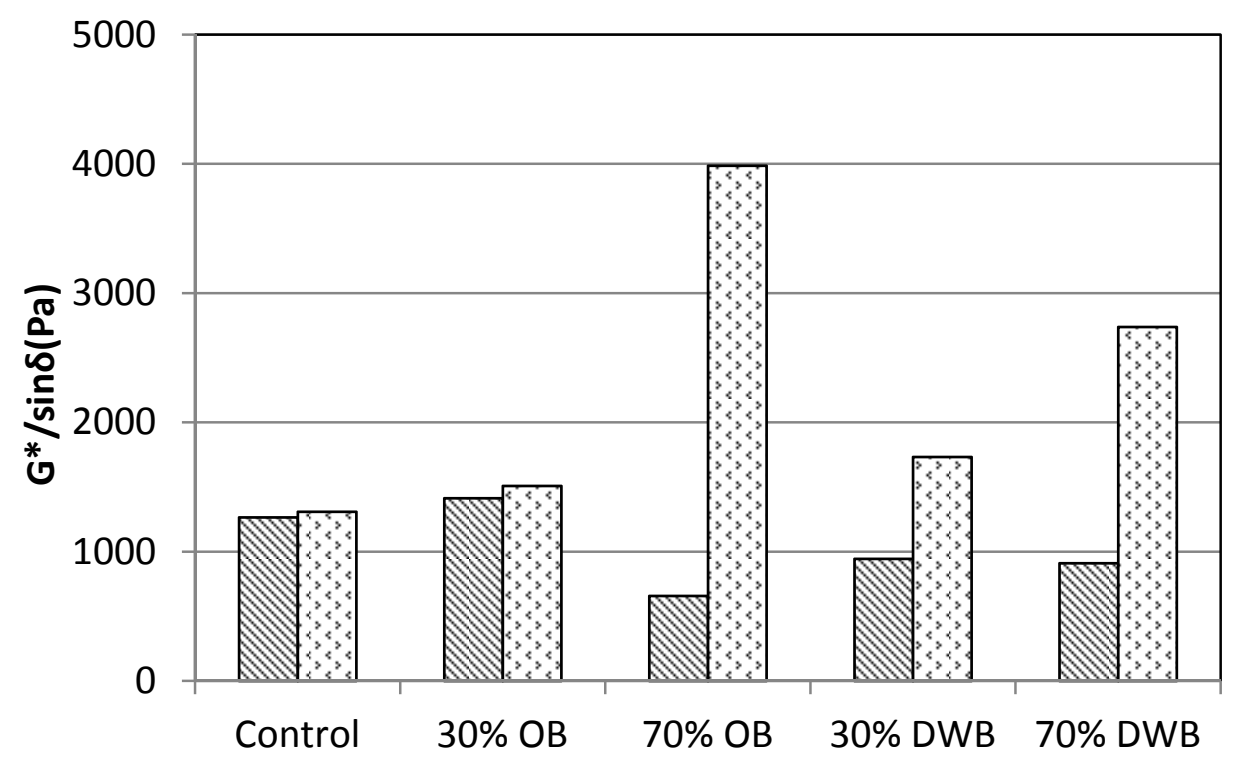

Figure 5-6: $\mathrm{G}^{*} / \sin \delta$ for control asphalt binder and binder blending containing bio binders at $58^{\circ} \mathrm{C}$ and $1.59 \mathrm{~Hz}$

\subsection{Bending Beam Rheometer}

Figure 5-7 and Figure 5-8 plot the BBR test results for the control asphalt binder and binder blending containing bio binders. Figure 5-7 displays the creep stiffness of the binders throughout the whole BBR test while Figure 5-8 shows the m-vales at 60 second for the tested binders. It is found that with the increase of the bio binder content, the creep stiffness increased. The creep stiffness of binder blending containing 30\% and $70 \%$ DWB were averagely $74.8 \%$ and $101.9 \%$ higher than that of the control asphalt binder, respectively. The creep stiffness of binder blending containing 30\% and 70\% DWB were averagely $49.9 \%$ and $218.8 \%$ higher than that of the control asphalt binder, respectively. Since a lower creep stiffness and higher $m$-value are beneficial for the low temperature performance of asphalt binder, the addition of bio binder into the petroleum asphalt would sacrifice the low temperature performance. 


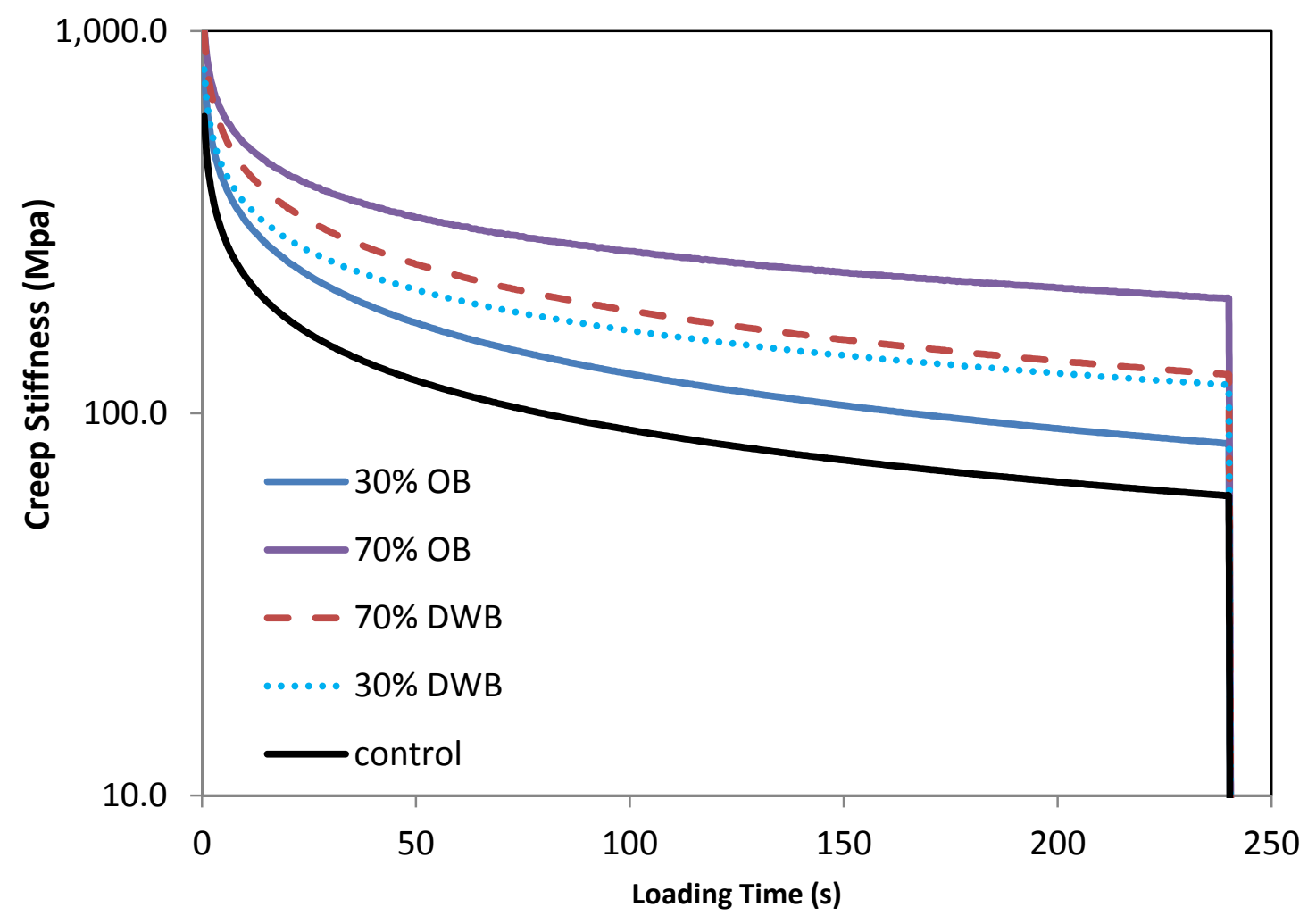

Figure 5-7: Creep stiffness test results of control binder and binder blending containing bio binders

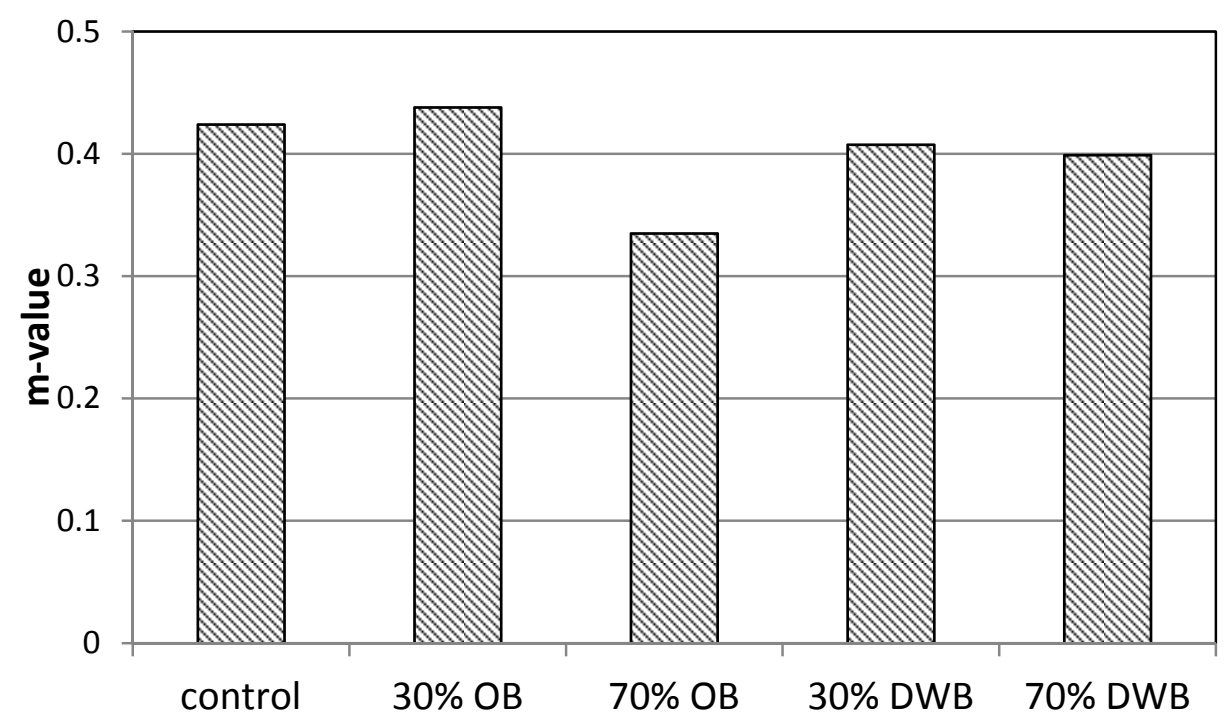

Figure 5-8: $\mathrm{m}$-values at $60 \mathrm{sec}$ of control binder and binder blending containing bio binders 


\subsection{Aging Mechanism Analysis}

As mentioned before, the short term aging of the asphalt binder is mainly from the loss of volatiles and oxidization on asphalt binders. In addition, the mass loss is an indication of potential emission of asphalt binders during the construction, so the mass loss test is conducted through the RTFO test in this study. Figure 5-9 shows the loss of volatiles for control asphalt binder and binder blending containing bio binders. With the increase of bio binder content in the binder blending, the mass loss also increased. The mass loss of control asphalt binder is almost zero while the pure untreated bio binder had mass loss as high as $5.37 \%$. Comparing the results between the two types of bio binders, it is found that the untreated bio binder had slight higher mass loss than the treated bio binder. This is probably due to the higher water content in the untreated bio binder. The temperature of the RTFO test in this study is $120^{\circ} \mathrm{C}$, which is higher than the boiling point of water. SuperpaveTM specification makes requirement that the mass loss experiencing the RTFO test should be lower than $1 \%$. Based on this, most of the binder blending containing bio binder cannot meet this requirement. On the other hand, because of the loss of the light weight components, the asphalt binder will be of higher stiffness and shear modulus, which is beneficial for the asphalt rutting performance. Considering the RV test for both virgin and RTFO aged binders, the high mass loss of bio binder should contribute much on the short term aging of the binder blending containing bio binders.

On the other hand, the high mass loss of bio oil during the short term aging also indicates that the emission of the practical construction may be a potential problem. In addition, the chemical components of the escaped compounds should also be investigated to know the environmental impact. 


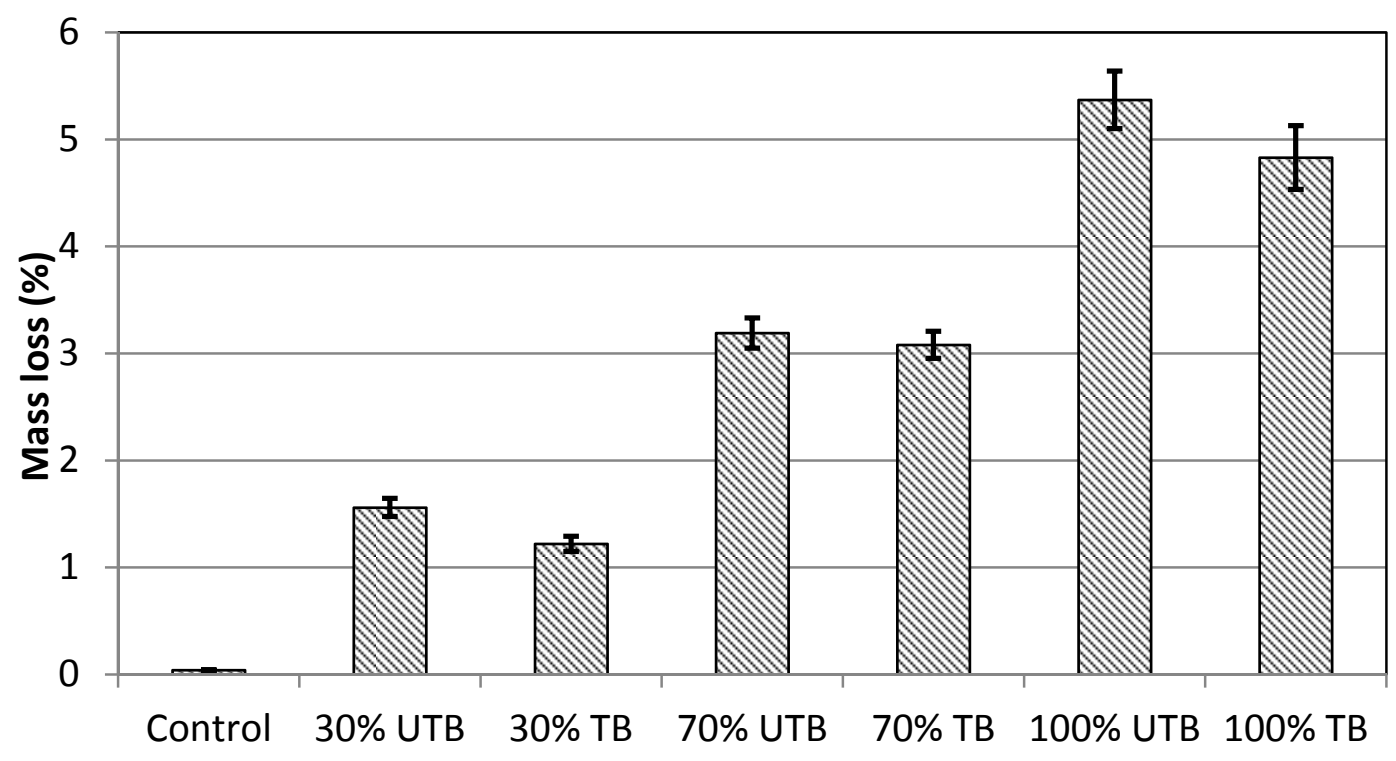

Figure 5-9: The mass loss of control asphalt binder and bind blending containing bio binders during the RTFO aging

Figure 5-10 and Figure 5-11 display the FTIR spectra for the control binder and bio-blended asphalt binders before and after RTFO aging. From the spectra, The main spectra peaks for control asphalt are located at 2950, 2925 and $2855 \mathrm{~cm}-1$ (C-H stretch), 1375 cm-1 (CH3 bend), 1465 cm-1 (CH2 bend), $1030 \mathrm{~cm}-1(\mathrm{~S}=\mathrm{O}), 1600 \mathrm{~cm}-1$ (C=C stretch), 700 to $900 \mathrm{~cm}-1$ (C-H bend), and 1650 to $1740 \mathrm{~cm}-1(\mathrm{C}=\mathrm{O}$ stretch). The corresponding functional groups are seen in Table 5-1. For the bio-blended asphalt binders, there are additional peaks at $3500 \mathrm{~cm}-1$ (O-H stretch broadened by hydrogen bond), $1120 \mathrm{~cm}-1$ (C-O-C stretch) and $1214 \mathrm{~cm}-1$ (C-O). From Table 5-1, the peak at 3500, 1120 and 1214 are representative for alcohols/acids, ethers and esters, respectively. In addition, it is found that a trace of sulfur (S) element exists in wood resourced bio oil (Mohan, Pittman et al. 2006), so the peak at $1035 \mathrm{~cm}-1$ for bio-blended asphalt binder is representative for $\mathrm{C}-\mathrm{O}$ stretch (alcohols) rather than $\mathrm{S}=\mathrm{O}$ (sulfoxides). Since waste wood resourced bio-oils contain a number of compounds such as acid, alcohols, alkenes, esters and ketones (Mullen and Boateng 2008), the FTIR spectra for both control binder and the bio-blended asphalt binders are as expected.

Previous research shows that the oxidation of asphalt binders has great influence on the bonding change of carbonyl $(\mathrm{C}=\mathrm{O}$ stretch around $1700 \mathrm{~cm}-1)$ and sulfoxide $(\mathrm{S}=\mathrm{O}$ 
stretch located at $1030 \mathrm{~cm}-1$ ) (Ouyang, Wang et al. 2006; Petersen 2009; Xu and Huang 2010). However, since sulfoxide is not an oxidation index for bio-binder from wood resources, it is not considered in the bio-binder oxidation. Literature review shows that the oxidation of bio-binder is associated with the increase of ketones $(\mathrm{C}=\mathrm{O}$ around 1715 cm-1), carbonyl $(\mathrm{C}=\mathrm{O}$ around $1700 \mathrm{~cm}-1)$, ester $(\mathrm{C}-\mathrm{O}$ stretch at $1214 \mathrm{~cm}-1)$ and ether groups (C-O stretch at $1120 \mathrm{~cm}-1$ ) (Czernik, Johnson et al. 1994; Diebold 2000; Scholze and Meier 2001; Hilten and Das 2010). Thus, the oxidation analysis for petroleum asphalt only take account into the carbonyl and sulfoxide but for the bio-blended asphalt binder, $\mathrm{C}=\mathrm{O}$ around $1700 \mathrm{~cm}-1$ stretch and $\mathrm{C}-\mathrm{O}$ stretch at 1035, 1120 and $1214 \mathrm{~cm}-1$ are considered.

To make direct comparisons, a normalization approach was applied for all of the spectra. An absorbance height of 1 was adapted for peak at $1465 \mathrm{~cm}-1$ without changing the relative heights of the spectra. Peak height or area calculation is the widely used approach for the quantitative analysis based on FTIR spectra. For asphalt oxidation quantitative analysis, band area rather than the peak height is used for the quantitative analysis for two reasons: 1) band areas provide less variations (Yut and Zofka 2011); and 2) several vibrations may occur in the same band so that it's difficult to obtain the single peak height (Lamontagnea, Dumasb et al. 2001).

Previous studies provide the quantitative calculation for the oxidation analysis. the carbonyl $(\mathrm{C}=\mathrm{O})$ and sulfoxide $(\mathrm{S}=\mathrm{O})$ indexes are introduced and calculated by the following equations (Lamontagnea, Dumasb et al. 2001; Yut and Zofka 2011):

Carbonyl index: $\mathrm{I}_{\mathrm{C}=\mathrm{O}}=\mathrm{AR}_{1600} / \sum \mathrm{AR}$

Sulfoxide index: $\mathrm{I}_{\mathrm{S}=\mathrm{O}}=\mathrm{AR}_{1030} / \sum \mathrm{AR}$

Where: $\mathrm{AR}_{1600}$ is the band area around $1700 \mathrm{~cm}^{-1}$;

$\mathrm{AR}_{1030}$ is the band area around $1030 \mathrm{~cm}^{-1}$;

$\sum \mathrm{AR}$ is the total area of all bands;

Similarly, the indexes of $\mathrm{C}-\mathrm{O}$ bonds at different locations are calculated by: 
Bond index for alcohol: $\mathrm{I}_{\mathrm{C}-\mathrm{O} \text { at } 1035}=\mathrm{AR}_{1035} / \sum \mathrm{AR}$

Bond index for ether: $\mathrm{I}_{\mathrm{C}-\mathrm{O} \text { at } 1120}=\mathrm{AR}_{1120} / \sum \mathrm{AR}$

Bond index for ester: $\mathrm{I}_{\mathrm{C}-\mathrm{O} \text { at } 1214}=\mathrm{AR}_{1214} / \sum \mathrm{AR}$

Where:

$\mathrm{I}_{\mathrm{C}-\mathrm{O} \text { at } 1035}, \mathrm{I}_{\mathrm{C}-\mathrm{O} \text { at } 1120}$ and $\mathrm{I}_{\mathrm{C}-\mathrm{O} \text { at } 1214}$ are the band areas around 1035,1120 and $1214 \mathrm{~cm}^{-1}$, respectively.

The oxidation index $(\mathrm{OI})$ is calculated by the equations below:

$$
\text { Oxidation Index: } \mathrm{OI}=\frac{\sum \mathrm{I} \text { after aging }}{\sum \mathrm{I} \text { before aging }}
$$

Where:

$\sum \mathrm{I}_{\text {after aging }}$ is the sum of bond indexes after aging

$\sum \mathrm{I}$ before aging is the sum of bond indexes before aging

The bond indexes and oxidation indexes for the control binder and the bioblended asphalt binders are shown in Table 5-2. For the control binder, there was almost no band area change for the $\mathrm{C}=\mathrm{O}$ stretch (around $1700 \mathrm{~cm}-1$ ) and $\mathrm{S}=\mathrm{O}$ stretch (at 1030 $\mathrm{cm}-1$ ) after RTFO-aging. The oxidation is only 1.01. This indicates that little oxidation occurred during the RTFO-aging for control asphalt binder. Considering that the RTFO test condition is only $120^{\circ} \mathrm{C}$ and 20 minutes, both of which are much lower than the condition in the standard RTFO test $\left(163^{\circ} \mathrm{C}\right.$ and 85 minutes), the result is as expected. For the bio-blended asphalt binders, most of the bond indexes increased after the RTFO aging, indicating a concentration increase of alcohol, ether, ester and carbonyl groups after the RTFO-aging. Literature review shows that an increased concentration of carbonyl $(\mathrm{C}=\mathrm{O}$ around $1700 \mathrm{~cm}-1)$, ester $(\mathrm{C}-\mathrm{O}$ stretch at $1214 \mathrm{~cm}-1)$ and ether $(\mathrm{C}-\mathrm{O}$ stretch at $1120 \mathrm{~cm}-1$ ) is a characteristic for the oxidation in bio-binders (Czernik, Johnson et al. 1994; Diebold 2000). In this study, the increase of alcohol (C-O at 1030 $\mathrm{cm}-1$ ) was also observed after the aging. In fact, it is thought that the oxidation occurs as long as the ratio of carbon content to oxygen content decreases (Scholze and Meier 2001). In terms of this, the increase of alcohol group in the bio-blended asphalt binders is an indication of reduced ratio of carbon content to oxygen content, thus a characteristic of 
oxidation. Thus, the FTIR results show that there is a significant oxidation for bioblended asphalt binders. The oxidation is accompanied with the increase of alcohols, ethers, esters and carbonyls in the system. Comparison between the two types of biobinders shows that the TB-blended asphalt binders had higher OI than the UTB-blended asphalt binders, indicating a higher oxidation level. The possible reason for this is that the moisture in the UTB prevent the contact of the oxygen and the chemical compounds. In addition, it should be noticed that since there are some mass loss for the bio-blended asphalt binders, if the lost compounds have high concentration of these functional groups, the oxidation indexes are expected to be even higher for bio-blended asphalt binders.

Table 5-2: Band areas of representative bonds before and after aging

\begin{tabular}{|c|c|c|c|c|c|c|c|}
\hline \multirow[b]{2}{*}{$\begin{array}{l}\text { Binder } \\
\text { types }\end{array}$} & \multirow{2}{*}{$\begin{array}{c}\text { Before/after } \\
\text { aging }\end{array}$} & \multicolumn{5}{|c|}{ Bond locations $\left(\mathrm{cm}^{-1}\right)$ and bond index $\left(\times 10^{-3}\right)$} & \multirow{2}{*}{$\begin{array}{c}\text { Oxidatio } \\
\mathrm{n} \text { index } \\
(\mathrm{OI})\end{array}$} \\
\hline & & $\begin{array}{c}\mathrm{S}=\mathrm{O} \\
(1030)\end{array}$ & $\begin{array}{c}\mathrm{C}-\mathrm{O} \\
(1035)\end{array}$ & $\begin{array}{c}\mathrm{C}-\mathrm{O} \\
(1120)\end{array}$ & $\begin{array}{c}\mathrm{C}-\mathrm{O} \\
(1214)\end{array}$ & $\begin{array}{c}\mathrm{C}=\mathrm{O} \\
(\sim 1700)\end{array}$ & \\
\hline \multirow{2}{*}{ Control } & Before & 5.65 & \multirow{2}{*}{--} & \multirow{2}{*}{--} & \multirow{2}{*}{--} & 5.74 & \multirow{2}{*}{1.01} \\
\hline & After & 5.72 & & & & 5.78 & \\
\hline \multirow{2}{*}{$30 \% \mathrm{OB}$} & Before & \multirow{2}{*}{--} & 8.31 & 7.60 & 10.75 & 16.5 & \multirow{2}{*}{1.09} \\
\hline & After & & 9.97 & 7.62 & 10.86 & 19.07 & \\
\hline \multirow{2}{*}{$70 \% \mathrm{OB}$} & Before & \multirow{2}{*}{-- } & 6.28 & 5.60 & 8.28 & 14.84 & \multirow{2}{*}{1.26} \\
\hline & After & & 6.67 & 7.09 & 10.66 & 21.06 & \\
\hline \multirow{2}{*}{$\begin{array}{l}30 \% \\
\text { DWB }\end{array}$} & Before & \multirow{2}{*}{-- } & 9.50 & 7.21 & 10.30 & 22.94 & \multirow{2}{*}{2.11} \\
\hline & After & & 21.68 & 16.14 & 19.27 & 46.23 & \\
\hline \multirow{2}{*}{$\begin{array}{l}70 \% \\
\text { DWB }\end{array}$} & Before & \multirow{2}{*}{-- } & 6.97 & 5.12 & 8.55 & 14.03 & \multirow{2}{*}{1.26} \\
\hline & After & & 6.73 & 8.09 & 11.62 & 16.08 & \\
\hline
\end{tabular}

Note: "--" means no visible peaks were observed.

To sum up the aging of petroleum asphalt and bio-blended asphalt binders, there is almost no loss of volatiles and oxidation for petroleum asphalt during the RTFO-aging in this study. However, both the volatile loss and oxidation are significantly observed for bio-blended asphalt binders. Since it is well known that the loss of light weight compounds and oxidation are main reasons of asphalt aging, the aging of the bio-blended asphalt binders in this study should be attributed to these two factors. The results are supported by the rheological test results of petroleum asphalt and bio-blended asphalt binders. 


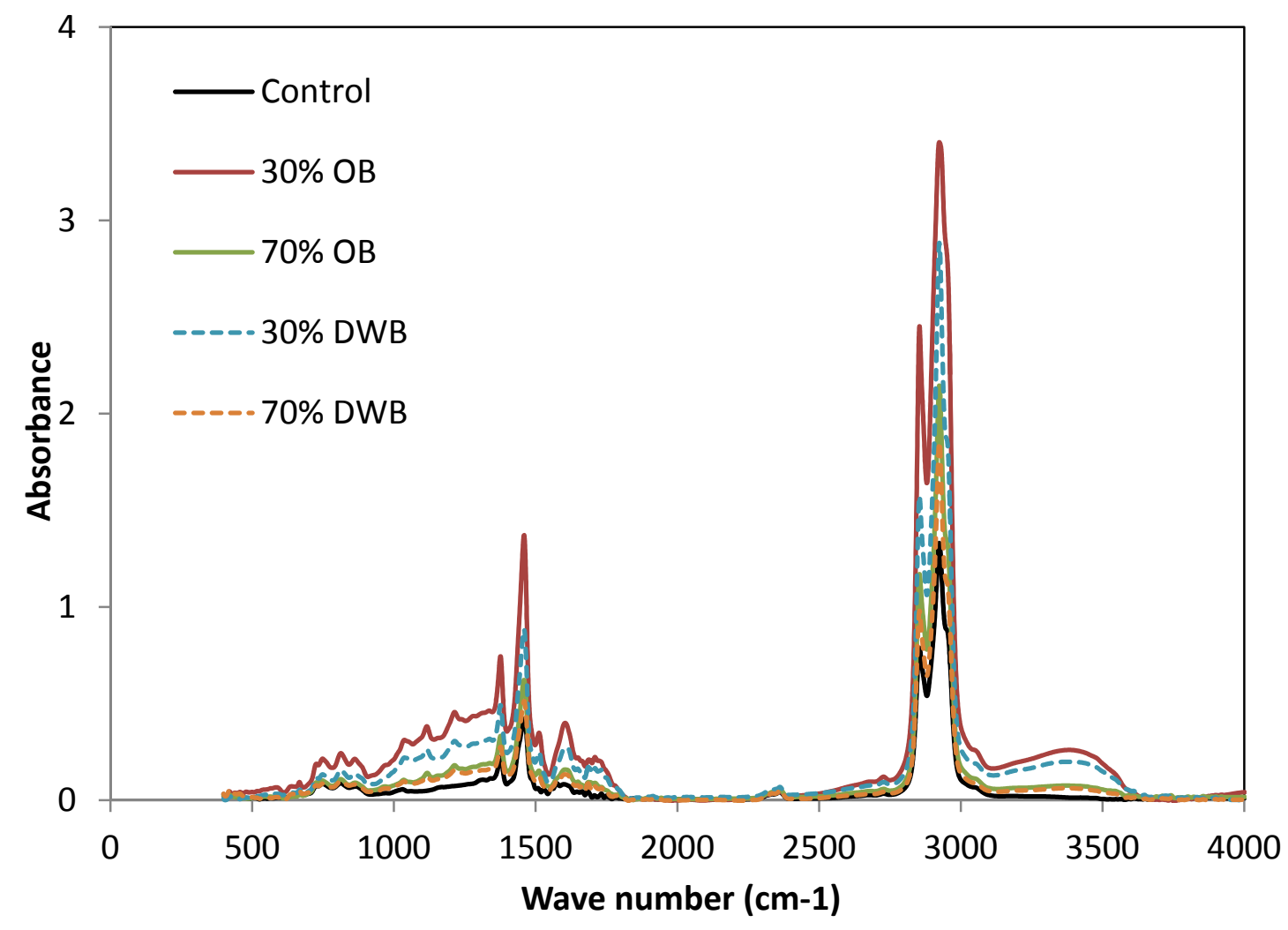

Figure 5-10: FTIR spectra of control asphalt binder and binder blending containing bio binders before RTFO aging (after baseline correction) 


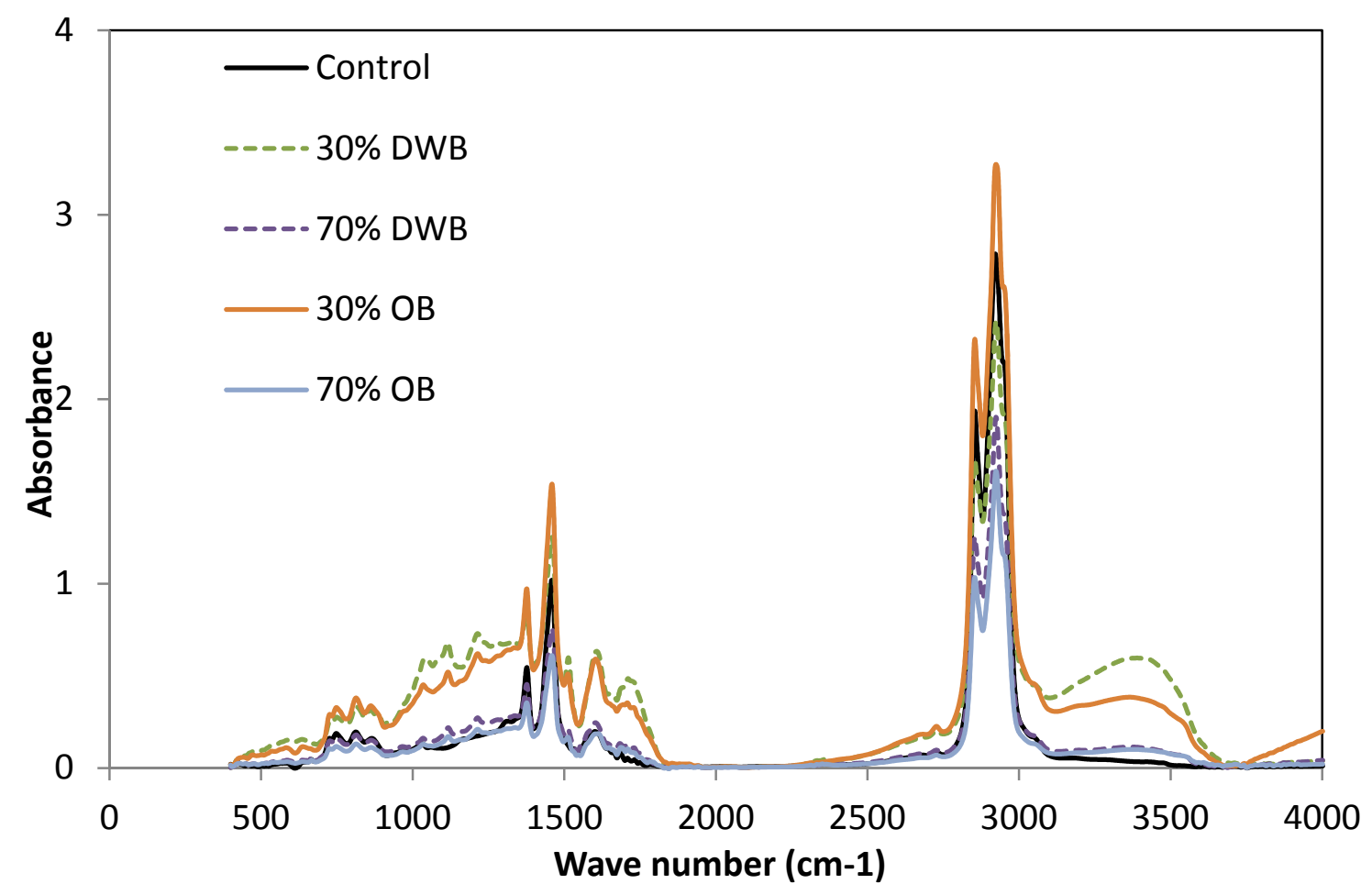

Figure 5-11: FTIR spectra of control asphalt binder and binder blending containing bio binders before RTFO aging (after baseline correction)

Figure 5-12 and Figure 5-13 display the ratios of carbonyl and sulfoxide for control asphalt binder and binder blending containing bio oils, respectively. It is observed that bio oil has significant higher amount of carbonyl and sulfoxide, which is as expected because bio oil has much higher oxygen element content. However, no significant increment of carbonyl or sulfoxide ratios was observed after the RTFO aging. In fact, both the carbonyl and sulfoxide ratios of 100\% OB and 100\% DWB are decreased after RTFO aging. This may be due to the escape of light weight compounds which have higher carbonyl and sulfoxide. For the control asphalt binder and binder blending containing bio oils, there were slightly increase for the sulfoxide after RTFO aging. However, there is no good relation between the ratio changes and bio oil percent in the binder blending. This may indicate that the oxidation is not a main reason for the aging in the RTFO test in this study considering the RTFO condition is only 20 minutes at $120^{\circ} \mathrm{C}$. However, both the RV and DSR test results showed that the viscosity and complex shear 
modulus increase a lot after the RTFO aging. Thus, the main reason for the aging is due to the molecular loss of light weight compounds in the bio oil.

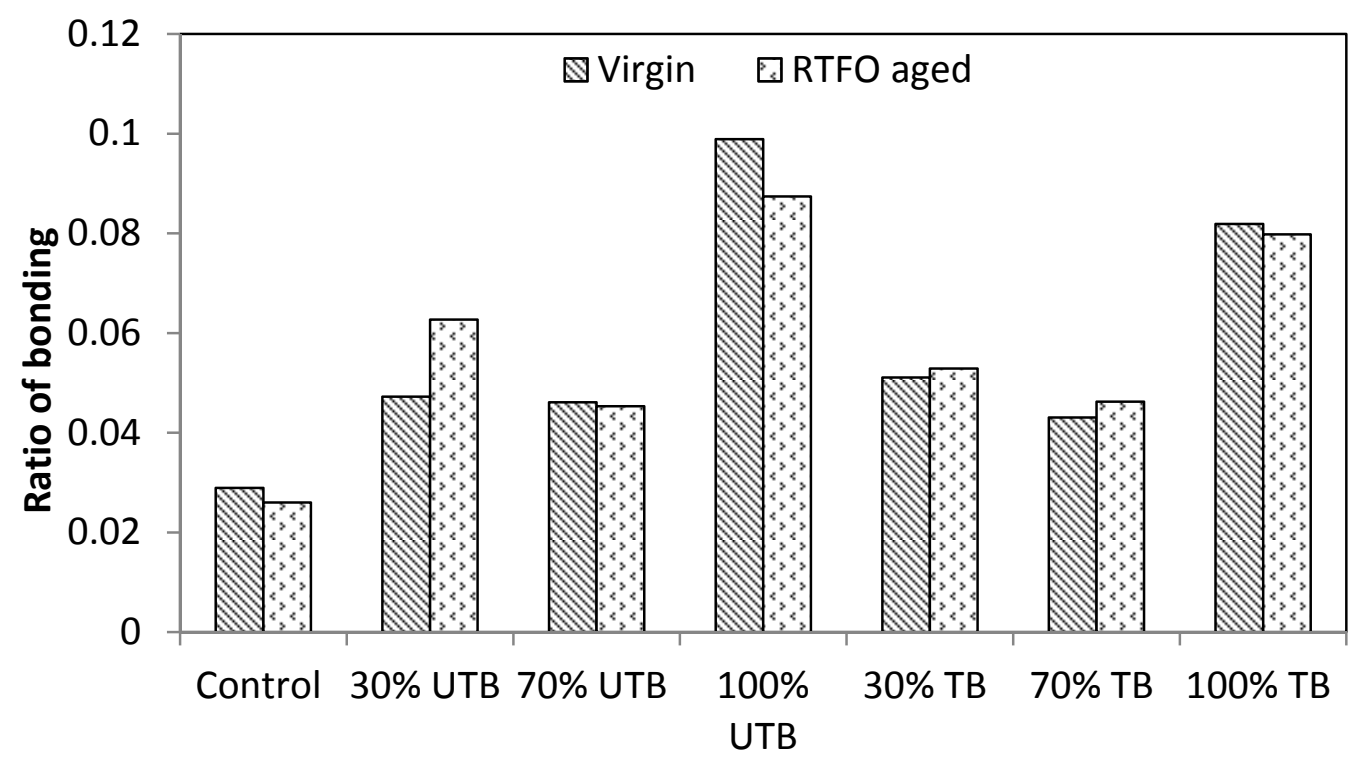

Figure 5-12: Ratio of $\mathrm{C}=\mathrm{O}$ bonding of control asphalt binder and binder blending containing bio binder before and after RTFO aging

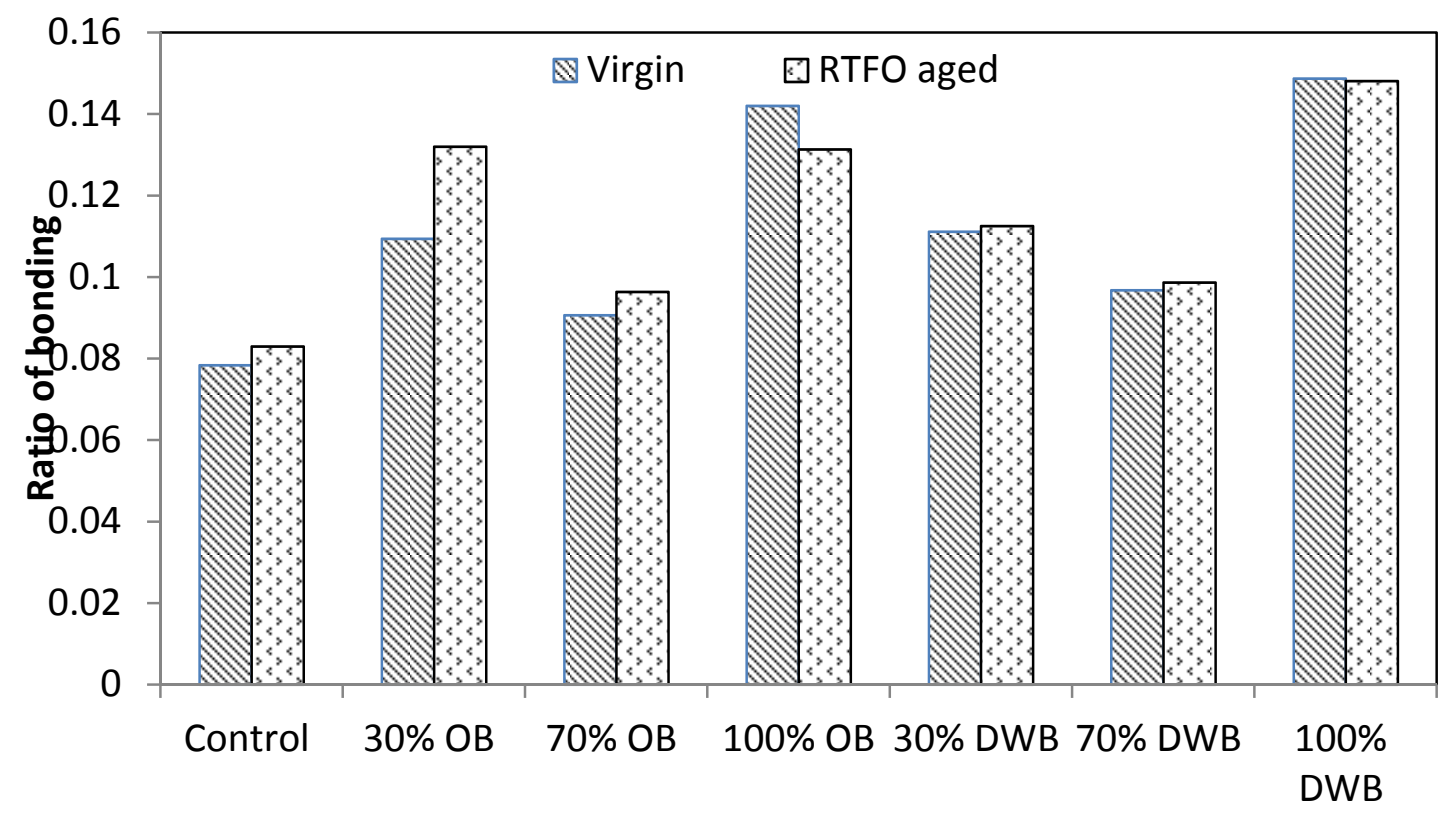

Figure 5-13: Ratio of $\mathrm{S}=\mathrm{O}$ bonding of control asphalt binder and binder blending containing bio binder before and after RTFO aging 


\subsection{Findings and Conclusions}

The research studied the rheological properties and conducted the aging analysis of petroleum asphalt binder and asphalt binders partially replaced by untreated biobinders (UTB) and treated bio-binders (TB) at the fractions of $30 \%$ and $70 \%$. The rotational viscometer (RV) and dynamic shear rheometer (DSR) were conducted for the rheological property characterization. The mass loss test from rolling thin film oven (RTFO) and oxidation index from Fourier Transform Infrared (FTIR) Spectroscopy were conducted to analyze the aging performance. The main findings and conclusions are summarized as below:

1) Before RTFO aging, the bio-blended asphalt binders overall showed lower rotational viscosity compared to the petroleum asphalt. In addition, the UTBblended binder had lower viscosity than the TB-blended binder, which is thought due to the foaming of untreated bio-binders.

2) After the RTFO-aging, the bio-blended asphalt binders had higher rotational viscosities and dynamic shear modulus $\left(\left|\mathrm{G}^{*}\right|\right)$ than the control asphalt binder, which was due to the fast aging of bio-binders.

3) According to Superpave specification, the bio-blended asphalt can reduce the mixing temperature while increase the high temperature performance compared to the control asphalt.

4) Both the loss of volatiles and oxidation were significantly observed for the bioblended asphalt binders, indicating the aging mechanisms of bio-blended asphalt binders. Comparison between the two types of bio-binders showed that UTB resulted in higher mass loss while TB caused higher oxidation index.

5) The high mass loss of bio-oils or binder blending containing bio-oils indicates a high emission during the practical construction. The detailed information of the escaped compounds should be further revealed to evaluate the environmental impacts. 


\section{Chapter 6: Mechanical Performance Evaluation for Asphalt Mixtures Modified by Bio Oil ${ }^{3}$}

In this chapter, the mechanical properties of asphalt mixtures modified by bio oils are investigated. The asphalt binder is blended with up $10 \%$ bio oils by weight and then mixed with the aggregate to make the asphalt mixtures. The mechanical performances of asphalt binders include rutting performance, dynamic modulus, moisture susceptibility, fatigue performance. The corresponding test methods are asphalt pavement analyzer, dynamic modulus test, indirect tensile strength test, four point beam fatigue test.

\subsection{Introduction}

This section of the research addresses the design, laboratory preparation and performance characterization of bio oil modified asphalt mixtures. Essentially, this chapter addresses the challenge of whether $\mathrm{bi}^{3} \mathrm{o}$ oil modified asphalt mixtures prepared with typical Michigan aggregate materials can work satisfactorily when used for road pavements in the State.

Five characterization approaches are selected to achieve the principal objective of evaluating the mechanical performance properties of bio-modified asphalt mixtures in relation to its resistance against permanent deformation, moisture susceptibility and fatigue cracking. The characterization methods used are: 1) Permanent deformation or rutting using the Asphalt Pavement Analyzer (APA); 2) Indirect Tensile Strength Ratio (TSR) for moisture susceptibility and; 3) Dynamic modulus for stiffness or E* test; 4) Flow Number (FN) for permanent deformation evaluation; 5) Beam Fatigue Test for fatigue evaluation. Based on the research, recommendations and a guiding framework are made on the proposed use of the three types of bio oil in Michigan asphalt road design and construction.

\footnotetext{
${ }^{3}$ Text prepared for submission to Construction and Building Materials-Yang, X., You. Z, Mills-Beale, J., (2013) Mechanical Performance of Asphalt Mixtures Modified by Bio Oils Derived from Waste Wood Resources. Construction and Building Materials.
} 


\subsection{Material preparation}

\subsubsection{Asphalt Binders}

In this study, the bio oil blends with petroleum based asphalt binder first. Then the asphalt mixture is made by mixing the aggregate and the bio oil blended asphalt binders. The petroleum based asphalt binder used in this study is PG 58-28, which is also the control asphalt binder in this study. To make the bio oil modified asphalt binders, the control asphalt binder was blended with 5\% and $10 \% \mathrm{OB}, 5 \%$ and $10 \% \mathrm{DWB}$, and $5 \%$ and $10 \%$ PMB, respectively. Thus, totally seven asphalt binder blends were investigated in this study. These seven asphalt binders will be mixed with the same aggregate to make asphalt mixtures. The procedures of preparing the bio oil modified asphalt binders include two steps. First, preheat the control asphalt binder and the three types of bio oils to $130^{\circ} \mathrm{C}$ and $110^{\circ} \mathrm{C}$, respectively. Secondly, mix the control asphalt binder and the bio oil modifier for 20 minutes at $130^{\circ} \mathrm{C}$ using a high shear mixer. The shearing rate of the mixing was 5000 rounds per minute (RPM).

\subsubsection{Aggregates and Gradation}

The aggregates used in this study were a mix of natural sand, washed natural sand and $1 / 4$ minus screen, collected from Eagle River, Wisconsin, US. The nominal aggregate size is $9.5 \mathrm{~mm}$. The detailed gradation of the HMA mixtures in this study is shown in Table 6-1. The mixture design for the HMA mixture follows the Michigan Department of Transportation (MDOT) specification for an E3 mixture(Vitton, Williams et al. 2007), which is designed for a pavement with traffic level between 1 million and 3 million equivalent single axle loads (EASLs) (Michigan Department of Transportation (MDOT) 2003).

Table 6-1: Detailed gradation of the HMA mixture used in this study

\begin{tabular}{lcccc}
\hline & & \multicolumn{3}{c}{ Retained percent (\%) } \\
\cline { 3 - 5 } $\begin{array}{l}\text { Sieve size } \\
\text { No. }\end{array}$ & Passing percent (\%) & $1 / 4$ minus screen & Natural sand & $\begin{array}{c}\text { Washed } \\
\text { natural } \\
\text { sand }\end{array}$ \\
\hline $1 / 2 "$ & 94.0 & -- & 2.6 & 3.5 \\
$(13.2 \mathrm{~mm})$ & 86.3 & -- & 3.3 & 4.4 \\
$3 / 8 "(9.5 \mathrm{~mm})$ & 68.2 & 10.1 & 1.7 & 6.4 \\
$\# 4(4.75 \mathrm{~mm})$ & & & & \\
\hline
\end{tabular}




\begin{tabular}{lcccc}
\hline$\# 8(2.36 \mathrm{~mm})$ & 49.2 & 8.8 & 2.1 & 8.1 \\
$\# 16$ & 38.4 & 5.0 & 1.2 & 4.6 \\
$(1.18 \mathrm{~mm})$ & 27.8 & 4.9 & 1.2 & 4.5 \\
$\# 30(0.6 \mathrm{~mm})$ & 15.0 & 5.9 & 1.4 & 5.5 \\
$\# 50(0.3 \mathrm{~mm})$ & 6.7 & 3.8 & 0.9 & 3.5 \\
$\# 100$ & & & & \\
$(0.15 \mathrm{~mm})$ & 4.5 & 1.0 & 0.2 & 0.9 \\
$\# 200$ & 0 & 2.1 & 0.5 & 1.9 \\
$(0.075 \mathrm{~mm})$ & & & & \\
PAN & & &
\end{tabular}

\subsubsection{HMA Mixture Preparation}

Before the preparation of the asphalt mixtures, the rotational viscosities (RV) test for asphalt binders were conducted to determine the mixing and compaction temperatures. The mixing and compaction temperatures were determined where the rotational viscosities were 0.17 and $0.28 \mathrm{~Pa}-\mathrm{S}$, respectively. HMA sample in this study were prepared according to the Superpave ${ }^{\mathrm{TM}}$ mixture preparation process from MDOT (Michigan Department of Transportation 2008). The RV test results for control asphalt binder and bio oil modified asphalt binders were shown in Figure 6-1. It is found that all of the virgin bio oil modified asphalt binders had lower rotational viscosities than the control asphalt binder but most of the bio oil modified asphalt binders had slightly higher rotational viscosities than the control asphalt binders. The viscosities of bio oil modified asphalt binders were $10.1 \%$ lower than that of the control asphalt binder by average. However, the average viscosity of bio oil modified asphalt binders was $3.7 \%$ higher than that of the control asphalt binders after the standard rolling thin film oven (RTFO) aging. This indicates that the aging of bio oil is faster compared to the control asphalt binder. Based on the RV test result, the asphalt mixtures were mixed and compacted at $148^{\circ} \mathrm{C}$ and $135^{\circ} \mathrm{C}$, respectively. After the mixing, the loose asphalt mixtures were aged in the oven for two hours before compaction. 


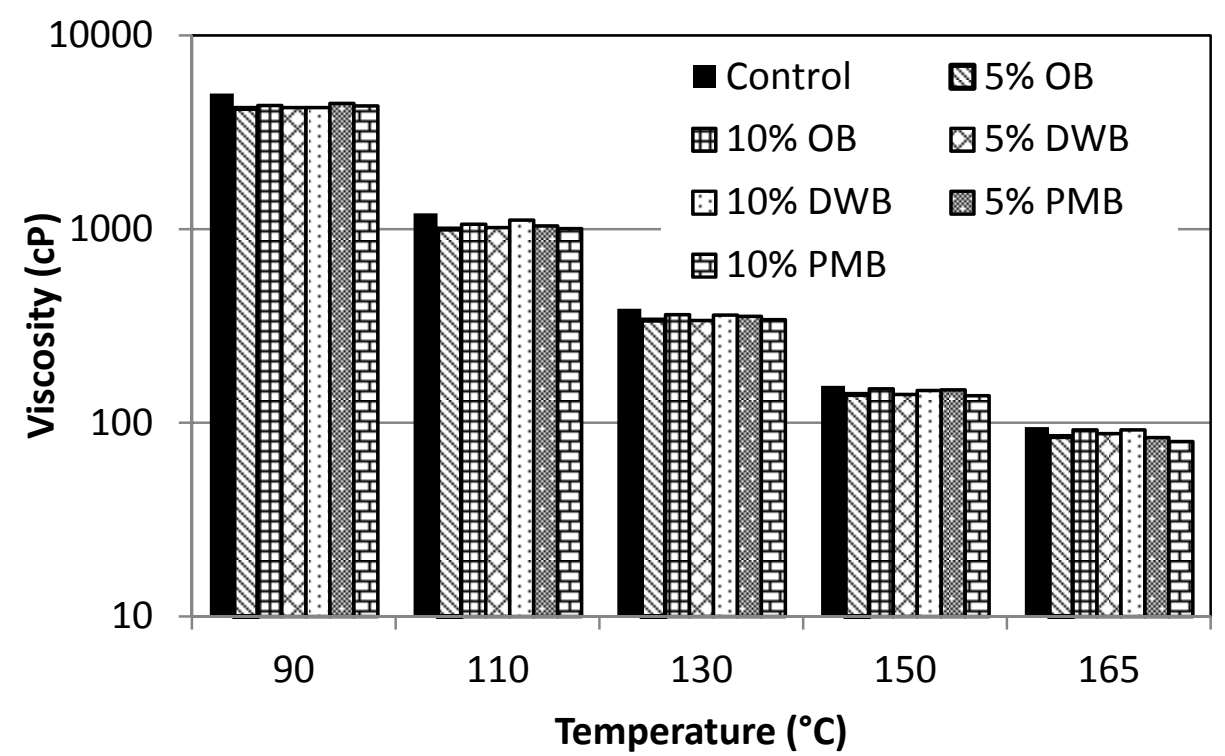

(a) Rotational viscosities of asphalt binders before RTFO aging

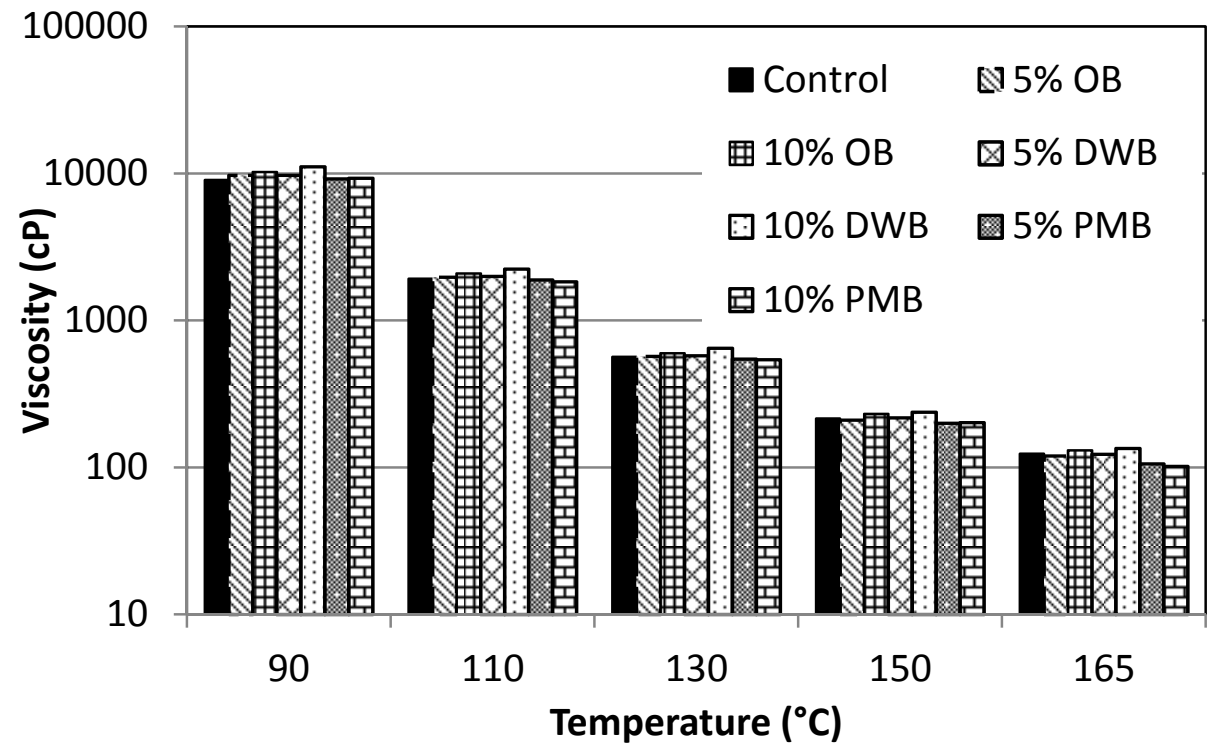

(b) Rotational viscosities of asphalt binders after RTFO aging

Figure 6-1: Rotational viscosities of asphalt binders before and after RTFO aging

\subsection{Experimental}

The tests conducted in this study are to evaluate the effect of the bio oils on the asphalt mixture performances. The performance tests and the related test functions are shown in Table 6-2. 
Table 6-2: testing plans in this study

\begin{tabular}{|c|c|}
\hline \multirow{2}{*}{ Test function } & Test approach \\
\hline \multirow{2}{*}{ Stiffness } & Dynamic modulus $\left(\left|\mathrm{E}^{*}\right|\right)$ \\
\cline { 2 - 2 } & Resilient modulus $\left(\mathrm{M}_{\mathrm{R}}\right)$ \\
\cline { 2 - 2 } & Flexural modulus \\
\hline Strength & Indirect tensile (IDT) strength \\
\hline Moisture susceptibility & Tensile strength ratio (TSR) \\
\hline \multirow{2}{*}{ Rutting resistance } & Asphalt pavement analyzer $(\mathrm{APA})$ \\
\cline { 2 - 2 } & Flow number $\left(\mathrm{F}_{\mathrm{N}}\right)$ \\
\hline Fatigue performance & Four point beam fatigue \\
\hline
\end{tabular}

\subsubsection{Dynamic Modulus (E*) Test}

Dynamic modulus $\left(\mathrm{E}^{*}\right)$ is developed to obtain the material stiffness under a various range of temperatures and frequencies. It can present the visco-elastic properties of the asphalt mixtures and determine the mechanical responses of asphalt pavement under traffic load. The $\left|E^{*}\right|$ has been investigated as one of the most important input parameters in the Mechanistic-Empirical Pavement Design Guide (MEPDG) (NCHRP 2011). The $\left|E^{*}\right|$ test procedure in this study followed AASHTO TP 62-03 standard (AASHTO 2010). The testing temperatures were $-10^{\circ} \mathrm{C}, 4^{\circ} \mathrm{C}, 21.3^{\circ} \mathrm{C}$ and $39.2^{\circ} \mathrm{C}$, and the loading frequencies were $0.01 \mathrm{~Hz}, 0.1 \mathrm{~Hz}, 1 \mathrm{~Hz}, 5 \mathrm{~Hz}, 10 \mathrm{~Hz}$ and $25 \mathrm{~Hz}$. The test equipment for the $\left|\mathrm{E}^{*}\right|$ test in this study is a universal testing machine (UTM). During the test, a uniaxial sinusoidal loading is applied on the cylindrical asphalt mixture specimen. The strain and stress amplitudes are obtained and the dynamic modulus $\left(\left|\mathrm{E}^{*}\right|\right)$ is determined as the ratio of the stress and strain amplitude. The set up and the stress-strain relationship of the test are shown in Figure 6-2. The magnitude of the dynamic modulus is:

$$
\left|E^{*}\right|=\frac{\Delta \sigma}{\Delta \varepsilon}
$$

Where: $\Delta \sigma$ is the peak stress amplitude, $\mathrm{Pa}$

$\Delta \varepsilon$ is the peak amplitude of recoverable axial strain. 

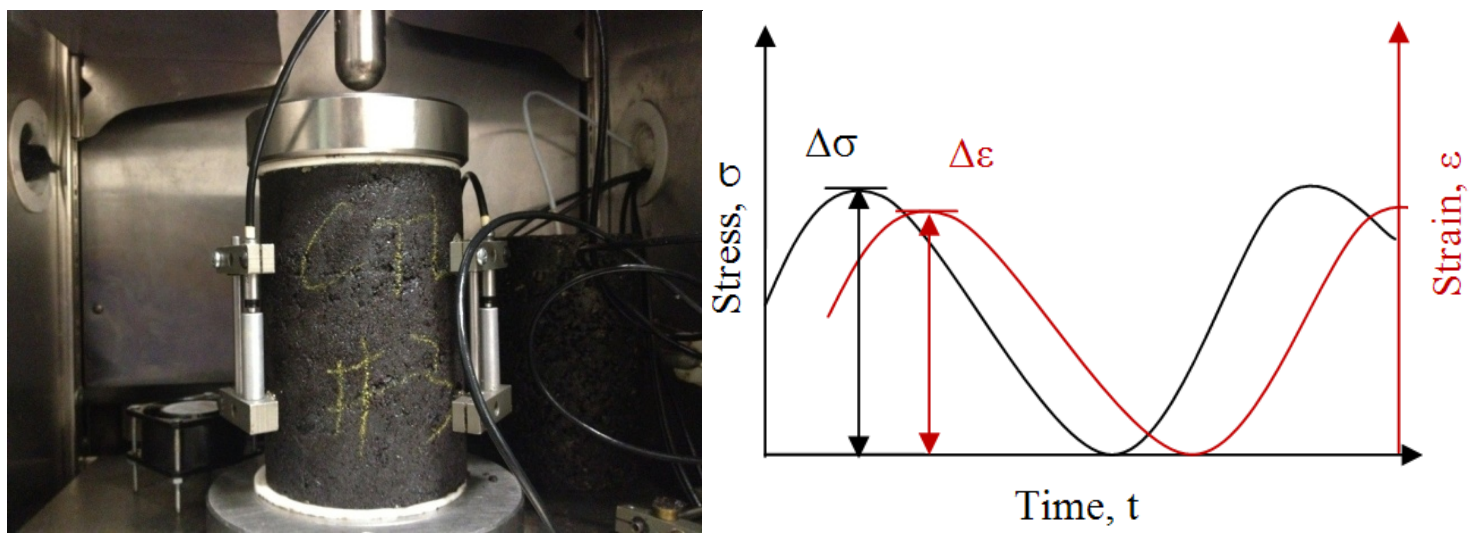

Figure 6-2: The set up and the strain-stress relation of dynamic modulus test

\subsubsection{Indirect Tensile (IDT) strength}

Tensile strength of HMA mixture is related to the cracking performances, such as thermal and fatigue cracking. The moisture susceptibility can evaluate the moisture damage resistances of HMA mixtures. In this study, the influence of bio oil on the indirect tensile (IDT) strength and the moisture susceptibility were investigated through the IDT test. The set up of the IDT test is shown in Figure 6-3. The indirect tensile strength of the specimen is determined as follows:

Where: $\quad d=$ the diameter of the specimen,

$$
\sigma_{x y}=\frac{2 P}{\pi t d}
$$

$\mathrm{P}=$ the applied load, and

$\mathrm{t}=$ the thickness of the specimen.

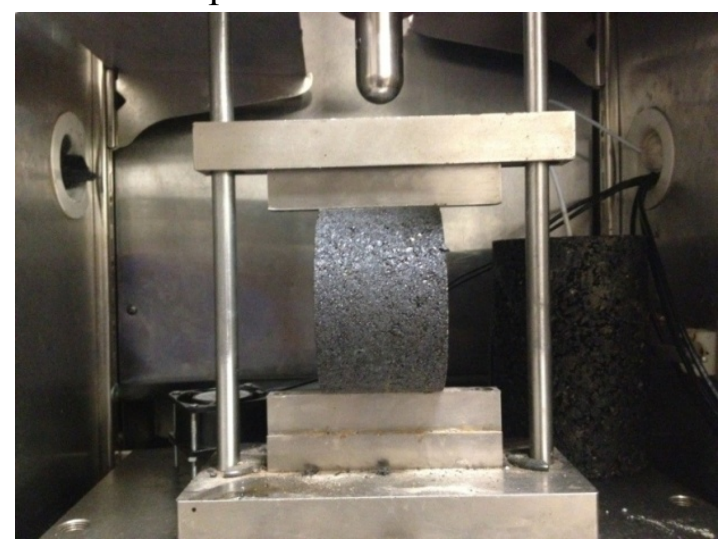

Figure 6-3: The indirect tensile (IDT) strength test

\subsubsection{Rutting resistance}

Rutting or permanent deformation is an indication of the high temperature performance of asphalt mixtures. In this study, asphalt pavement analyzer (APA) test is 
conducted to analyze the rutting resistance of asphalt mixtures. The set up of the APA test is shown in Figure 6-4. During the test, a repeated wheel loading $(100 \mathrm{kN})$ is applied on the sample every one second. The test stops when 8000 loading cycles are applied and then the rutting depth is obtained. The test procedure follows AASHTO T 340 (AASHTO 2007), and the test temperature is $58^{\circ} \mathrm{C}$.

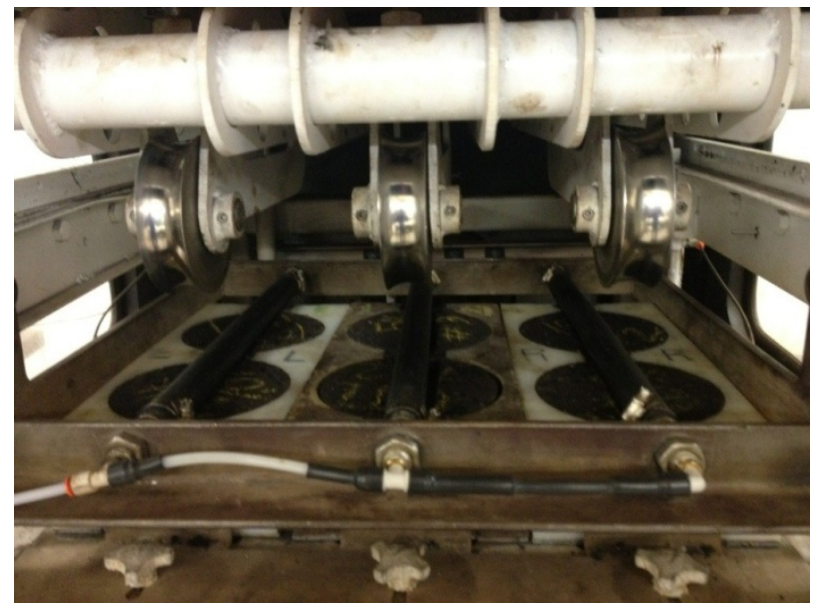

Figure 6-4: The asphalt pavement analyzer (APA) test

\subsubsection{Four point beam fatigue test}

The fatigue resistance of the control asphalt mixture and the bio oil modified asphalt mixtures were investigated by four point beam fatigue test. The purpose of this test is to determine the fatigue life of asphalt mixtures subjected to repeated bending load. The test procedure follows AASHTO T 321 (AASHTO 2007). The fatigue life is determined when the flexural modulus of the asphalt mixture is $50 \%$ of the initial modulus (AASHTO 2007). In the test, 200 and 400 micro-strains were applied to all of the samples with a frequency of $10 \mathrm{~Hz}$ at $21^{\circ} \mathrm{C}$. The set up of the four point beam fatigue test is shown in Figure 6-5. 


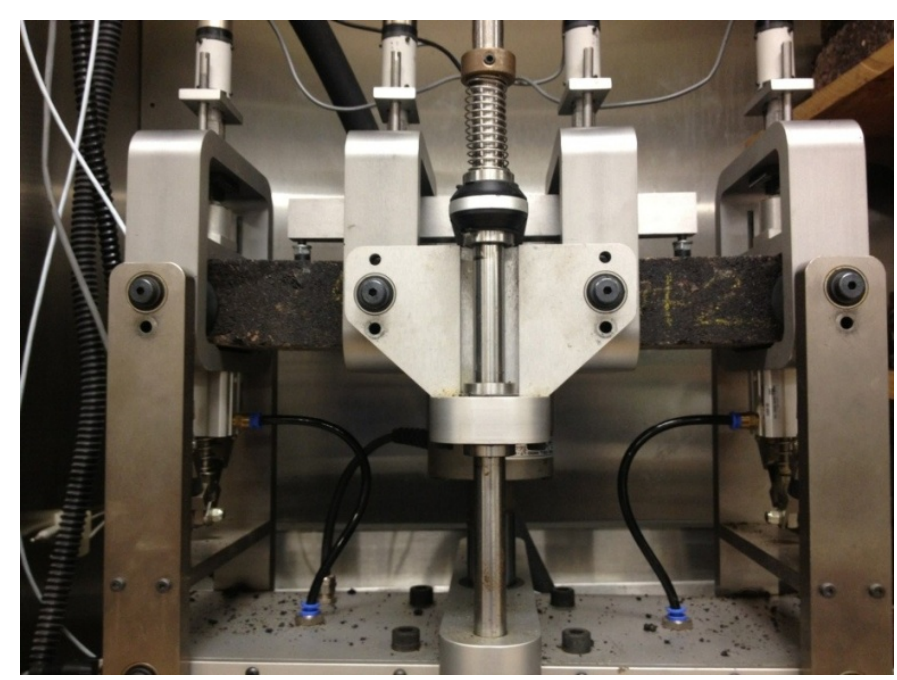

Figure 6-5: The four point beam fatigue test

\subsubsection{Flow number test}

Flow number test is based on the theory that the cumulative axial strain develops in three phases, the primary phase, second phase and tertiary phase, as shown in Figure 6-6. The flow number is determined as the load cycles at which the tertiary phase starts. The flow number test, which is also referred as dynamic creep test, was found to have good relationships with the field rutting performance of asphalt mixtures (Zhou and Scullion 2003; Witczak 2007; Dongre, D'Angelo et al. 2009). In this study, the flow number test for the control asphalt mixture and bio oil modified asphalt mixtures were conducted at $45^{\circ} \mathrm{C}$. The test procedures followed AASHTO TP 79 (AASHTO 2010). The effect of the bio oil on the resilient modulus of the asphalt mixture was also investigated. 


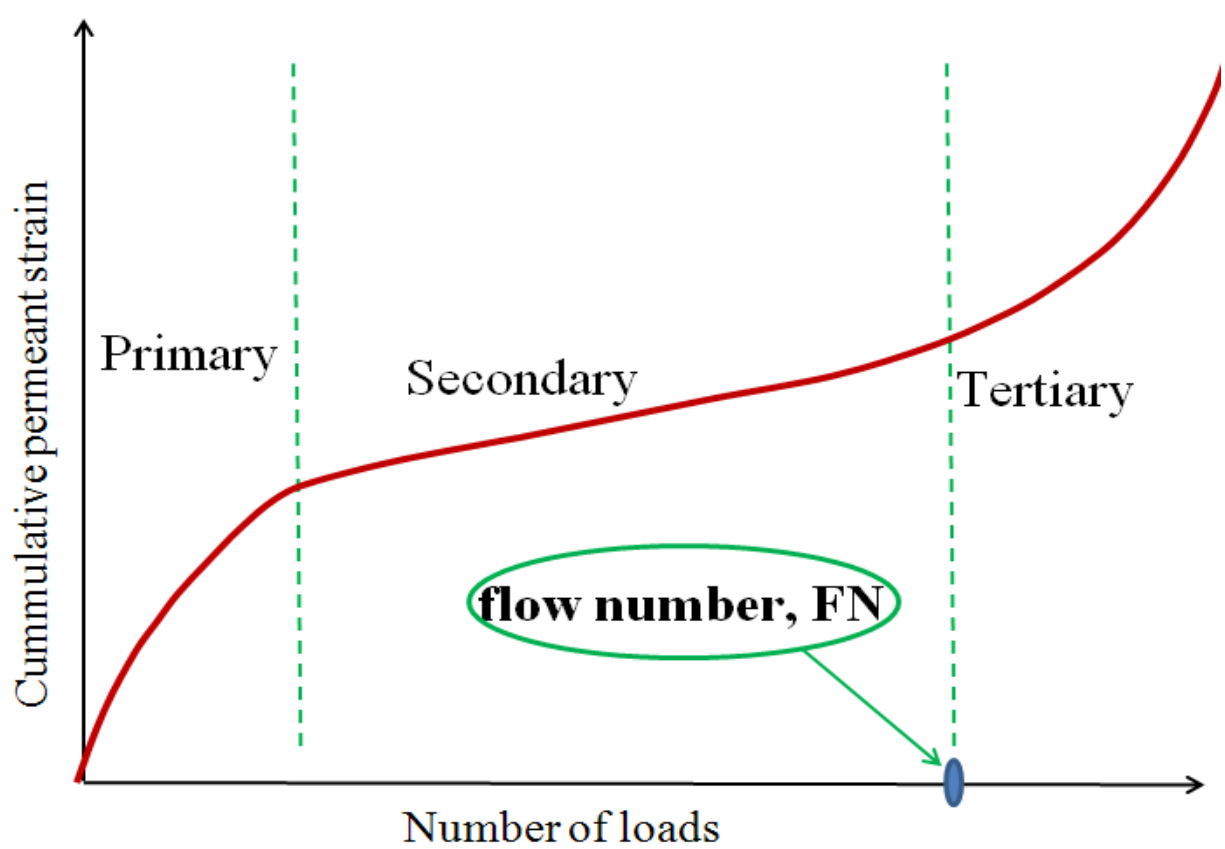

Figure 6-6: Flow number test protocol

\subsection{Results and Discussions}

\subsubsection{Dynamic modulus $\left(\left|\mathrm{E}^{*}\right|\right)$}

Since dynamic modulus $\left(\left|\mathrm{E}^{*}\right|\right)$ is tested at different temperatures and frequencies, master curve was used to plot $\left|\mathrm{E}^{*}\right| \mathrm{s}$ at different frequency and temperatures in a single graph. Reduced frequency was used to represent both the frequency and temperature. Figure 6-7 to Figure 6-9 displayed the $\left|E^{*}\right|$ master curve for control asphalt mixture and three types of bio oil modified asphalt mixtures. In general, the $\left|E^{*}\right| s$ of bio oil modified asphalt mixture were slightly higher than the control asphalt mixture. The average increases of $\left|\mathrm{E}^{*}\right| \mathrm{s}$ for $\mathrm{OB}, \mathrm{DWB}$ and $\mathrm{PMB}$ modified asphalt mixtures were $8.1 \%, 6.1 \%$ and $10.3 \%$, respectively, compared to the control asphalt mixture. This indicates that the bio oil modified asphalt mixtures were stiffer than the control asphalt mixture. The main reason for this is that the fast aging of bio oil resulted in stiffer asphalt binders which enhance the stiffness of asphalt mixtures. From the master curves, it is also found that the $\left|E^{*}\right| s$ increase in the low reduced frequency (high temperature and low frequency) area is more significant than that in the high reduced frequency (low temperature and high frequency). This indicates that the addition of bio oil can increase the stiffness of asphalt mixture more significantly at relative higher temperatures. 
Compared among the three types of bio oil modified asphalt mixtures, no apparent differences were observed for the dynamic modulus. This is easy to understand because the bio oil is only $5 \%$ and $10 \%$ of the total asphalt binder weight. As a result, the limited change of bio oil didn't result in visible difference for asphalt mixtures.

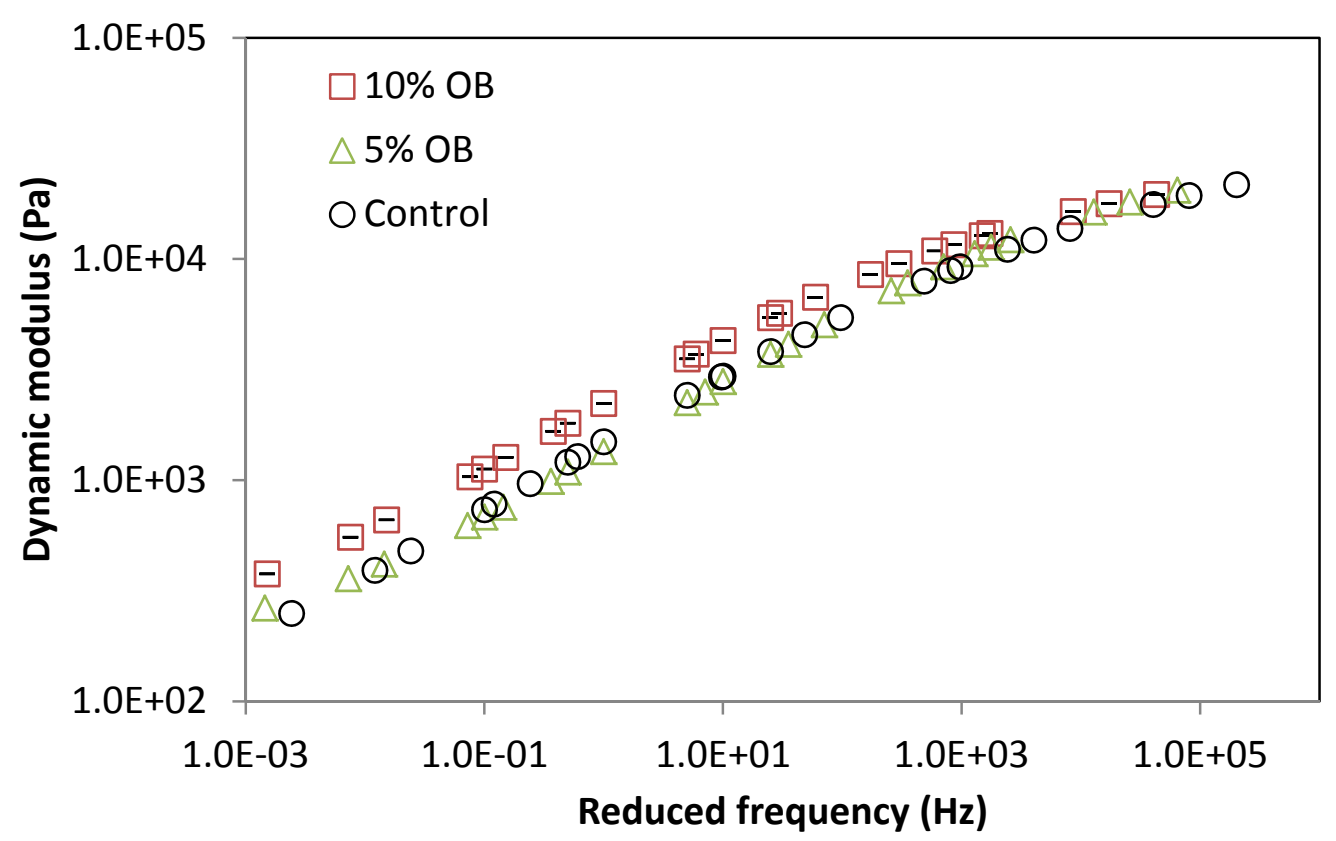

Figure 6-7: Dynamic modulus master curve plot for control asphalt mixture, $5 \%$ and $10 \%$ OB modified asphalt mixture 


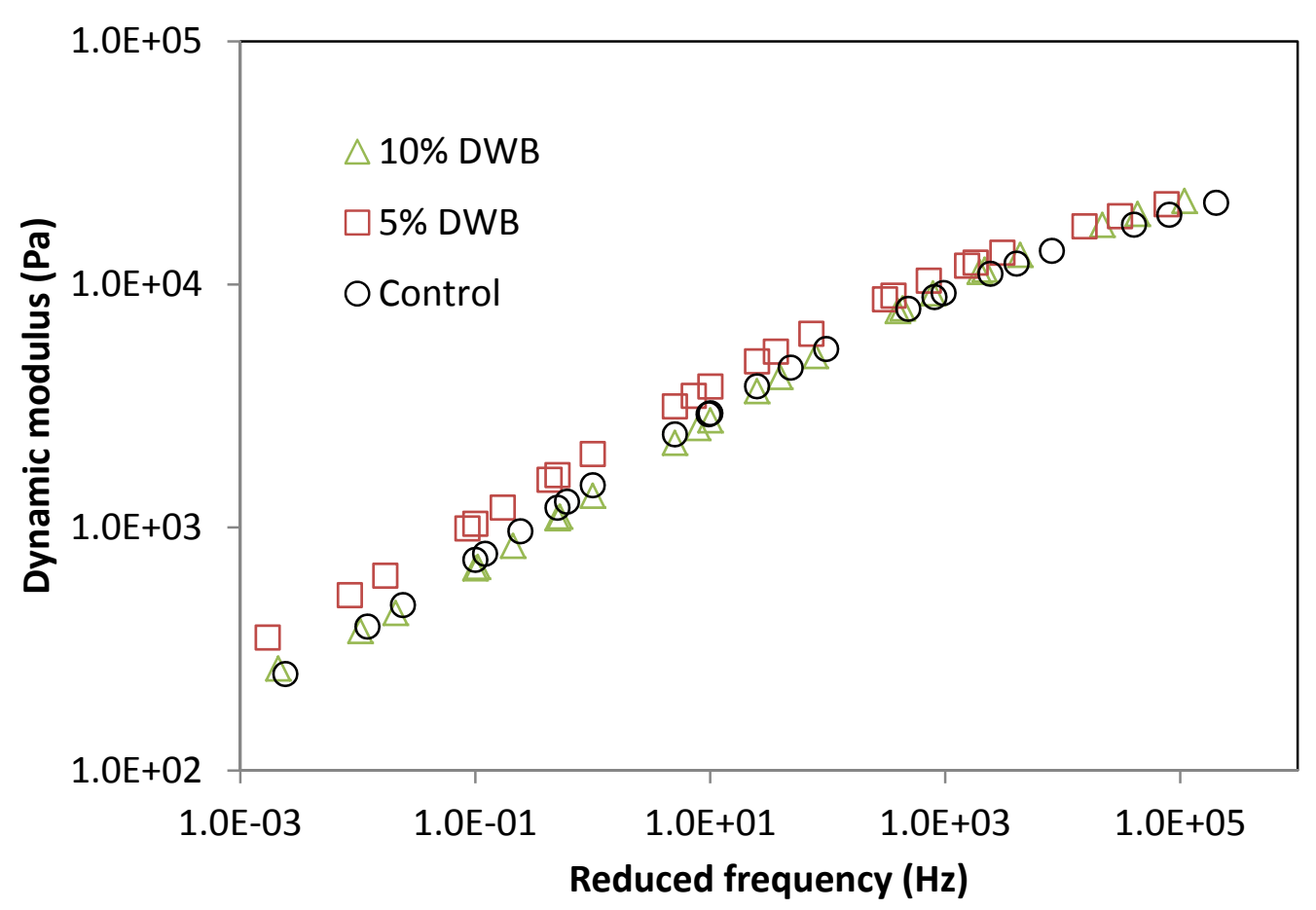

Figure 6-8: Dynamic modulus master curve plot for control asphalt mixture, $5 \%$ and $10 \%$ DWB modified asphalt mixture

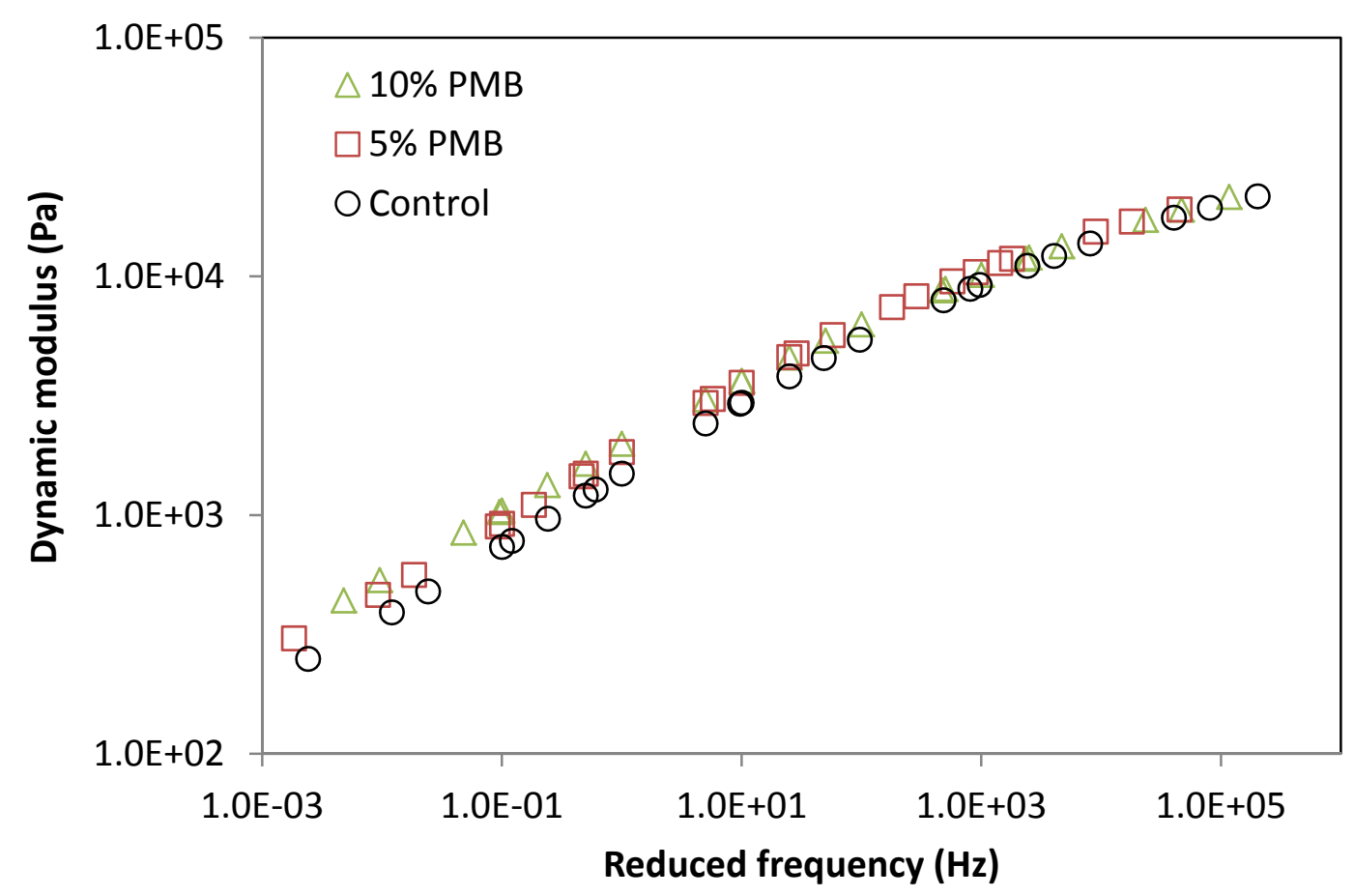

Figure 6-9: Dynamic modulus master curve plot for control asphalt mixture, $5 \%$ and $10 \%$ PMB modified asphalt mixture 


\subsubsection{Indirect tensile (IDT) test and moisture susceptibility}

Figure 6-10 displays the IDT test results for the asphalt mixtures. It is found that most of the bio oil modified asphalt mixtures had lower indirect tensile strength than the control asphalt mixture. The average indirect tensile strengths of $\mathrm{OB}, \mathrm{DWB}$ and $\mathrm{PMB}$ modified asphalt mixtures were $16.7 \%, 18.3 \%$ and $9.3 \%$ lower than that of the control asphalt mixture, respectively. The possible reason for this is that bio chars were generated during the bio oil aging and decreased the cohesion inside the asphalt binder. The reason why the PMB modified asphalt mixture had relative higher IDT strength is probably due to the polymer, which enhanced the tensile strength.

Compared among the three types of bio oil modified asphalt mixtures, the PMB modified asphalt mixtures acquired higher indirect tensile strengths than the $\mathrm{OB}$ and DWB modified asphalt mixtures. This indicates that the polymer in the bio oil contributed to the higher tensile strength.

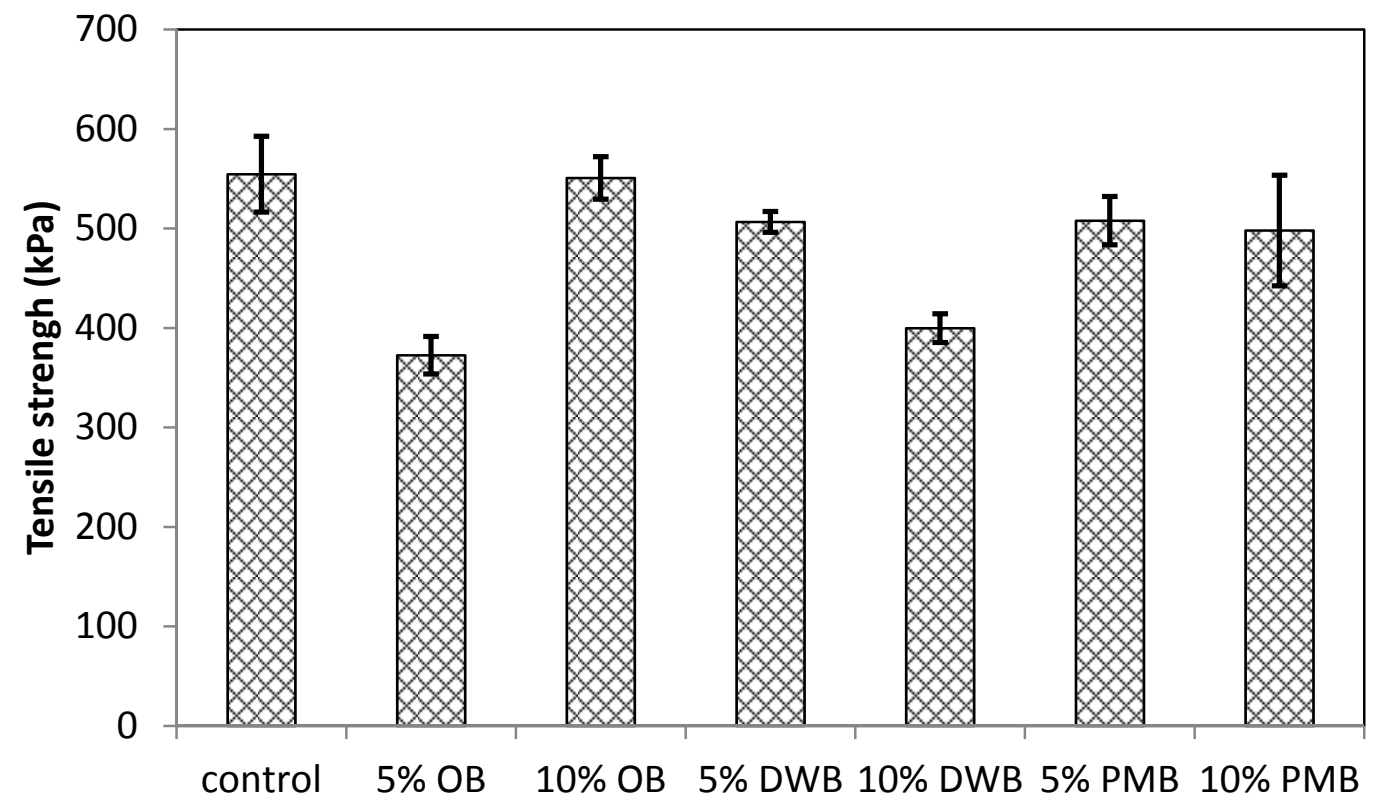

Figure 6-10: Indirect tensile strength results for dry and conditioned asphalt mixtures

\subsubsection{Rutting resistance}

Figure 6-11 displays the APA test results of control asphalt mixture and the three types of bio oil modified HMA mixtures at $58^{\circ} \mathrm{C}$. It is observed that most of the bio oil modified asphalt mixtures showed slightly higher rutting depth than the control asphalt 
mixture. From the rutting development curves in Figure 6-11, it is found that the rutting develops more quickly in the bio oil modified asphalt mixtures compared to the control asphalt mixture. The final rutting depths of $\mathrm{OB}, \mathrm{DWB}$ and PMB modified asphalt mixtures were $8.6 \%, 6.1 \%$ and $5.6 \%$ higher than that of the control asphalt mixture. This indicates that the addition of bio oil into the asphalt mixtures has slightly negative effect on the rutting performance.

Comparison among the three types of bio oil modified asphalt mixtures showed that the PMB modified asphalt mixture performs better than the other two types of asphalt mixtures. This is also resulted from the effect of polymer in the bio oil.

Although the $\left|E^{*}\right|$ test results showed that the bio oil modified asphalt mixtures were slightly stiffer than the control asphalt mixtures, the rutting performances from APA test didn't show consistent results as the $\left|E^{*}\right|$ test. The primary reason may be that the addition of bio oil slightly decreases the tensile strength as well as the cohesive strength because bio char is generated during the aging. Some other potential reasons may be: 1) the highest temperature in the $\left|\mathrm{E}^{*}\right|$ was $39.4^{\circ} \mathrm{C}$ while the temperature conditioned in the APA test was $58^{\circ} \mathrm{C}$. The temperature difference may cause the different results; 2) the short-term aging during the preparation of the asphalt mixture samples may be not as high as that in the standard rolling thin film oven (RTFO) test, which represents a shortterm aging of asphalt binders. This may result that the bio oil modified asphalt binders were still softer than the control asphalt binder; 3) the strain level in the $\left|E^{*}\right|$ test is about 75 micro-strains, which is much lower than that in the APA test. In addition, some previous studies point that the $\left|\mathrm{E}^{*}\right|$ is to determine the mechanical response under loading and doesn't necessarily have good relation with rutting depth (Zhou and Scullion 2003; Birgisson and Roque 2004). 


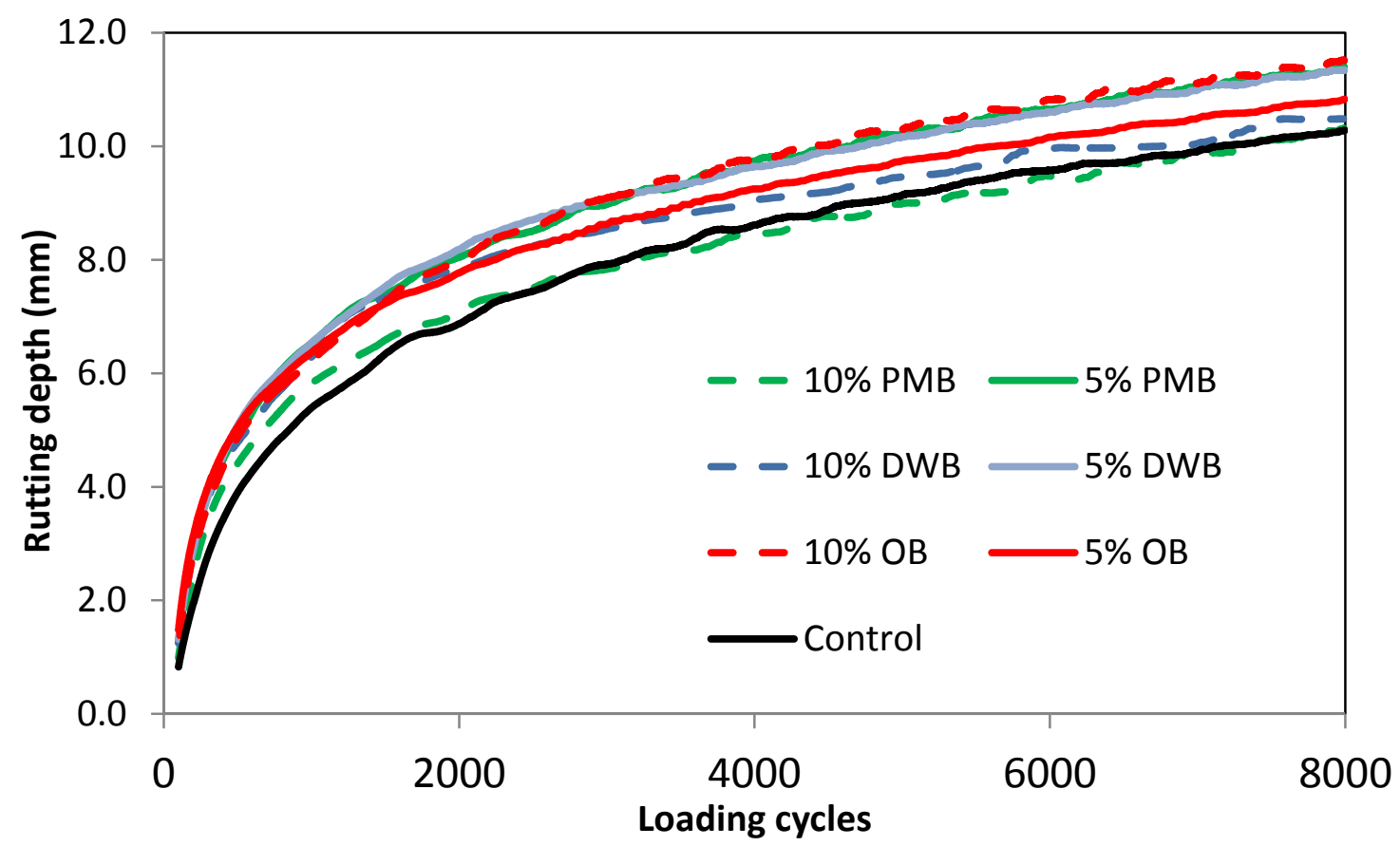

Figure 6-11: Rutting depth development of control asphalt mixture and bio oil modified asphalt mixture in APA test

\subsubsection{Flow Number (FN) test}

As mentioned before, flow number test is an approach to evaluate the rutting resistance of asphalt mixtures. Figure 6-12 displays the flow number test results for the control asphalt mixture and bio oil modified asphalt mixtures. Overall, the flow numbers of bio oil modified asphalt mixtures were slightly lower than the control asphalt mixture except for 5\% DWB modified asphalt mixture. The average flow number value of bio oil modified asphalt mixtures was $10.8 \%$ lower than the control asphalt mixture. This overall test result is consistent with the APA test result that most of bio oil modified asphalt mixtures had a slightly higher rutting depth than the control asphalt mixture. 


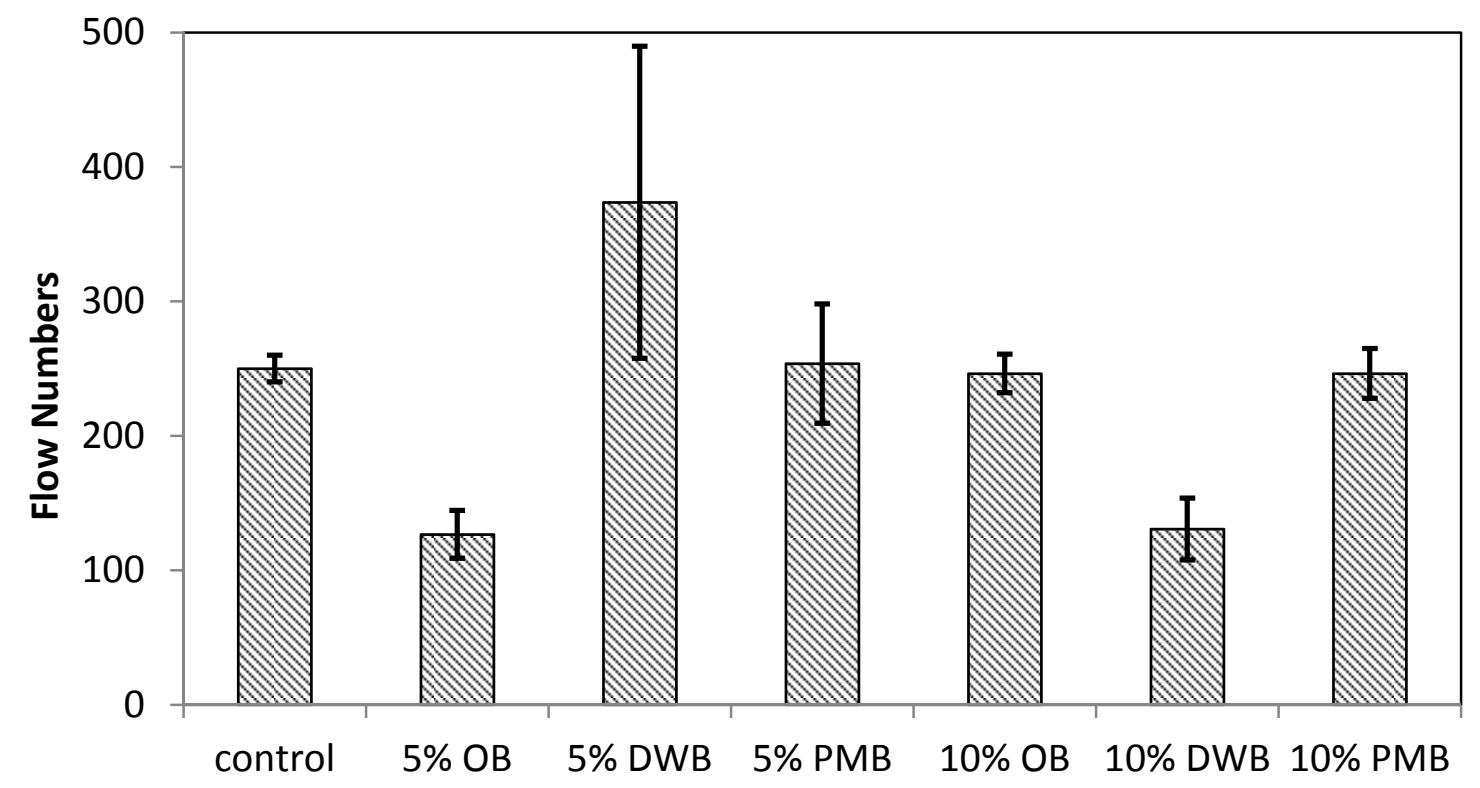

Figure 6-12: Flow numbers of asphalt mixtures at $45{ }^{\circ} \mathrm{C}$ obtained from the flow number test

\subsubsection{Resilient modulus test}

The resilient modulus of bio oil modified asphalt mixtures were also conducted in this study through dynamic creep loading at $45^{\circ} \mathrm{C}$. The resilient test results were displayed in Figure 6-13. It is found that the addition of bio oil had no significant effect on the resilient moduli except for 5\% OB modified asphalt mixture. The average resilient modulus of the bio oil modified asphalt mixtures was 3.2\% lower than that of the control asphalt mixture. This indicates that the addition of bio oil into the asphalt mixtures doesn't have significant effect on the high temperature stiffness. 


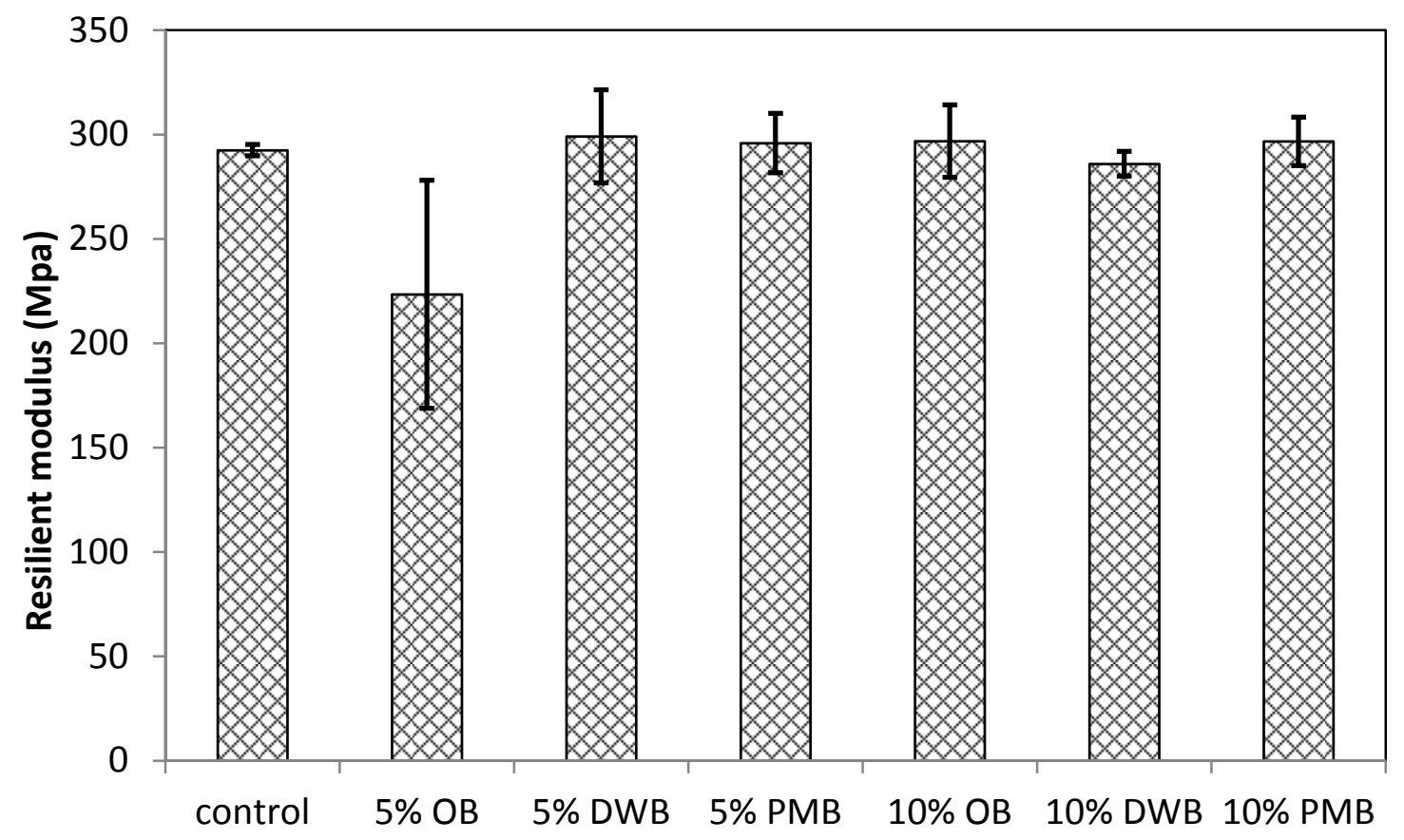

Figure 6-13: Resilient moduli of asphalt mixtures at $45.0^{\circ} \mathrm{C}$ obtained from the dynamic creep test

\subsubsection{Fatigue performance}

Figure 6-14 displays the four point beam fatigue test results for control asphalt mixture and bio oil modified asphalt mixtures under 200 micro-strains and 400 microstrains, respectively. It is observed that all of the bio oil modified asphalt mixtures had higher fatigue lives than the control asphalt mixture at both 200 and 400 micro-strains. The average fatigue life of bio oil modified asphalt mixtures were $680 \%$ and $85.4 \%$ higher than those of the control asphalt mixture under 200 and 400 micro-strains levels, respectively. The test results indicate that the bio oil modified asphalt mixtures are expected to obtain better fatigue performances than the control asphalt mixtures. 


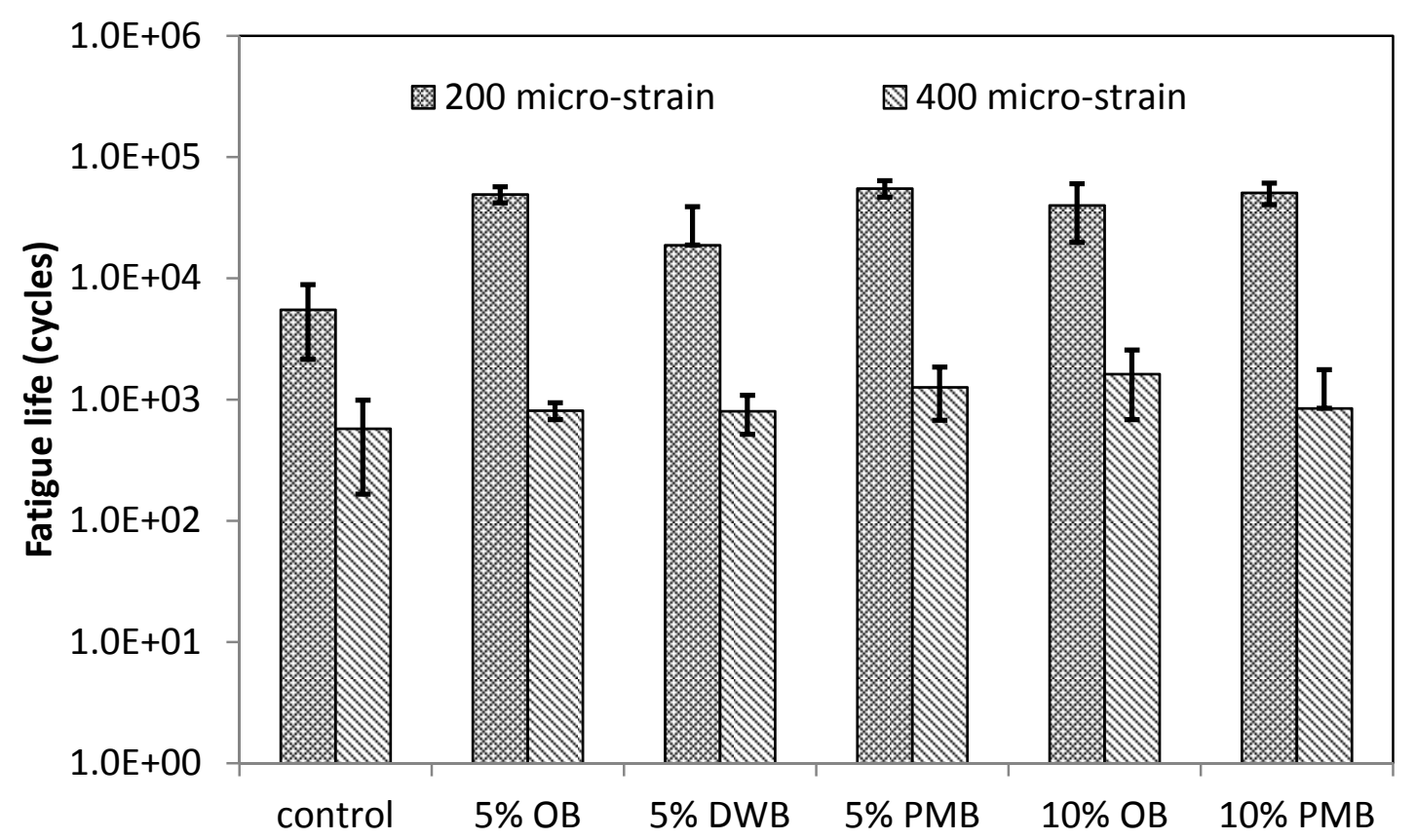

Figure 6-14: Four point beam fatigue test results for control asphalt mixture and bio oil modified asphalt mixtures at $21^{\circ} \mathrm{C}$

\subsubsection{Relation between initial dissipated energy and fatigue life}

The fatigue life can reflect the fatigue performance of asphalt mixtures under a certain bending strain level. In the four point beam fatigue test, energies were dissipated during every flexural bending cycle because of the viscoelastic properties of asphalt mixtures. Normally the initial dissipated energy (IDE) is the energy dissipated in the $50^{\text {th }}$ loading cycle during the four point beam fatigue test. It is found that there is a good relationship between the IDE and the fatigue life (Rowe 1993). A fit model was developed by SHRP-A-404 to fit the relation between IDE and fatigue life, as shown below(SHRP A-404 1994):

$$
N_{f}=6.72 e^{0.049 V F B}\left(w_{0}\right)^{-2.047}
$$

Where:

$N_{f}$ is the fatigue life of asphalt mixtures;

$V F B$ is the void percentage in aspahlt;

$w_{0}$ is the initial dissipated energy.

Figure 6-15 shows the initial dissipated energies of the control asphalt mixture and bio oil modified asphalt mixtures in this study. It is found that the bio oil modified asphalt mixtures obtained much lower dissipated energies in the beam fatigue test. The 
average cumulative dissipated energy of $\mathrm{OB}$, DWB and PMB modified asphalt mixtures were $35.0 \%, 65.4 \%$ and $69.1 \%$ lower than the control asphalt mixture, respectively. According to the relation between fatigue life and initial dissipated energy, higher fatigue lives were likely to be accompanied for the bio oil modified asphalt mixtures compared to the control asphalt mixture. The relationship between the fatigue life and the initial dissipated energy in the beam fatigue test was plot in Figure 6-16. It is found that a similar equation was obtained as that modeled by SHRP-A-404.

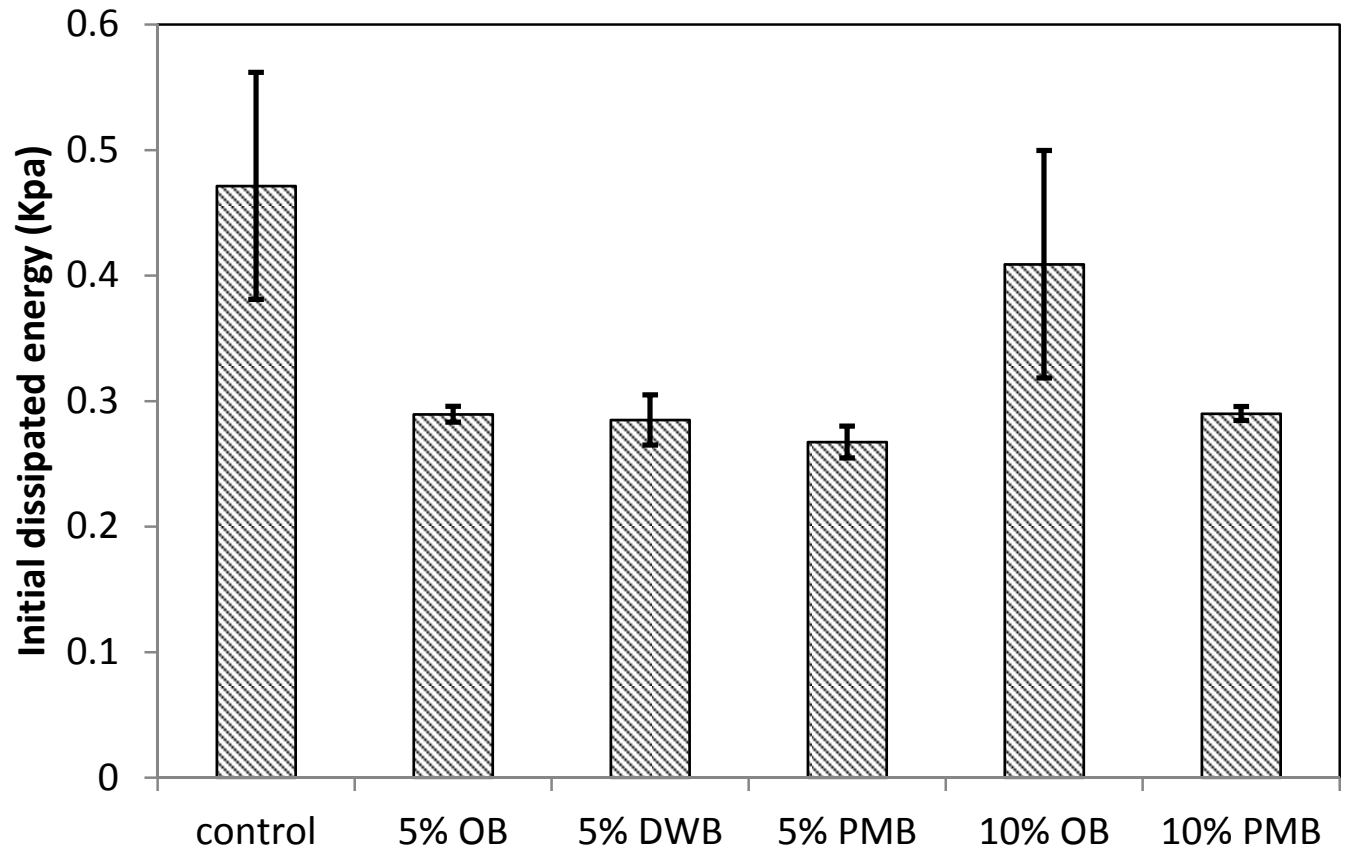

Figure 6-15: The initial dissipated energy during the four point beam fatigue test under 200 micro-strain levels 


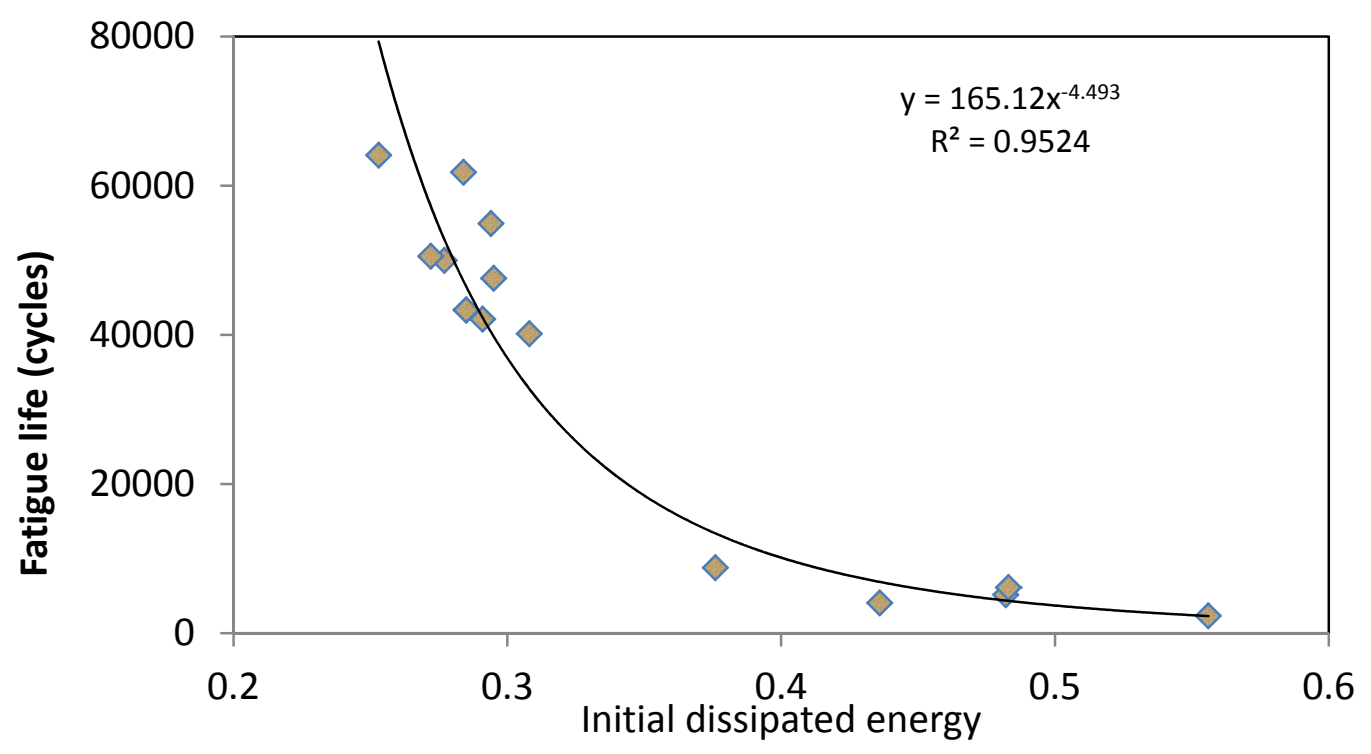

Figure 6-16: relationship between the fatigue life and the initial dissipated energy in the beam fatigue test

\subsubsection{Flexural modulus}

Flexural modulus of asphalt mixtures were obtained from the four point beam bending test following AASHTO T 321 (AASHTO 2007). Figure 6-17 displays the flexural moduli of control asphalt mixture and bio oil modified asphalt mixtures at $21^{\circ} \mathrm{C}$. It is found that all of the bio oil modified asphalt mixtures had lower flexural moduli than the control asphalt mixture. The flexural moduli of $\mathrm{OB}, \mathrm{DWB}$ and PMB modified asphalt mixtures were $18.2 \%, 58.6 \%$ and $28.5 \%$ lower than the control asphalt mixtures, respectively. Considering that the fatigue lives of bio oil modified asphalt mixtures were much higher than that of the control asphalt mixture, it is likely that a lower flexural modulus can result in a better fatigue performance for asphalt mixtures. 


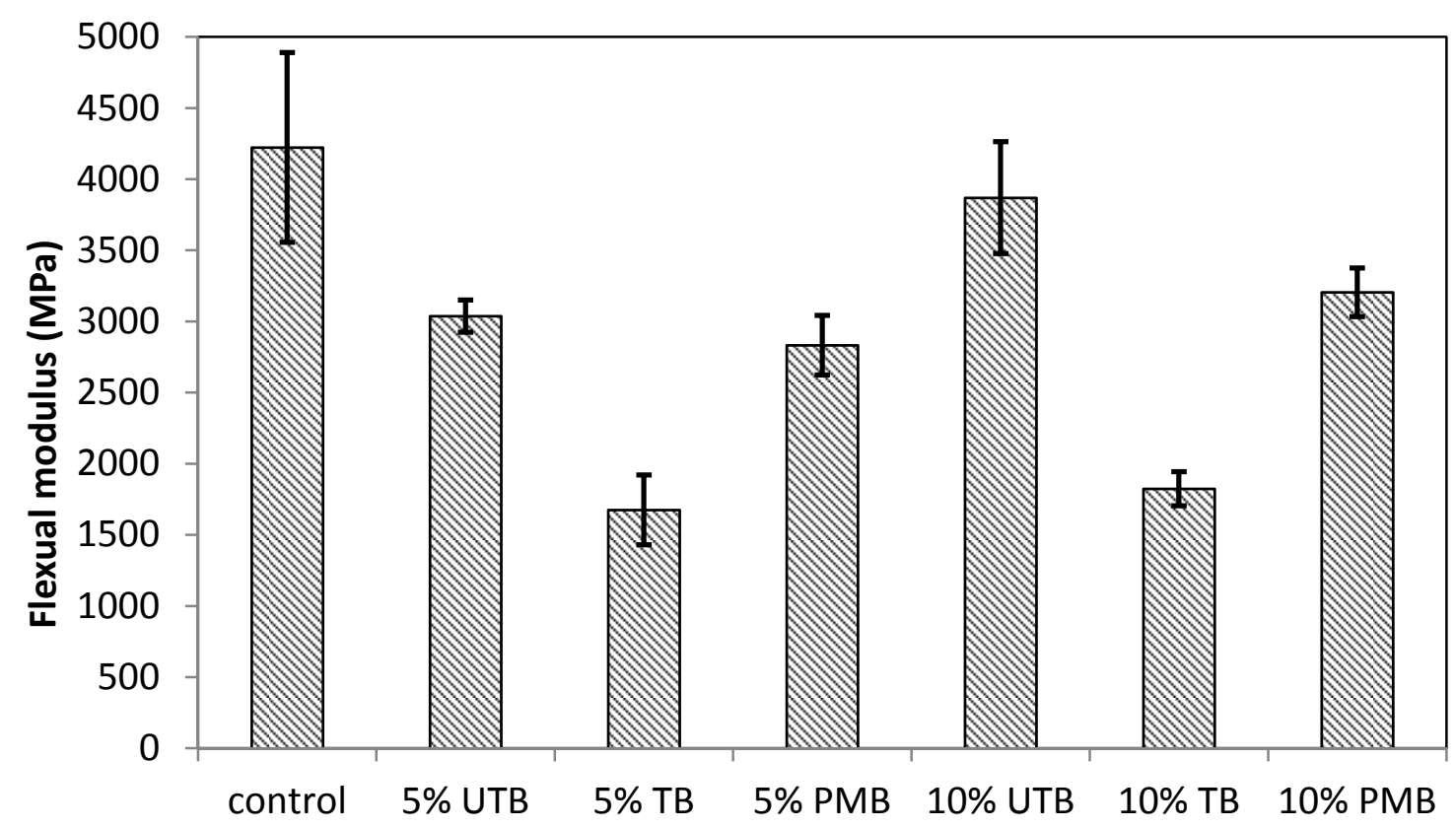

Figure 6-17: Flexural moduli of asphalt mixtures from four point beam bending test at $21^{\circ} \mathrm{C}$

\subsection{Statistical analysis}

The statistical analysis is conducted for the test results to evaluate the effect significance of bio oil type and bio oil content on the mixture performance. There are three types of bio oils (OB, DWB and PMB) and three bio oil concentrations $(0 \%, 5 \%$ and $10 \%$ ) in this study. It is necessary to find whether bio oil type or bio oil concentration has significant effect on the asphalt mixture performance. In addition, the understanding of the interactive effect between bio oil type and bio oil concentration is beneficial for the mixture design in future studies. In term of such considerations, the statistical analysis is conducted using the general linear model in SPSS to make the analysis of variance (ANOVA). The dependent variables are the test results from three replicates and the fixed factors are the bio oil type and bio oil percentage. An alpha value of 0.05 was selected to obtain a $95 \%$ confidence level. The P-values of bio oil type, bio oil percentage and type*percentage are obtained through the analysis. If the P-value is lower than 0.05 , the null hypothesis is rejected and there is a significant effect statistically. Otherwise, there is no significant effect. 


\subsubsection{Dynamic modulus $\left(\left|E^{*}\right|\right)$}

The statistical analysis for the $\left|E^{*}\right|$ test results is shown in Table 6-3. It is found both the P-vales for bio oil type and bio percent were higher than 0.05 . This indicates that neither the bio oil type nor the bio oil concentration had significant effect on the $\left|E^{*}\right| s$ of asphalt mixtures. In addition, the P-value of type*percent indicate that there is no significant interactive effect for the bio oil type and the bio oil percentage. The statistical analysis results enhance the view that there is no significant difference among the $\left|E^{*}\right|$ values of three types of bio oil. It should be noticed that the statistical analysis is only valid when bio oil percentage is not higher than $10 \%$. If the bio oil percentage is much higher, the results may be different.

Table 6-3: Tests of between-subject effects on dynamic modulus

\begin{tabular}{ccccccc}
\hline source & $\begin{array}{c}\text { Type } \\
\text { III sum } \\
\text { of } \\
\text { squares }\end{array}$ & $\begin{array}{c}\text { Mean } \\
\text { square }\end{array}$ & df & F-value & P-value & $\begin{array}{c}\text { Significant } \\
\text { effect? }\end{array}$ \\
\hline Corrected & $1.0 \mathrm{E} 8$ & $1.7 \mathrm{E} 7$ & 6 & 0.437 & 0.853 & \\
model & & & & & & \\
Intercept & $7.6 \mathrm{E} 9$ & $7.6 \mathrm{E} 9$ & 1 & 189.7 & 0.000 & \\
Bio type & $3.9 \mathrm{E} 5$ & $2.0 \mathrm{E} 5$ & 2 & 0.0048 & $\mathbf{0 . 9 9 5}$ & No \\
Bio percent & $7.0 \mathrm{E} 7$ & $3.5 \mathrm{E} 7$ & 2 & 0.870 & $\mathbf{0 . 4 2 0}$ & No \\
Type*percent & $1.4 \mathrm{E} 7$ & $7.4 \mathrm{E} 6$ & 2 & 0.183 & $\mathbf{0 . 8 3 2}$ & No \\
Error & $6.9 \mathrm{E} 9$ & $4.0 \mathrm{E} 7$ & 172 & & & \\
Total & $1.5 \mathrm{E} 10$ & & 179 & & & \\
Corrected error & $7.0 \mathrm{E} 9$ & & 178 & & & \\
\hline
\end{tabular}

\subsubsection{Asphalt pavement analyzer (APA)}

The APA test results are statistically analyzed and shown in Table 6-4. Similar to the results as of dynamic modulus, it is found that neither the bio oil type nor the bio oil percentage has significant effect on the rutting depth. The ANOVA results are in agreement of the former analysis that the rutting performances of the asphalt mixtures were only slightly impacted when bio oils are added. In addition, the ANOVA results also support the former view that there is no significant difference in rutting performance among the three types of BOM mixtures. 
Table 6-4: Tests of between-subject effects on rutting depth

\begin{tabular}{crrrrrr}
\hline Source & $\begin{array}{c}\text { Type III } \\
\text { sum of } \\
\text { squares }\end{array}$ & $\begin{array}{c}\text { Mean } \\
\text { square }\end{array}$ & df & F-value & $\begin{array}{c}\text { P- } \\
\text { value }\end{array}$ & $\begin{array}{c}\text { Significant } \\
\text { effect? }\end{array}$ \\
\hline Corrected model & 4.304 & 0.717 & 6 & 1.386 & 0.337 & \\
Intercept & 1467.157 & 1467.157 & 1 & 2835.078 & 0.000 & \\
Bio type & 1.091 & 0.545 & 2 & 1.054 & $\mathbf{0 . 3 9 8}$ & No \\
Bio percent & 3.203 & 1.601 & 2 & 3.094 & $\mathbf{0 . 1 0 9}$ & No \\
Type*percent & 0.915 & 0.457 & 2 & 0.884 & $\mathbf{0 . 4 5 5}$ & No \\
Error & 3.623 & 0.518 & 7 & & & \\
Total & 1689.979 & & 14 & & & \\
Corrected error & 7.926 & & 13 & & & \\
\hline
\end{tabular}

\subsubsection{Indirect tensile test (IDT)}

Similar to the dynamic modulus and rutting depth, statistical analysis is also conducted on the indirect tensile strength of asphalt mixtures. The tests of betweensubject effects are shown in Table 6-5. It is found that both the bio oil type and bio oil percent have statistically significant effect on the IDT test results. The significant differences between the bio oil types are mainly from the relative higher indirect tensile strength of PMB modified asphalt mixtures when compared to OB and DWB modified mixtures. The significant differences between the bio oil percentages are mainly from the reduction of the indirect tensile strength when bio oil is added. In addition, it is also found that there is a significant interactive effect between the bio oil type and percentage. This means the effects of bio oil type and percentage on the asphalt mixture tensile strength are affected by each other. The effect of bio oil types on the asphalt mixture tensile strength is dependent on the bio oil percentage, and vice versa. In terms of this, in the IDT results in this study, the asphalt mixture containing 0\% PMB (in fact the control mixture) has the highest indirect tensile strength, which is supported by the interactive effect.

Table 6-5: Tests of between-subject effects on indirect tensile strength

\begin{tabular}{|c|c|c|c|c|c|c|}
\hline source & $\begin{array}{l}\text { Type III } \\
\text { sum of } \\
\text { squares }\end{array}$ & $\begin{array}{c}\text { Mean } \\
\text { square }\end{array}$ & $\mathrm{df}$ & F-value & $\begin{array}{r}\text { P- } \\
\text { value }\end{array}$ & $\begin{array}{l}\text { Significant } \\
\text { effect? }\end{array}$ \\
\hline
\end{tabular}




\begin{tabular}{rrrrrrr}
\hline Corrected & 90581.8 & 15096.9 & 6 & 16.855 & 0.000 & \\
model & & & & & & \\
Intercept & $4.5 \mathrm{E} 6$ & $4.5 \mathrm{E} 6$ & 1 & 5098.637 & 0.000 & \\
Bio type & 8466.9 & 4233.4 & 2 & 4.726 & $\mathbf{0 . 0 2 7}$ & Yes \\
Bio percent & 19094.2 & 9547.1 & 2 & 10.659 & $\mathbf{0 . 0 0 2}$ & Yes \\
Type*percent & 62982.3 & 31491.1 & 2 & 35.159 & $\mathbf{0 . 0 0 0}$ & Yes \\
Error & 12539.1 & 895.6 & 14 & & & \\
Total & $5.2 \mathrm{E} 6$ & & 21 & & & \\
Corrected & & & 20 & & & \\
error & 103121.0 & & & & &
\end{tabular}

\subsubsection{Fatigue performance}

Table 6-6 shows the tests of between-subject effects on fatigue lives of asphalt mixtures. It is found that both the bio oil type and the bio oil percentage have statistically significant effects on the mixture fatigue lives. This result supports the former view that the addition of bio oil can increase the fatigue lives of asphalt mixtures significantly. In addition, the significant effect of bio oil type on mixture fatigue life is consistent with the test results in Figure 6-14, which shows the PMB modified asphalt mixtures have relative higher fatigue lives when compared to the OB and DWB modified mixtures. It is found that there is no significant interactive effect between bio oil type and bio oil percentage. This indicates that the effects of bio oil type and bio oil percentage on mixture fatigue performance are independent on each other.

Table 6-6: Tests of between-subject effects on fatigue life

\begin{tabular}{rrrrrrr}
\hline source & $\begin{array}{r}\text { Type III } \\
\text { sum of } \\
\text { squares }\end{array}$ & $\begin{array}{r}\text { Mean } \\
\text { square }\end{array}$ & df & F-value & P-value & $\begin{array}{c}\text { Significant } \\
\text { effect? }\end{array}$ \\
\hline Corrected model & $5.553 \mathrm{E} 9$ & $1.111 \mathrm{E} 9$ & 5 & 3.374 & 0.043 & \\
Intercept & $1.027 \mathrm{E} 10$ & $1.027 \mathrm{E} 10$ & 1 & 31.205 & 0.000 & \\
Bio type & $2.781 \mathrm{E} 9$ & $1.391 \mathrm{E} 9$ & 2 & 4.225 & $\mathbf{0 . 0 4 4}$ & Yes \\
Bio percent & $2.763 \mathrm{E} 9$ & $1.382 \mathrm{E} 9$ & 2 & 4.198 & $\mathbf{0 . 0 4 4}$ & Yes \\
Type*percent & $1.661 \mathrm{E} 8$ & $1.661 \mathrm{E} 8$ & 1 & 0.505 & $\mathbf{0 . 4 9 2}$ & No \\
Error & $3.620 \mathrm{E} 9$ & $3.291 \mathrm{E} 8$ & 11 & & & \\
Total & $2.398 \mathrm{E} 10$ & & 17 & & & \\
Corrected error & $9.174 \mathrm{E} 9$ & & 16 & & & \\
\hline
\end{tabular}




\subsection{Conclusions}

In this study, the three types of bio oils (original, de-watered and polymer modified bio oils) derived from waste wood resources were added into the petroleum asphalt binders to evaluate the effect of the bio oils on the asphalt mixture performances. Based on the test results, the following conclusions were made:

1) The addition of bio oil can improve the fatigue performances of asphalt mixtures significantly.

2) The addition of bio oil has slightly negative effect on the indirect tensile strength and rutting performance of the asphalt mixtures, but the effect on rutting performance is not statistically significant.

3) The polymer-modified bio oil overall performs better than the original bio oil and the dewatered bio oil for the asphalt mixture performances. However, this effect is limited when the bio oil content is low.

4) The statistical analysis results show that the bio oil type and bio oil content have no significant effect on the $\left|\mathrm{E}^{*}\right|$ and rutting performance, but they have significant effect on the indirect tensile strength and fatigue lives. It is also found there is an interactive effect on the indirect tensile strength between bio oil type and bio oil content.

5) Overall, bio oils generated from waste wood resources can be a good extender and modifier for the petroleum asphalt binders when the bio oil fraction is low (not higher than $10 \%$ by weight). 


\section{Chapter 7: Summary and Recommendations}

\subsection{Summary and Conclusion}

This study discussed the implementation of bio oil as a sustainable transportation material. Four main parts were investigated in the study, including: 1) literature review to understand the source collection, producing process, chemical components and some chemical and physical properties of bio oil; 2) rheological property characterization of asphalt binders modified and partially replaced by bio oil; and 3) mechanical performance evaluation of asphalt mixture modified by bio oil. The asphalt binder test results showed that: 1) The addition of bio oil can reduce the rotational viscosity of virgin asphalt binders, and hence can reduce the mixing temperature; 2) The addition of bio oil can increase the dynamic shear modulus and improve the high temperature performance of asphalt binders; 3) Bio oil has negative effect on the low temperature performance because of the higher stiffness and lower m-value; 4) The original bio oil (OB) has the lowest effect on the asphalt binder properties compared to de-watered bio oil (DWB) and polymer modified bio oil (PMB). Based on the mixture performance test, it is found that: 1) The addition of bio oil can improve the fatigue performances of asphalt mixtures significantly; 2) Bio oil doesn't negatively affect the moisture susceptibility of asphalt mixtures although there is a slight reduction for the indirect tensile strength; 3) The addition of bio oil has slightly negative effect on the rutting performance of the HMA mixtures; 4) The polymer modified bio oil overall performs better than the original bio oil and the dewatered bio oil for the asphalt mixture performances. However, this effect is limited when the bio oil content is low.

\subsection{Recommendations for Bioasphalt Use}

Bioasphalt is a mixture production consisting of bio oil and petroleum-based asphalt. The first step to produce bioasphalt is to mix the bio oil and the petroleum-based asphalt binder. As mentioned before, bio oil is very sensitive for temperature higher than $120^{\circ} \mathrm{C}$, so the mixing temperature of bio oil and base asphalt should be not higher than $120^{\circ} \mathrm{C}$. In fact, in the experience of the research team, all the three types of bio oils (OB, 
$\mathrm{DWB}, \mathrm{PMB}$ ) have enough fluidity for the mixing at temperature less than $100^{\circ} \mathrm{C}$ for the research team took out the bio oil from the plastic bottle by water bath. In the lab mixing, the bio oil and base asphalt were mixed at $110^{\circ} \mathrm{C}$ by high shear mixer. However, because the bio oil is softer than the base asphalt, the bio oil can obtain equal viscosity at a lower temperature compared to the base asphalt. Thus, in the practical mixing, it is recommended that the mixing temperature for bio oil and base asphalt are different. From the RV test results for control asphalt binder PG 58-28 and pure bio oil in Chapter 4, it is found that the viscosity of pure bio oil at $100^{\circ} \mathrm{C}$ is close to that of pure PG $58-28$ at $120^{\circ} \mathrm{C}$. Thus, it is recommended that the mixing temperatures for bio oil and PG 58-28 are $100^{\circ} \mathrm{C}$ and $120^{\circ} \mathrm{C}$ respectively.

\subsection{Current challenges and Future Efforts}

In this study, the research team conducted a series of tests to evaluate the rheological roperties of bioasphalt and the mechanical performances of bioasphalt mixtures. Some findings were obtained based on the test results. However, the chemical mechanism during bio oil aging and how to simulate the short-term and long-term aging are the two main obstacles for the better use of bioasphalt.

Firstly, to reveal the inside chemical mechanism of bio oil aging can present full explanation for the test results and further, to find ways to control the aging in a proper level. For instance, different chemical reactions that result in different rheological properties may occur at different temperatures. If these chemical reactions can be well understood, better ways to deal with the bioasphalt can be found.

Secondly, the standard RTFO and PAV aging are not suitable for bioasphalt, especially that with high percent of bio oil, because of the faster aging of bio oil. The short-term aging simulation can make guidance on the practical work of mixing and compaction. For example, the construction time and temperature should be reduced to avoid over aging of the bioasphalt. Theoretically, bioasphalt with different bio oil percentage should result in different construction time and temperatures to get the same

aging level. Thus, to find a proper short-term aging method for bioasphalt would be very helpful for the design and construction of bioasphalt mixture. The long-term aging is mainly dependant on the climate condition of the pavement located. The aging 
temperature for standard PAV test is $100^{\circ} \mathrm{C}$. However, the actual high temperature for pavement is about 60 to $70^{\circ} \mathrm{C}$, which is lower than the test temperature. The PAV test increased the aging temperature to accelerate the aging in a short time. However, this may be not suitable for bioasphalt because the aging increase of traditional asphalt from $60^{\circ} \mathrm{C} / 70^{\circ} \mathrm{C}$ to $100^{\circ} \mathrm{C}$ may be lower than that of bioasphalt. In that case, the standard PAV test would over-estimate the long-term aging of bioasphalt. Thus, to find proper ways to simulate short-term and long-term aging for bioasphalt is very important for the application of bioasphalt.

The future direction for the research would be the design and practice for bio oil based asphalt mixture, especially for high percent bio oil containing asphalt mixtures. The mixture design should include: 1) bio oil percent selection and base asphalt selection; 2) aging level determination which can be adapted by changing the construction time and temperature; 3) short-term and long-term performance evaluation; 4) life cycle assessment. 
Copyright Clearance of Published Journal Paper "Performance Evaluation of Asphalt Binder Modified by Bio-oil Generated from Waste Wood Resources", 6(4): 431-439. International Journal of Pavement Research and Technology.

The full article has been used in Chapter 4 of this thesis. The permission to reuse in the thesis is as follows:

\section{Wei-Hsing Huang \\ to me \\ Dear Ms.Mr. Yang:}

Oct 15

The copyright transfer you signed does not include the right to revise, adapt, prepare derivative works, present orally, or distribute the work, provided that all such use is for the personal noncommercial benefit of the author. So, I think it's alright for you to use of the paper in your thesis.

Wish you do very well with your MS thesis.

Regards,

Wei-Hsing Huang, Ph D

Editor-in-Chief, I.JPRT

Professor of Civil Engineering

National Central University

Jhongli, Taiwan 32001

Email: t321655@ncu.edu.tw

Website: mmwijprt.org.tw

----- Original Message ----- 


\section{REFERENCES}

Agarwal, A. K., TERI Inf. (1998). "Vegetable oils versus diesel fuel: development and use of biodiesel in a compression ignition engine." Digest on EnergyVol. 8: pp. 191-204

Banse, M., H. van Meijl, et al. (2008). "Impact of EU Biofuel Policies on World Agricultural and Food Markets." Paper prepared for presentation at the 107th EAAE Seminar on Modelling of Agricultural and Rural Development Policies, Sevilla, Spain.

Fan, J., T. N. Kalnes, et al. (2011). "Life cycle assessment of electricity generation using fast pyrolysis bio-oil." Renewable EnergyVol. 36.

Harrison, T. and L. Christodulaki (2000). "Innovative processes in asphalt production and application - strengthening asphalt's position in helping build a better world." First International Conference of Asphalt Pavement.

Huang, Y., R. Bird, et al. (2009). "Development bof a life cycle assessment tool for construction and maintenance of asphalt pavements." Journal of Cleaner ProductionVol. 17: pp. 283-296.

Manyele, S. V. (2007). "Lifecycle assessment of biofuel production from wood pyrolysis technology." Educational Research and ReviewVol. 2(6): pp. 141-150.

Williams, N. H. and W. M. Whitten (1983). "Orchid floral fragrances and male euglossine bees: methods and advances in the last sesquidecade." Biol. Bull.Vol. 164: pp. 355-395.

Wright, M. M., R. C. Brown, et al. (2008). "Distributed processing of biomass to bio-oil for subsequent production of Fischer-Tropsch liquids." Biofuels, Bioprod. BiorefVol. 2: pp. 229-238.

AASHTO (2010). AASHTO T 315: Standard Method of Test for Determining the Rheological Properties of Asphalt Binder Using a Dynamic Shear Rheometer (DSR), AASHTO: American Association of State Highway and Transportation Officials.

AASHTO (2011). AASHTO T 316: Standard Method of Test for Viscosity Determination of Asphalt Binder Using Rotational Viscometer, AASHTO: American Association of State Highway and Transportation Officials.

ASTM (2006). D4402-06 Standard Test Method for Viscosity Determination of Asphalt at Elevated temperatures Using a Rotational Viscometer, ASTM: American Standard Testing Methods.

Bahia, H. U. and D. A. Anderson (1995). The Pressure Aging Vessel (PAV): A Test to Simulate Rheological Changes Due to Field Aging. . ASTM Special Technical Publication 1241, Hardin, J.C., ed. West Conshohocken, PA, American Society for Testing and Materials. 
Bahia, H. U., Anderson, D. A. (1994). "The Pressure Aging Vessel (PAV): A Test to Simulate the Rheological Changes Due to Field Aging." American Society for Testing and Materials Special technical Publication1241.

McGennis, R. B., S. Shuler, Bahia, H. U. (1994). "Background of Superpave Asphalt Binder Test Methods." FHWAReport No. FHWA-SA-94-069.

Roberts, F., Kandhal, P. S., Brown, E. R. (1996). "Hot Mix Asphalt Materials, Mixture Design, and Construction." National Asphalt Pavement Association2nd Edition: pp. 7-119.

Roberts, F. L., P. S. Kandhal, et al. (2009). Hot Mix Asphalt Materials, Mixture Design and Construction, 3rd edition. Lanham, Maryland.

Roberts, F. L., Kandhal, P. S., Brown, E. R., Lee, D.-Y., Kennedy, T. W. (1996). "Hot Mix Asphalt Materials, Mixture Design and Construction." 2nd Edition.

Williams, R. C., Tang, S. (2009). "Antioxidant Effect of Bio-Oil Additive ESP on Asphalt Binder." Proceedings of the 2009 Mid-Continent Transportation Research Symposium, Ames, Iowa: p. 1-14.

AASHTO (2007). Standard Method of Test for Determining the Fatigue Life of Compacted Hot-Mix Asphalt (HMA) Subjected to Repeated Flexural Bending, AASHTO: American Association of State Highway and Transportation Officials.

AASHTO (2007). Standard Method of Test for Determining the Rutting Susceptibility of Asphalt Paving Mixtures Using the Asphalt Pavement Analyzer (APA), AASHTO: American Association of State Highway and Transportation Officials.

AASHTO (2009). Standard Method of Test for Effect of Heat and Air on a Moving Film of Asphalt Binder (Rolling Thin-Film Oven Test), AASHTO: American Association of State Highway and Transportation Officials.

AASHTO (2009). Standard Practice for Accelerated Aging of Asphalt Binder Using a Pressurized Aging Vessel (PAV), FHWA Multi-Regional Asphalt Training and Certification Group.

AASHTO (2010). AASHTO T 313: Standard Method of Test for Determining the Flexural Creep Stiffness of Asphalt Binder Using the Bending Beam Rheometer (BBR), AASHTO: American Association of State Highway and Transportation Officials

AASHTO (2010). AASHTO T 315: Standard Method of Test for Determining the Rheological Properties of Asphalt Binder Using a Dynamic Shear Rheometer (DSR), AASHTO: American Association of State Highway and Transportation Officials.

AASHTO (2010). Standard Method of Test for Determining the Dynamic Modulus and Flow Number for Hot Mix Asphalt (HMA) Using the Asphalt Mixture Performance Tester (AMPT), American Association of State and Highway Transportation Officials.

AASHTO (2011). AASHTO T 316: Standard Method of Test for Viscosity Determination of Asphalt Binder Using Rotational Viscometer, AASHTO: American Association of State Highway and Transportation Officials. 
Barras, C. (2008). "Technology, Ahead of the Curve, Chemical Breakthrough Turns Sawdust into Biofuel." NewScientist.com news service carried on ABC News.

Birgisson, B. and R. Roque (2004). The Use of Complex Modulus to Characterize the Performance of Asphalt Mixtures and Pavements in Florida, University of Florida.

Brown, E. R., P. S. Kandhal, et al. (2009). Hot Mix Asphalt Materials, Mixture Design and Construction: Third Edition, Lanham, MD, National Asphalt Pavement Association.

Brown, T. R., Wright, M. M., Brown, R. C. (2010). "Estimating profitability of two biochar production scenarios: slow pyrolysis vs fast pyrolysis." Biofuels, Bioprod. Bioref. Society of Chemical Industry and John Wiley \& Sons, Ltd 5: pp. 54-68.

Chailleux, E., M. Audo, et al. (2012). "Alternative Binder from Microalgae: Algoroute Project." Transportation Research E-Circular(E-C165): 7-14.

Chaiya, C. (2011). Production of Bio Oil from Coffee Residue using Pyrolysis Process Proceedings of the World Congress on Engineering and Computer Science, San Francisco, USA.

Czernik, S. and A. V. Bridgwater (2004). "Overview of Applications of Biomass Fast Pyrolysis Oil." Energy \& Fuels 18(2): 590-598.

Czernik, S., D. K. Johnson, et al. (1994). "Stability of wood fast pyrolysis oil." Biomass and Bioenergy 7(1-6): 187-192.

Diebold, J. P. (2000). A review of the chemical and physical mechanisms of the storage stability of fast pyrolysis bio-oils. Lakewood, Colorado, National Renewable Energy Laboratory.

Dongre, R., J. D'Angelo, et al. (2009). "Refinement of Flow Number as Determined by Asphalt Mixture Performance." Journal of the Transportation Research Record 2(2127): 127-136.

Ertaş, M. and M. Hakkı Alma (2010). "Pyrolysis of laurel (Laurus nobilis L.) extraction residues in a fixed-bed reactor: Characterization of bio-oil and bio-char." Journal of Analytical and Applied Pyrolysis 88(1): 22-29.

Fini, E., E. Kalberer, et al. (2011). "Chemical Characterization of Biobinder from Swine Manure: Sustainable Modifier for Asphalt Binder." Journal of Materials in Civil Engineering 23(11): 1506-1513.

Fini, E. H., E. W. Kalberer, et al. (2011). Biobinder From Swine Manure: Sustainable Alternative for Asphalt Binder. Transportation Research Board 90th Annual Meeting. Washington DC.

Hill, D. R. and A. A. Jennings (2011). Bioasphalt from Urban Yard Waste Carbonization A Student Study, Case Western Reserve University; Ohio Department of Transportation.

Hilten, R. N. and K. C. Das (2010). "Comparison of three accelerated aging procedures to assess bio-oil stability." Fuel 89(10): 2741-2749.

Jensen, W. and M. Abdelrahman (2006). Use of Crumb Rubber in Performance Graded Binder. Lincoln, NE, University of Nebraska, Lincoln.

Karlsson, R. and U. Isacsson (2003). "Application of FTIR-ATR to Characterization of Bitumen Rejuvenator Diffusion." Journal of Materials in Civil Engineering 15(2): 157-165. 
Lamontagne, J., F. Durrieu, et al. (2001). "Direct and continuous methodological approach to study the ageing of fossil organic material by infrared microspectrometry imaging: application to polymer modified bitumen." Analytica Chimica Acta 444(2): 241-250.

Lamontagnea, J., P. Dumasb, et al. (2001). "Comparison by Fourier transform infrared (FTIR) spectroscopy of different ageing techniques: application to road bitumens." Journal of Fuel 80(4): 483-488.

Metwally, M. A. R. M. and R. C. Williams (2010). Development of Non-petroleum Based Binders for Use in Flexible Pavements, Iowa Highway Research Board.

Michigan Department of Transportation (2008). HMA Production Manual.

Michigan Department of Transportation (MDOT) (2003). Special Provision for Superpave HMA mixtures. Lansing, MI: 6.

Mills-Beale, J., Z. You, et al. (2012). "Aging Influence on Rheology Properties of Petroleum-Based Asphalt Modified with Bio-Binder." Journal of Materials in Civil Engineering 0(ja): null.

Mohan, D., C. U. Pittman, et al. (2006). "Pyrolysis of Wood/Biomass for Bio-oil: A Critical Review." Energy \& Fuels 20(3): 848-889.

Mullen, C. A. and A. A. Boateng (2008). "Chemical Composition of Bio-oils Produced by Fast Pyrolysis of Two Energy Cropst." Energy \& Fuels 22(3): 2104-2109.

NCHRP (2011). Mechanistic-Empirical Design of New \& Rehabilitated Pavement Structures. Washington DC.

Onay, O. and O. M. Koçkar (2006). "Pyrolysis of rapeseed in a free fall reactor for production of bio-oil." Fuel 85(12-13): 1921-1928.

Ouyang, C., S. Wang, et al. (2006). "Improving the aging resistance of asphalt by addition of Zinc dialkyldithiophosphate." Fuel 85(7-8): 1060-1066.

Peralta, J., R. C. Williams, et al. (2012). "Development of Rubber-Modified Fractionated Bio-Oil for Use as Noncrude Petroleum Binder in Flexible Pavements." Transportation Research E-Circular(E-C165): 23-36.

Petersen, J. C. (2009). "A Review of the Fundamentals of Asphalt Oxidation: Chemical, Physicochemical, Physical Property, and Durability Relationships." Transportation Research Circular E-C140: 1-54.

Raouf, M. A. and R. C. Williams (2009). Determination of Pre-Treatment Procedure Required for Developing Bio-Binders from Bio-Oils. Proceedings of the 2009 Mid-Continent Transportation Research Symposium, Ames, IA

Raouf, M. A. and R. C. Williams (2010). "Rheology of Fractionated Cornstover Bio-oil as a Pavement Material." International Journal of Pavements 9(1-2-3): 58-69.

Roaouf, M. A., M. Metwally, et al. (2010). Development of Non-Petroleum Based Binders for Use in Flexible Pavements. Ames, IA, Iowa State University, Ames.

Rowe, G. M. (1993). "Performance of Asphalt Mixtures in the Trapezoidal Fatigue Test." Proceedings of Associations of Asphalt Paving Technologists 62: 344-384.

Scholze, B. and D. Meier (2001). "Characterization of the water-insoluble fraction from pyrolysis oil (pyrolytic lignin). Part I. PY-GC/MS, FTIR, and functional groups." Journal of Analytical and Applied Pyrolysis 60(1): 41-54.

Şensöz, S. and I. Kaynar (2005). "Bio-oil production from soybean (Glycine max L.); fuel properties of Bio-oil." Industrial Crops and Products 23(1): 99-105. 
SHRP A-404 (1994). Fatigue Response of Asphalt-Aggregate Mixes, Institute of Transportation Studies, University of California, Berkeley. Strategic Highway Research Program, National Research Council.

Silverstein, R. M., G. C. Bassler, et al. (1981). Spectrometric Identification of Organic Compounds. 4th ed. New York, John Wiley and sons.

U.S.D.O.E. (2005). "Pyrolysis and Other Thermal Processing " Energy Efficiency and Renewable Energy Program Biomass Program.

Uzun, B. B., E. Apaydin-Varol, et al. (2010). "Synthetic fuel production from tea waste: Characterisation of bio-oil and bio-char." Fuel 89(1): 176-184.

Vitton, S., R. Williams, et al. (2007). Evaluation of Fine Aggregate Characteristics Tests and Their Relationship to HMA Performance. Houghton, Michigan, Michigan Technological University: 351.

Wang, H., Z. Dang, et al. (2012). "Effect of warm mixture asphalt (WMA) additives on high failure temperature properties for crumb rubber modified (CRM) binders." Construction and Building Materials 35(0): 281-288.

Williams, C. R. S., J.; Rover, M.; Brown, R. C.; Teng, S.; (2008). "Utilization of Fractionated Bio Oil in Asphalt." Journal of the Transportation Research Board 09(3187): 1-19.

Williams, R. C., J. Satrio, et al. (2008). "Utilization of Fractionated Bio Oil in Asphalt." Journal of the Transportation Research Board 9(3187): 1-19.

Williams, R. C., Tang, S. (2009). "Antioxidant Effect of Bio-Oil Additive ESP on Asphalt Binder." Proceedings of the 2009 Mid-Continent Transportation Research Symposium, Ames, Iowa: p. 1-14.

Witczak, M. W. (2007). Specification Criteria for Simple Performance Tests for Rutting NCHRP Report 580, National Cooperative Highway Research Program.

$\mathrm{Xu}, \mathrm{T}$. and $\mathrm{X}$. Huang (2010). "Study on combustion mechanism of asphalt binder by using TG-FTIR technique." Fuel 89(9): 2185-2190.

Yang, J., Q. Du, et al. (2011). "Concrete with recycled concrete aggregate and crushed clay bricks." Construction and Building Materials 25(4): 1935-1945.

You, Z., J. Mills-Beale, et al. (2011). "Evaluation of Low-Temperature Binder Properties of Warm-Mix Asphalt, Extracted and Recovered RAP and RAS, and Bioasphalt." Journal of Materials in Civil Engineering 23(11): 1569-1574.

Yut, I. and A. Zofka (2011). "Attenuated Total Reflection (ATR) Fourier Transform Infrared (FT-IR) Spectroscopy of Oxidized Polymer-Modified Bitumens." APPLIED SPECTROSCOPY 65(7): 765-770.

Zhou, F. and T. Scullion (2003). Case Study: Preliminary Field Validation of Simple Performance Tests for Permanent Deformation. Transportation Research Board for 2003 Annual Meeting. Washington, D, C.

Zofka, A. and I. Yut (2012). "Investigation of Rheology and Aging Properties of Asphalt Binder Modified with Waste Coffee Grounds." Transportation Research ECircular(E-C165): 61-72. 